Incluindo funções de distância e extratores de características para suporte a consultas por similaridade

\author{
Marcos Vinícius Naves Bedo
}


Data de Depósito:

Assinatura:

\title{
Incluindo funções de distância e extratores de características para suporte a consultas por similaridade
}

\author{
Marcos Vinícius Naves Bedo
}

Orientador: Prof. Dr. Caetano Traina Jr.

Dissertação apresentada ao Instituto de Ciências Matemáticas e de Computação - ICMC-USP, como parte dos requisitos para obtenção do título de Mestre em Ciências - Ciências de Computação e Matemática Computacional. VERSÃO REVISADA 
Ficha catalográfica elaborada pela Biblioteca Prof. Achille Bassi e Seção Técnica de Informática, ICMC/USP, com os dados fornecidos pelo(a) autor(a)

Bedo, Marcos Vinícius Naves
Incluindo funçós de distância e extratores de
características para suporte a consultas por
similaridade / Marcos Vinícius Naves Bedo;
orientador Traina Jr. Caetano. -- São Carlos, 2013.
89 p.
Dissertação (Mestrado - Programa de Pós-Graduação
em Ciências de Computaço e Matemática
Computacional) -- Instituto de Ciências Matemáticas
e de Computação, Universidade de São Paulo, 2013.
1. Consultas por Similaridade. 2. SQL estendido.
3. Extratores de Caracteristica. 4. Funçóes de
Distância. 5. CBMIR. I. Caetano, Traina Jr., orient.
II. Título.



Ao meu irmão e à minha família. À única ligação para sempre nesse mundo. 
"Nemo est tam fortis, quin rei novitate perturbetur"

(Caius Julius Caesar, Perpetual Lord of Rome) 


\section{Agradecimentos}

Agradeço a minha família por acreditar que se pode ser,

E agradeço aos amigos.

Rafael Bedo, o meu melhor amigo,

Patricia Gurgel, a minha melhor amiga,

Davi Santos e Thiago Galante, praticamente "sangue do mesmo sangue",

Aos demais amigos agradeço a companhia, as histórias e a paciência,

Por ordem cronológica: Daniel Ferreira, Uziel, Michell Macedo, Rodrigo Girckus, Murilo

Ramiro e Felipe Brunini.

Agradeço ao meu orientador, o Prof. Dr. Caetano Traina Jr. pelo apoio profissional, E também pela amizade que sempre me ofertou durante a realização desse trabalho, Aos amigos do laboratório e competentes Srs.: William, Marcelo Ponciano, Daniel Kaster e Lúcio.

Este trabalho teve o apoio financeiro da Fundação de Amparo a Pesquisa do Estado de São Paulo - FAPESP. 


\section{Resumo}

Sistemas Gerenciadores de Bases de Dados Relacionais (SGBDR) são capazes de lidar com um alto volume de dados. As consultas nestes sistemas são realizados a partir da relação de ordem total, domínio sob o qual estão definidos dados simples como números ou strings, por exemplo. No caso de dados complexos, como imagens médicas, áudio ou séries-temporais financeiras que não obedecem as propriedade da relação acima citada é necessária uma abordagem que seja capaz de realizar a recuperação por conteúdo destes dados em tempo hábil e com semântica adequada. Nesse sentido, a literatura nos apresenta, como paradigma consolidado, as consultas por similaridade. Esse paradigma é a base para o funcionamento de muitos aplicativos de auxílio a tomada de decisão pelo especialista como Recuperação de Imagens Médicas por Conteúdo (CBMIR) e Recuperação de Áudio por Conteúdo (CBAR) e inclui diversas sub-áreas de pesquisa tais como extratores de características, funções de distância e métodos de acesso métrico. O desenvolvimento de novos métodos extratores de características e novas funções de distância são de fundamental importância para a diminuição do gap semântico entre os aplicativos e usuários, enquanto os métodos de acesso métricos são os reponsáveis diretos pela rápida resposta dos sistemas. Integrar todas essas funcionalidades em um framework de suporte a consultas por similaridade dentro de um SGBDR permanece um grande desafio. Esse trabalho objetiva estender uma proposta inicial dos recursos disponíveis no SIREN, inserindo novos extratores de características e funções de distância para imagens médicas e séries-temporais financeiras transformando-o em um framework, de forma que seus componentes possam ser utilizados via comandos Structured Query Language (SQL). Os resultados poderão ser diretamente utilizados por aplicativos de auxílio a tomada de decisão pelo especialista.

Palavras-Chave: Consulta por Similaridade, SQL estendido, Extratores de Características, Funções de Distância, CBMIR.

BEDO, M. V. N. Incluindo Funções de Distância e Extratores de Características para Suporte a Consultas por Similaridade, São Carlos, 2013. (Dissertação de Mestrado) - ICMC - USP. 
Database Management Systems (DBMS) can deal with large amount of data. The queries on those systems obey the total order relation (TOR), domain where simple data such as numbers or strings are defined. In the case of complex data (e.g.: medical images, audio or temporal time-series) which does not obey the TOR properties, it's mandatory a new approach that can retrieve complex data by content with time skilful and proper semantics. To do so, the literature presents us, as consolidated paradigm, the similarity queries. This paradigm is the base of many computer aided applications (e.g.: Content-Based Medical Image Retrieval (CBMIR) and Content-Based Audio Retrieval $(\mathrm{CBAR}))$ and include several research areas such as features extraction, distance functions and metrical access methods (MAM). Developing new features extractors methods and new distance functions (and combine them) are crucial to reduce the semantic gap between the content-based applications and the users. The MAM are responsible to provide fast and scalable answer to the systems. Integrate all those functionalities in one framework that can provide support to similarity queries inside a DBMS remains a huge challenge. The main objective of this work is extend the initial resources of the system SIREN, inserting new features extractor methods and distance functions to medical images, audio and financial time-series, turning it into a framework. All components may be used by extended Structured Query Language (SQL) commands. The SQL can be directly used by computer-aided applications.

Keywords: Similarity-Queries, extended SQL, Features Extraction, Distance Functions, CBMIR. 
1 Introdução 1

1.1 Considerações Iniciais . . . . . . . . . . . . . . . . . . . . . . . . . . . . . . . . . . . . . . . .

1.2 Definição do Problema . . . . . . . . . . . . . . . . . . . . 4

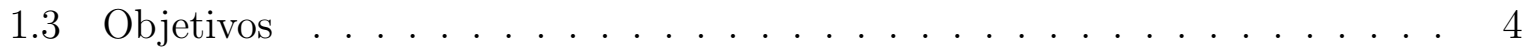

1.4 Principais Contribuições . . . . . . . . . . . . . . . . 5

1.5 Organização do Trabalho . . . . . . . . . . . . . . . . . . . . 6

2 Consultas por Similaridade: Definições e Estruturação 9

2.1 Introdução . . . . . . . . . . . . . . . . . . . . . . . . . . 10

2.1 .1 Imagens Médicas . . . . . . . . . . . . . . . . . . 11

$2.1 .2 \mathrm{DICOM} \ldots \ldots \ldots \ldots \ldots \ldots$

2.2 Extratores de Características . . . . . . . . . . . . . . . . . . . . 13

2.2.1 Extratores de Características de Imagens Baseados em Cor . . . . . 14

2.2.2 Extratores de Características Baseados em Textura . . . . . . . . 16

2.2.3 As Características de Haralick . . . . . . . . . . . . . . . . . . . . . 16

2.2.4 Wavelets . . . . . . . . . . . . . . . . 17

2.2.5 Extratores de Características Baseadas em Forma . . . . . . . . . . 18

2.2.6 Extratores de Características para Áudio baseados em Frequência e Tempo . . . . . . . . . . . . . . . . . . 19

2.2.7 Séries-Temporais Financeiras: Estruturas e Indicadores . . . . . . . 20

2.2.8 Extração de Características para Séries-Temporais Financeiras . . . 21

2.3 Funções de Distância . . . . . . . . . . . . . . . . . . . . . . . 22

2.3.1 A função de Distância Metric Histogram - MHD . . . . . . . . . . . 23

2.3.2 Data Time Warping - Função de Distância Não-Métrica . . . . . . . 23

2.4 Consultas por Similaridade . . . . . . . . . . . . . . . . . 24

2.4.1 Estruturas de Indexação . . . . . . . . . . . . . . . . . . 25

2.4.2 O Método de Acesso Métrico Slim-Tree . . . . . . . . . . . . . 26

2.4.3 Linguagens de Sistemas de Recuperação por Conteúdo . . . . . . . 27

2.4.4 Sistemas . . . . . . . . . . . . . . . . . . . . 28

2.5 Considerações Finais . . . . . . . . . . . . . . . . . . . . . . . 28 
3 Recuperação de Dados por Conteúdo em SGBDR

3.1 Introdução . . . . . . . . . . . . . . . . . . . . . . . 31

3.2 Adicionando Suporte a Consultas por Similaridade em SQL . . . . . . . . 32

3.3 SQL Estendido para SGBDR . . . . . . . . . . . . . . . . 33

3.4 Novas Estruturas de Dados para SQL Estendido . . . . . . . . . . . . . 34

3.5 Definindo Métricas em SQL . . . . . . . . . . . . . . . . . 35

3.6 Criação de Tabelas com Dados Complexos . . . . . . . . . . . . . . . 36

3.7 Criação de Índices envolvendo Dados Complexos . . . . . . . . . . . . . . . 37

3.8 Predicados de Seleção por Similaridade . . . . . . . . . . . . . . . . . 38

3.8.1 Variações de Seleção por Similaridade em SQL . . . . . . . . . . . . 39

3.9 Junção por Similaridade em SQL . . . . . . . . . . . . . . . . . . . . . . . 41

3.10 As Propriedades dos Operadores de Consulta por Similaridade . . . . . . . 41

3.11 Considerações Finais . . . . . . . . . . . . . . . . . . . . . . . 42

4 Metodologia 45

4.1 Equipamentos e Detalhes de Implementação . . . . . . . . . . . . . . . . . . 45

4.2 Dicionário de Dados do Interpretador . . . . . . . . . . . . . . . . . . 46

4.3 Arquitetura da Solução . . . . . . . . . . . . . . . . . . . . 46

4.3.1 Estruturas de Tabelas de Dados Complexos em SGBDR . . . . . . 48

4.3.2 Armazenamento de Dados Complexos e Vetores de Características em SGBDR . . . . . . . . . . . . . . . . . . . . 49

4.4 Adicionando Suporte a Novos Tipos de Dados Complexos e Novos Extratores de Características. . . . . . . . . . . . . . . . . . . . 49

4.4.1 Definição de uma Biblioteca para Séries-Temporais Financeiras . . . 50

4.5 Adicionando novas Funções de Distância . . . . . . . . . . . . . . . . . . . 52

4.6 Definição de um Sistema de Recuperação de Imagens por Conteúdo sobre a Solução . . . . . . . . . . . . . . . . . . . . . . . 52

4.7 Considerações Finais . . . . . . . . . . . . . . . . . . . 53

5 Resultados e Discussão $\quad 55$

5.1 Uma Ferramenta para Séries-Temporais Financeiras . . . . . . . . . . . 55

5.1 .1 Configurações do Experimento . . . . . . . . . . . . . . . 56

5.1.2 Da Acurácia do forecasting via Consultas por Similaridade. . . . . . 58

5.1 .3 Escalabilidade . . . . . . . . . . . . . . . . . . . . 59

5.1 .4 Discussões Parciais . . . . . . . . . . . . . . . . . 61

5.2 Um Exemplo de Caso de Uso da Ferramenta Shell . . . . . . . . . . . . . . 61

5.2.1 Interpretação das Consultas por Similaridade . . . . . . . . . . . . 62

5.2.2 Dos Novos Recursos: Extratores de Características e Funções de

Distância . . . . . . . . . . . . . . . 66

5.2 .3 Discussões Parciais . . . . . . . . . . . . . . . . . . 66

5.3 Do SQL Estendido para Apoio a um Aplicativo CBMIR . . . . . . . . . . 68

$5.4 \mathrm{O}$ aplicativo Higiia . . . . . . . . . . . . . . . . . . . . 69

5.4.1 Resultados Preliminares do Uso do Sistema . . . . . . . . . . . . 71

5.4 .2 Discussões Parciais . . . . . . . . . . . . . . . . . . . 72

5.5 Conclusão . . . . . . . . . . . . . . . . . . . . . . . 73 
6 Conclusão $\quad 75$

6.1 Considerações Finais . . . . . . . . . . . . . . . . . . . . 75

6.2 Principais Contribuições . . . . . . . . . . . . . . . . . . 76

6.3 Propostas para Trabalhos Futuros . . . . . . . . . . . . 76

$\begin{array}{ll}\text { Referências Bibliográficas } & 79\end{array}$ 


\section{Lista de Figuras}

2.1 Workflow de um sistema de recuperação por conteúdo. . . . . . . . . . . . . 10

2.2 Diferentes visualizações de caixa craniana e torácia devido a operações de alargamento de contraste. . . . . . . . . . . . . . . . . 12

2.3 Imagem e respectivo histograma em escala de cinza. . . . . . . . . . . . . . 14

2.4 Histograma de cores de imagem, em escala RGB. . . . . . . . . . . . . . 15

2.5 Histograma métrico a partir do histograma tradicional. Adaptado de (Traina et al., 2003). . . . . . . . . . . . . . . . . . 15

2.6 Pirâmide de imagens. Adaptado de (Gonzalez e Woods, 2006). . . . . . . . 17

2.7 Exemplo de redução de escala para transformadas wavelets. . . . . . . . . . 18

2.8 Diversas visualizações gráficas para uma mesma série-temporal financeira. (A) Montanha. (B) Candlestick. (C) AMaMiF. . . . . . . . . . . . . . . 20

2.9 Extração de características gráficas. (A) Bandas de Bollinger. (B) Média Móvel Exponencial. . . . . . . . . . . . . . . . . . . . 21

2.10 Função MHD parcial para a região da figura limitada pelos quatro pontos indicados. Adaptado de (Traina et al., 2003). . . . . . . . . . . . . . . . 23

2.11 (A) Range-Query utilizando a família Minkowsky, para diversos valores de $p=1,2$ e $\infty$ e raio $\xi$. (B) $k$-Vizinhos mais próximos para $k=4$ e $p=2$. Adaptado de (Barioni, 2006). . . . . . . . . . . . . . 25

2.12 Slim-Tree com 15 elementos e capacidade $=3$. (A) Estrutura lógica (B) Representação hierárquica. Adaptado de (Barioni, 2006). . . . . . . . . . . 27

3.1 Módulos para recuperação por conteúdo. . . . . . . . . . . . . . . . 32

3.2 Funções de agregação para múltiplos centros de consulta, utilizando-se padrão de agregação $m_{p}$ como função avaliadora. Em (A) $\mathrm{O}$ primeiro objeto selecionado a partir de $p=1$. Em (B) O primeiro objeto selecionado tendo-se em $p=2$ e, em (C) O primeiro objeto selecionado considerando-se

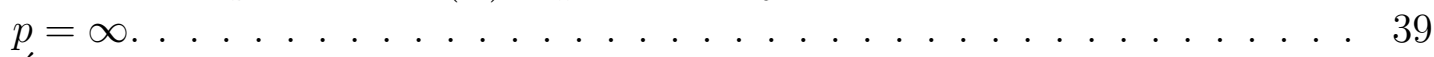

3.3 Árvore de comandos (bottom-up) que representa a ordem de execução de uma consulta SQL envolvendo operadores por similaridade e tradicionais. . 42

4.1 Tabelas que definem o dicionário de dados do interpretador de comandos. . 47

4.2 Arquitetura do shell. . . . . . . . . . . . . . . . . . . . 47

4.3 Estrutura de tabelas do sistema SIREN. Adaptado de (Barioni et al., 2006). 48

4.4 (A) Representação visual diária de uma série-temporal financeira via candlestick. (B) Representação de uma semana via candlestick iniciando em 15/09. . . . . . . . . . . . . . . . . . 50

4.5 Representação visual das características extraídas: (A) Relação Body-Shadow (B) Relação de Amplitude (C) Relação Gap e (D) Relação de Projeção. . . 52

4.6 Workflow do sistema CBMIR para mamografias. . . . . . . . . . . . . 53 
5.1 Workflow do possível tratamento a séries temporais financeiras. . . . . . . 56

5.2 A abordagem por similaridade: dado um centro de consulta (A), o especialista pode visualizar os $k=3$ fragmentos mais similares à série-temporal (B), (C) e (D) ou solicitar diretamente o forecast baseado na classe majoritária das mais similares. A imagem (E) mostra o comportamento real do centro de consulta ao final da sexta-feira. . . . . . . . . . . . . . . . . . 57

5.3 Comparação de tempos de respostas de abordagens de forecasting. (A) Tempo total. (B) Quantidade de cálculos de distância. (C) Quantidade de acessos a disco. . . . . . . . . . . . . . . . . . . . . . . 6 61

5.4 Shell para consultas por similaridade. (A) Interface para usuário / senha / SGBDR. (B) Visualização de resultado do comando DCL DESCRIBE <table . . . . . . . . . . . . . . . . . . 61

5.5 Consulta por similaridade, para $k=2 \ldots \ldots \ldots \ldots$. . . . . . . 64

5.6 Consulta por abrangência. . . . . . . . . . . . . . . . 65

5.7 Consulta por similiaridade aos 3 elementos mais similares, tendo como centro de consulta uma imagem em disco, por meio da métrica textura. . . 66

5.8 Arquitetura interna do CBMIR Higiia. . . . . . . . . . . . . . . . 68

5.9 Interface do sistema Higiia. . . . . . . . . . . . . . . . . . 70

5.10 Comparativo da taxa de acerto da classificação feita por radiologistas sobre as classes (A) Massa e (B) Calcificação. . . . . . . . . . . . . . . . . . . 71

5.11 Comparativo do grau de certeza de médicos residentes e radiologistas ao classificar uma imagem pertencente as classes (A) Massa e (B) Calcificação. 72 


\section{Lista de Tabelas}

2.1 Descrição de seis das características de Haralick. . . . . . . . . . . . . . . 17

2.2 Tabela comparativa SIREN e FMi-SiR. . . . . . . . . . . . . . . 28

5.1 Taxa de acerto sobre o dataset BM\&FBOVESPA_SHARES. . . . . . . . . 58

5.2 Taxa de acurácia referente ao forecasting de índices. . . . . . . . . . . . . 60

5.3 Comparativo de recursos: Shell versus primeira implementação versus FMi-SiR. 67

5.4 Comparação entre a taxa de acerto médicos residentes e a precisão do sistema. 71 
$\mathrm{ACR}$

ANN

ARIMA

AUDIO

BI-RADS

BLOB

CAD

CBAR

CBIR

CBMIR

DBA

DCL

DDL

DML

DFT

DICOM

DTW

EMA

FD

FMI-SiR

FULLTEXT
Associação de Radiologistas Americanos.

Artificial Neural Network - Rede Neural Artificial.

Autoregressive Integrated Moving Average-Modelo de Box-Jenkins.

Definição SQL/MM para de dados do tipo áudio.

Breast Imaging-Reporting and Data System.

Binary Large Object - Object Binário Longo.

Computer Aided Diagnosis - Sistema de Auxílio ao Diagnóstico.

Content-Based Audio Retrieval -

Recuperação de Áudio por Conteúdo.

Content-Based Image Retrieval -

Recuperação de Imagens por Conteúdo.

Content-Based Medical Image Retrieval -

Recuperação de Imagens Médicas por Conteúdo.

Database Administrator - Administrador de Banco de Dados.

Data Control Language - Linguagem de Controle de Dados.

Data Definition Language - Linguagem de Definição de Dados.

Data Manipulation Language -

Linguagem de Manipulação de Dados.

Transformada Discreta de Fourier.

Digital Imaging and Communications in Medicine.

Data-Time Warping.

Média Exponencial Móvel.

Função de Distância.

Sistema User defined Features, Metrics and Indexes

for Similarity Retrieval.

Palavra reservada do SQL/MM para definir textos longos. 
GBdI

Higiia

HCFMRP

HSV

IBL

ISO

$k-\mathbf{N N}$

Ledit

MedFMI-SiR

MFCC

MHD

MLP

MPEG-7

MVP-tree

NEMA

PARTICULATE
MAM

Grupo de Bases de Dados e Imagens.

Sistema CBMIR para mamografias.

Hospital das Clinícas da Faculdade de Medicina de Ribeirão Preto.

Hue-Saturation-Value color model.

Instance-Based Learn - Aprendizado Baseado em Instâncias.

Organização Internacional de Padrões.

$k$-Nearest Neighbor Query - Consulta por similaridade

aos $k$ vizinhos mais próximos.

Função de distância que compara duas strings.

Metric Access Method ou Método de Acesso Métrico.

Sistema Medical User defined Features, Metrics and

Indexes for Similarity Retrieval.

for Similarity Retrieval.

Mel Frequency Cepstral Coefficients.

Metric Histogram Distance.

Mult-Layer Perceptron - Rede neural multi-camadas.

Padrão de descrição de conteúdo multimídia.

Multi-Vantage-Point tree.

Associação de Fabricantes Elétricos Americanos.

Palavra reservada do SIREN para indicar dado

complexo formado a partir de dados simples.

RGB

$R_{q}$

Range Query

ROT

SGBDR

SIREN

SQL

SQL/MM

STILLIMAGE

STFT
RGB color model - Modelo de Cores Primárias.

Range Query - Consulta por similaridade por abrangência.

Range Query - Consulta por similaridade por abrangência.

Relação de Ordem Total.

Sistema de Gerenciamento de Bases de Dados Relacional.

Similarity Retrieval Engine.

Structured Query Language.

Padrão para adicionar suporte a dados multimídia em SQL.

Definição SQL/MM) para dados do tipo imagem.

Transformada de Fourier de Curta Duração. 


\section{Lista de Símbolos}

$\mathbb{S} \quad$ Domínio de Dados.

$S \quad$ Conjunto de dados onde as consultas são feitas $(S \subset \mathbb{S})$.

$S^{\prime} \quad$ Subconjunto resposta $\left(S^{\prime} \subseteq S\right)$.

$\left|S^{\prime}\right| \quad$ Cardinalidade do subconjunto resposta.

$s_{i}, s_{j}, s_{k} \quad$ Elementos de um domínio $s_{i}, s_{j}, s_{k} \in \mathbb{S}$.

$s_{q} \quad$ Elemento central da consulta $\left(s_{q} \in \mathbb{S}\right)$.

$x_{t} \quad$ Valor elemento da série-temporal no instante $t$.

$Q, W \quad$ Séries temporais.

$d\left(s_{q}, s_{i}\right) \quad$ Função distância $\left(d: \mathbb{S} \times \mathbb{S} \rightarrow \mathbb{R}^{+}, s_{i}, s_{j} \in \mathbb{S}\right)$.

$\xi \quad$ Raio da consulta.

$k \quad$ Número de elementos retornados na consulta.

$L_{p} \quad$ Família Minkowsky de distância: $p=1,2, \infty$.

$L \quad$ Limite tons de cinza em histograma. 


\subsection{Considerações Iniciais}

Cada vez é mais comum o armazenamento de dados complexos ${ }^{1}$ como imagens, vídeos, áudio e séries temporais em Sistemas Gerenciadores de Bases de Dados Relacionais (SGBDR). Realizar consultas sobre estes dados, bem como procurar por conhecimento intrínseco nos mesmos, é uma tarefa que tem despertado o interesse da comunidade acadêmica.

Quando se adota o Modelo Relacional para a armazenagem de dados, o paradigma mais utilizado em aplicações comerciais e científicas, a realização de consultas sobre dados complexos deve ser tratada de uma maneira que estende aquela usualmente empregada para as consultas sobre dados simples. Estes últimos estão definidos em domínios que atendem a chamada "Relação de Ordem Total" (ROT), permitindo que possam ser comparados por meio de operadores relacionais tais como $=, \neq,<, \leq, \geq$ e $>$. As propriedades ROT garantem que sempre é possível, dado dois elementos distintos de mesmo tipo e domínio, afirmar qual elemento é precedido por outro.

No entanto, em se tratando de dados complexos, por exemplo imagens médicas, as consultas necessárias não requerem o uso de relação de ordem entre os elementos. Semanticamente, em geral não é significativo expressar a relação de precedência entre estes tipos de dados. Os operadores $=\mathrm{e} \neq$ podem ser aplicados devido a sua definição universal, embora seu uso pouco signifique, dado ser incomum que dois elementos sejam exatamente iguais (por exemplo, a existência de duas imagens idênticas na base de dados).

\footnotetext{
${ }^{1}$ Nesta monografia, por dado complexo entende-se todo tipo de informação que não é armazenada na forma de cadeias de caracteres ou números dentro de um SGBDR.
} 
Dessa forma, um novo tipo de consulta, ajustada para estes novos domínios, é necessária. Historicamente, as abordagens mais sólidas à recuperação de dados complexos vêm sendo realizadas utilizando-se noções de medida de similaridade entre os elementos (Bozkaya e Ozsoyoglu, 1999). Esse paradigma é conhecido como "consulta por similaridade" onde, para dado elemento a ser consultado, a resposta envolve os dados mais próximos sob uma determinada ótica pré-definida (Kaur e Jyoti, 2013).

Formalmente, pode-se expandir o conceito de medida de similaridade para qualquer tipo genérico de dados considerando que o mesmo está representado em um espaço métrico. Um espaço métrico é definido pelo par $\langle\mathbb{S}, d()>$ (Chávez et al., 2001) onde $\mathbb{S}$ denota o domínio onde estão definidos os elementos a serem consultados e $d$ é uma função de distância que deve respeitar as propriedades de simetria, não-negatividade e desigualdade triangular (Santini e Jain, 1999) (Khamsi e Kirk, 2001). A definição de uma função d sobre $\mathbb{S}$ nos permite mensurar distâncias entre os seus elementos.

Por exemplo, dado um determinado elemento de consulta, poderíamos recuperar os elementos mais próximos de acordo com $d$ em um raio $r$ pré-determinado. Outra possibilidade seria recuperarmos os $k$ elementos mais próximos do elemento de consulta independemente de sua distância até o elemento consultado. À primeira consulta do exemplo nos referimos como Consulta por Abrangência (Range Query) (Eppstein et al., 2013), enquanto à segunda nos referimos como Consulta aos $k$-vizinhos mais próximos (k-Nearest Neighbours Query) (Doulkeridis e Norvag, 2013). Essas duas novas consultas também podem ser combinadas como em uma consulta $k$ And Range Query (Hu e Lee, 2006) (Traina et al., 2006).

Estes novos tipos de consultas são também o princípio de funcionamento de ambientes de recuperação de dados por conteúdo, como Sistemas de Recuperação de Imagens por Conteúdo (Content-Based Image Retrieval - CBIR) (Guld et al., 2007; Müller et al., 2004) e Sistemas de Recuperação de Áudio por Conteúdo (Content-Based Audio Retrieval CBAR) (Kovačević et al., 2010). Sistemas CBIR podem auxiliar especialistas, tais como médicos e radiologistas, a elaborarem diagnósticos mais precisos e com maior nível de certeza (Luz Jr. et al., 2007), enquanto sistemas CBAR são amplamente utilizados no mercado de transferências de músicas por internet ou utilizados no reconhecimento de padrões em vídeos (Kovačević et al., 2006).

Os dados complexos destes sistemas podem ser armazenados em SGBDR usando tipos de dados como Binary Large Object (BLOB). Para que uma função de distância possa ser corretamente usada em estruturas de indexação que auxiliem a recuperação destes dados, os mesmos precisam estar representados em um espaço métrico. Por meio de um extrator de características, os dados complexos podem ser colocados na forma de vetores de características (Aslandogan e Yu, 1999) sobre os quais é possível realizar medida direta de similaridade (Bansal et al., 2012). 
Um outro importante ponto a ser levado em consideração condiz com o desempenho (o quão rápido) são realizadas estas comparações de similaridade entre elementos do domínio. Como as aplicações decorrentes das consultas por similaridade usualmente precisam de respostas em tempo hábil, maximizar a eficiência da respostas das consultas Range Query e $k$-Nearest Neighbours Query é de fundamental importância. Diversos métodos, conhecidos como Métodos de Acesso Métrico (MAM), que incluem técnicas de indexação, como a Slim-Tree (Traina et al., 2002), a M-Tree (Ciaccia et al., 1997) e a família Omni-Tree (Traina et al., 2007) são capazes de aumentar consideravelmente a performance das consultas por dados complexos.

Um sistema básico de recuperação por conteúdo, então, poderia ser modularizado integrando extratores de características, funções de distância e estruturas de indexação. Cada um destes módulos possui uma sólida sustentação na literatura (Haralick et al., 1973) (Levenshtein, 1966) (Korn et al., 1996) e um conjunto de algoritmos bem definidos, o que sugere que a tecnologia está suficientemente madura para permitir que consultas por similaridade sejam diretamente incorporadas aos SGBDR, aos quais poderia ser adicionada uma linguagem de consulta estruturada estendida de modo a facilitar o uso indireto destes módulos por um administrador de bases de dados (DBA), programadores, e outros usuários.

Nesse sentido, têm sido desenvolvidos vários protótipos visando a integração entre esse suporte a dados complexos e dados tradicionais. Uma iniciativa que se destaca é o Similarity Engine Retrieval (SIREN) (Barioni et al., 2006), um framework capaz de realizar operações de similaridade sobre imagens e áudio armazendos em SGBDR. Outra notória iniciativa é a proposta por (Kaster et al., 2010) denominada User defined Features, Metrics and Indexes for Similarity Retrieval (FMI-SiR) um framework definido sobre o SGBDR Oracle ${ }^{\circledR}$ (Kaster et al., 2009) que permite a realização de consultas, via SQL estendido com parâmetros < extrator, função de distância> previamente definidos sobre imagens médicas.

Sistemas como o SIREN podem ser diretamente integrados a outros SGBDR, servindo como base de desenvolvimento para programação de ambientes de recuperação de dados por conteúdo. Para maximizar sua eficiência e acurácia, no entanto, devem ser flexíveis e dinâmicos para poderem suportar novos extratores e funções de distância, bem como o tratamento de novos dados complexos, o que não é contemplado no atual estágio do protótipo. Usando o Sistema SIREN como base de implementação, mas considerando um ambiente genérico que possa ser aplicado a outras iniciativas, este trabalho de mestrado visa contribuir com o estado da arte desenvolvendo uma estrutura genérica que possibilite essa flexibilidade e facilite a adição de novos extratores de características e funções de distância que não estão definidos na atual conjuntura do SIREN. 


\subsection{Definição do Problema}

Grandes volumes de dados (complexos ou não) podem ser armazenados integralmente dentro de Sistemas de Gerenciamento de Bases de Dados e posteriormente recuperados e/ou modificados de forma consistente e concorrente por diversos aplicativos externos.

Em se tratando de dados complexos, essa recuperação se dá por meio de consultas por similaridade e a organização interna dos dados é bastante relevante, conforme mostrado por (Barioni et al., 2006). Para mitigar o gerenciamento destes dados complexos diretamente em SGBDR é necessário:

- A especificação de arquitetura que suporte o armazenamento das características extraídas dos dados complexos em uma estrutura isolada;

- A especificação de arquitetura que suporte o armazenamento prévio de métricas onde seja possível associar livremente um extrator a uma função de distância.

Os SGBDR possibilitam a criação de estruturas internas e recuperação de dados por meio de um padrão declarativo de linguagem de dados, sendo o padrão SQL o mais utilizado para aplicativos acadêmicos e comerciais (Eisenberg et al., 2004). Vários padrões de extensão para a linguagem SQL foram propostos, como o SQL/MM (Melton e Eisenberg, 2001), no intuito de possibilitar a recuperação por conteúdo utilizando SQL diretamente. Com esse pressuposto os seguintes requisitos são necessários:

- Sintaxe de livre associação de extratores/funções de distância desde que sejam compatíveis;

- Sintaxe de especificação de tipos de dados complexos no momento de criação de estruturas internas aos SGBDR;

- Sintaxe de inserção/atualização de dados complexos a partir de diversas origens em estruturas previamente definidas.

\subsection{Objetivos}

Usualmente é possível empreender consultas por similaridade com resultados satisfatórios utilizando-se funções de distância e extratores concebidos para finalidades genéricas (Traina et al., 2003). No entanto, grande parte das vezes a acurácia destas consultas pode melhorar se, para um determinado tipo de dado complexo, utiliza-se um extrator e/ou uma função de distância específica do domínio.

Por exemplo, no caso de imagens médicas, os especialistas do domínio tem maior facilidade em detectar lesões utilizando determinado extrator específico em detrimento de outros (Eisa et al., 2009). Esse cenário se repete em muitos outros domínios como 
agrometeorologia, mercado de ações e detecção de voz (Lee e Jo, 1999)(Paliwal e Alsteris, 2005). Isso significa que cada aplicação deveria poder definir/usar seus proprios extratores e funções de distância.

Outro fator que impacta na acurácia das consultas por similaridade é a escolha da função de distância, que por diversas vezes frustra o especialista de domínio por não corresponder ao seu senso humano de comparação (Guld et al., 2007) (Jyothi et al., 2012). A escolha correta da função de distância, preferivelmente feita de forma automática, é de fundamental importância para a diminuição do gap semântico entre a modelagem feita para a consulta por similaridade e o mundo real.

Nesse sentido, flexibilizar a escolha destes dois componentes da consulta e suas eventuais combinações é de fundamental importância para a popularização do modelo de recuperação por conteúdo e do aumento da sua taxa de acurácia. Sobre esta constatação são traçados os objetivos deste trabalho:

- Proposição e validação de um modelo de dados que suporte novos dados complexos como, por exemplo, séries temporais financeiras.

- Proposição de novos métodos extratores de características para esses novos dados complexos.

- Proposição e validação de uma arquitetura que suporte a adição de novos extratores e funções de distância para os diversos tipos de dados complexos e que permita ao especialista combiná-las em qualquer ordem.

- Extensão/Adequação da linguagem DDL para a representação de funções de distância que ainda não foram definidos claramente na literatura.

- Extensão/Adequação da linguagem SQL estendida proposta no SIREN para suporte aos novos tipos de dados definidos.

Deve-se ressaltar que os objetivos do presente trabalho tem o caráter de integrar e estender ferramentas já conhecidas, bem como desenvolver novos extratores e funções de distância para imagens e séries temporais que possam ser associadas de acordo com o parecer e a necessidade do especialista, o que contribui com o avanço das pesquisas da área no sentido de reduzir o gap semântico entre o modelo consolidado na literatura e os ambientes existentes.

\subsection{Principais Contribuições}

As principais contribuições deste trabalho de mestrado são referentes a: 
- Ampliação dos recursos do framework Siren: Foram definidos novos tipos de dados, novos extratores de características, funções de distância e uma expansão da arquitetura de tabelas dos recursos iniciais do Siren. Através dessa nova arquitetura modular é possível a criação de novas definições que estendem a sintaxe padrão da linguagem SQL, sendo possível incorporar o módulo de interpretação de SQL estendido aos SGBDR Oracle ${ }^{\circledR}$, Postgres ${ }^{\circledR}$ e MySQL ${ }^{\circledR}$. Desta forma, também é possível incorporar novos recursos de otimização de consultas, estatísticas e realimentação de relevância a medida em que forem sendo desenvolvidos. Adicionalmente, foram desenvolvidas e adicionadas bibliotecas que abordam o tratamento de imagens, áudio e séries-temporais financeiras, a extração de características destes dados complexos e funções de distância para sua comparação. Como contribuição adicional este trabalho também implementou um protótipo de shell interpretativo para SQL estendido que utiliza os recursos disponíveis no framework.

\section{- Definição de uma nova abordagem para o tratamento de séries-temporais} financeiras: Foi definido um novo tipo de dado complexo para manipulação de séries-temporais financeiras. Sobre o mesmo foi proposto um novo extrator de característica que possibilita a abordagem de análise e, principalmente, forecasting via consulta por similaridade. Somados aos recursos diponibilizados pelo interpretador de consultas de SQL estendido, torna-se possível a realização de consultas por meio de um SGBDR que podem fornecer informações interessantes sobre tendências, manipulando grande volumes de dados em condições rigídas de tempo de resposta.

O suporte desenvolvido para séries-temporais permite validar o ambiente extensível desenvolvido para o SIREN e para arquiteturas de extensão para consultas por similaridade, para permitir que aplicações em geral possam acrescentar os extratores e funções de distância que lhes sejam interessantes.

\subsection{Organização do Trabalho}

Esta monografia está organizada da seguinte maneira:

Capítulo 1 - São apresentadas as considerações iniciais, a motivação para o desenvolvimento do trabalho, os objetivos de seu desenvolvimento e a organização desse documento;

Capítulo 2 - Inicia-se a revisão bibliográfica, abordando-se os conceitos básicos de consultas por similaridade como extratores de características e funções de distância;

Capítulo 3 - Continua-se a revisão bibliográfica, em particular, sobre SQL estendido para comandos DDL e DML; 
Capítulo 4 - Apresentam-se detalhes de implementação, conjuntos de teste e proposições utilizados neste trabalho;

Capítulo 5 - Apresentam-se os resultados alcançados sobre os objetivos traçados e realiza-se uma discussão inicial;

Capítulo 6 - Apresentam-se as considerações finais e possíveis continuações de trabalhos. 


$=$

\section{Consultas por Similaridade: Definições e Estruturação}

Sistemas Gerenciadores de Bases de Dados Relacionais são projetados para lidar eficientemente (em termos de performance e armazenamento) com os chamados dados tradicionais (números e strings) que estão definidos em um domínio onde é possível a integral aplicação das propriedades de relação de ordem total.

A expansão do uso de aplicações multimídia nos últimos anos, no entanto, indicou a necessidade de armazenar e integrar esses novos tipos de dados aos SGBDR. Esses dados possuem informações de característica subjetiva e interna de modo que as propriedades ROT, quando aplicáveis, não demonstram utilidade prática ou semântica.

Usualmente, um dado complexo é armazenado internamente em um SGBDR na forma de um atributo BLOB que consiste que uma grande sequência de bits sem interpretação direta. Alguns SGBDR mais robustos (Kaster et al., 2009) já incorporaram em sua arquitetura interna um tratamento especial para alguns destes tipos de dados complexos mais definidos, como o tipo de imagem DICOM (Pianykh, 2008), um padrão de imagens médicas sobre o qual é possível realizar consultas tradicionais através de metadados.

No entanto, em se tratando de recuperar informações internas aos dados armazenados como BLOB ainda é necessária a utilização de uma estrutura que possibilite que o paradigma das consultas por similaridade possa ser aplicável.

Neste capítulo far-se-á um recorte da revisão bibliográfica do arcabouço já consolidado de técnicas que permitem a realização de consultas por similaridade, em particular para os tipos de dados: imagens médicas, séries temporais financeiras e áudios (Hjaltason e Samet, 2003). 


\subsection{Introdução}

O tratamento de dados complexos em ambientes de classificação, clusterização e recuperação de dados por conteúdo exige uma abordagem sistematizada e computacionalmente eficiente, pois estes dados ocupam grandes espaços em disco e não suportam as tradicionais operações com operadores como $>,<,>=,<=, \neq \mathrm{e}=$.

A evolução do desenvolvimento de técnicas de extração de características para imagens e funções de distância (Yianilos, 1993) possibilitou o surgimento das primeiras aplicações de Recuperação de Imagens por Conteúdo (CBIR) (Müller et al., 2004). Desta forma, vários surveys que descrevem o comportamento de novos extratores e funções de distância, podem ser encontrados na literatura (Zezula et al., 2010) bem como seus desdobramentos em áreas correlatas como os parâmetros de percepção (Ponciano-Silva, 2008), utilizados em aplicativos médicos.

Com o aumento da capacidade de armazenamento de dispositivos de hardware e a scanners médicos de alta resolução, cresceu também a quantidade de imagens armazenadas, bem como a quantidade de áudios digitais como músicas e entrevistas e outros tipos de dados complexos como séries-temporais financeiras e agrometereológicas.

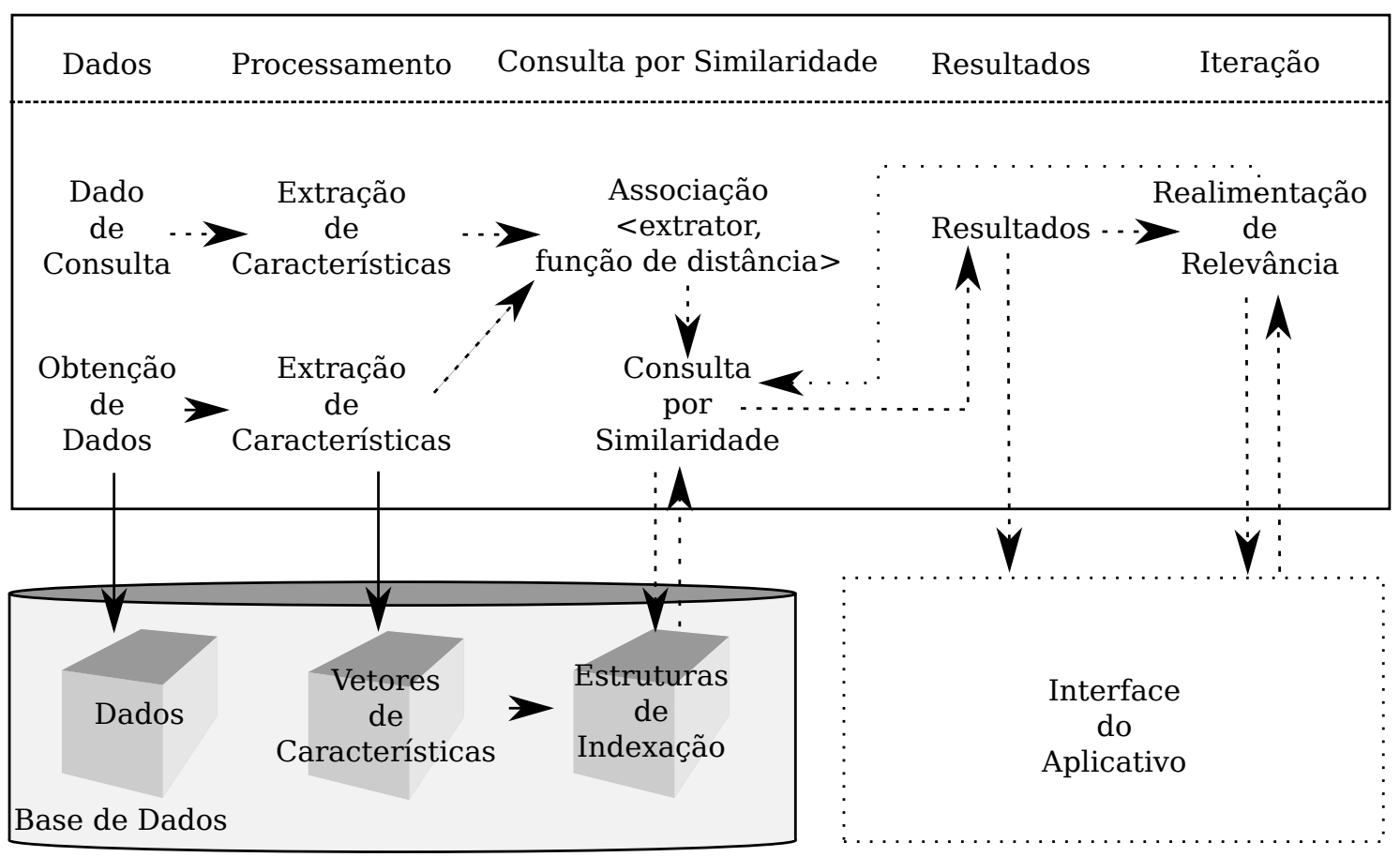

Figura 2.1: Workflow de um sistema de recuperação por conteúdo.

Um estudo aprofundado sobre a estrutura de dados de áudio e aplicações de Recuperação de Áudio por Conteúdo (CBAR) pode ser encontrado em (Kovačević et al., 2010). Um survey sobre extratores de características de áudio pode ser encontrado em (Lu, 2001). Com relação a séries-temporais (sejam financeiras ou meterológicas), a maioria dos aplicativos tem por objetivo realizar atividades de forecasting (predição), 
associando extratores de características próprios para este domínio e técnicas de agrupamento/classificação (Atsalakis e Valavanis, 2009).

Um dos principais componentes dos sistemas de recuperação de dados por conteúdos são os métodos extratores de características. Esses métodos, usualmente, são capazes de descrever um objeto complexo usando um valor ou um conjunto de dados numéricos denominado vetor de características.

Uma vez extraídas as características, o sistema CBIR ou CBAR pode realizar a comparação dos dados complexos, comparando os vetores de características para encontrar os objetos mais similares. Um sistema genérico de recuperação de dados por conteúdo é apresentado na Figura 2.1. Estruturado desta forma, um sistema de recuperação por conteúdo possui, basicamente, quatro módulos (Datta et al., 2008):

- Um módulo responsável pela extração automática de características;

- Um conjunto de métricas capazes de mensurar a similaridade entre dados complexos;

- Um mecanismo de execução de consultas por similaridade capaz de realizar a recuperação dos dados em tempo hábil;

- Uma interface com o usuário capaz de identificar as consultas feitas pelo usuário e fornecer-lhe respostas adequadas.

As próximas seções discutem os módulos acima e demais conceitos relacionados às consultas por similaridade como extratores de características, funções de distância e estruturas de indexação para cada tipo de dado complexo tratado neste trabalho.

\subsubsection{Imagens Médicas}

Doenças ou defeitos em sistemas fisiológicos podem levar a processos patológicos identificados por diversos sinais. Estes, por sua vez, podem ser representados na forma de imagens que são um meio de representação visual de grande importância para a área médica. O uso destas imagens muitas vezes está ligado ao diagnóstico de uma doença ou alteração biológica. Por isso, é extremamente desejável que as imagens obtidas sejam capazes de representar (com adequada resolução e contraste) possíveis não-conformidade fornecendo a maior quantidade de informações visuais possíveis. Além disso, as amostras (radiografias) coletadas são de propriedade do paciente e estão sob legislação específica bem como sujeitas ao código deontológico dos profissionais que a manipulam (Ponciano-Silva, 2008).

Para atender a este aspecto legal de privacidade, os fabricantes de scanners utilizavam diversos padrões de armazenamento de imagens e troca de informações. Em 1985, a Associação de Radiologistas Americanos junto com a Associação de Fabricantes Elétricos Americanos (ACR/NEMA) publicou o primeiro conjunto de normas que deveriam reger a obtenção, comunicação e armazenamento de imagens médicas (Eichelberg et al., 2005). 
A pesquisa originada pela publicação destas primeiras normas evoluiu até chegar na publicação do padrão de imagens médicas mais utilizado pelos fabricantes de scanners: o padrão DICOM (Pianykh, 2008).

\subsubsection{DICOM}

O formato Digital Image and Communications in Medicine (DICOM) pode ser entendido como um stream de dados (Eichelberg et al., 2005), onde cada bloco de dados do stream tem um significado específico. Por sua vez, cada bloco é composto de um par de valores, conhecidos como tag's, que definem (1) o metadado do qual se trata a informação e (2) o valor do metadado.

Esses pares descrevem toda a informação de um arquivo DICOM, o que inclui a imagem propriamente dita e uma sequência de metadados que dão informações pessoais sobre o paciente e sobre a realização do exame (máquina, firmware, operadors, etc.). Essa organização foi proposta para atender os princípios de uma transmissão de informação segura seguindo os moldes de comunicações em redes de computadores (Pianykh, 2008).
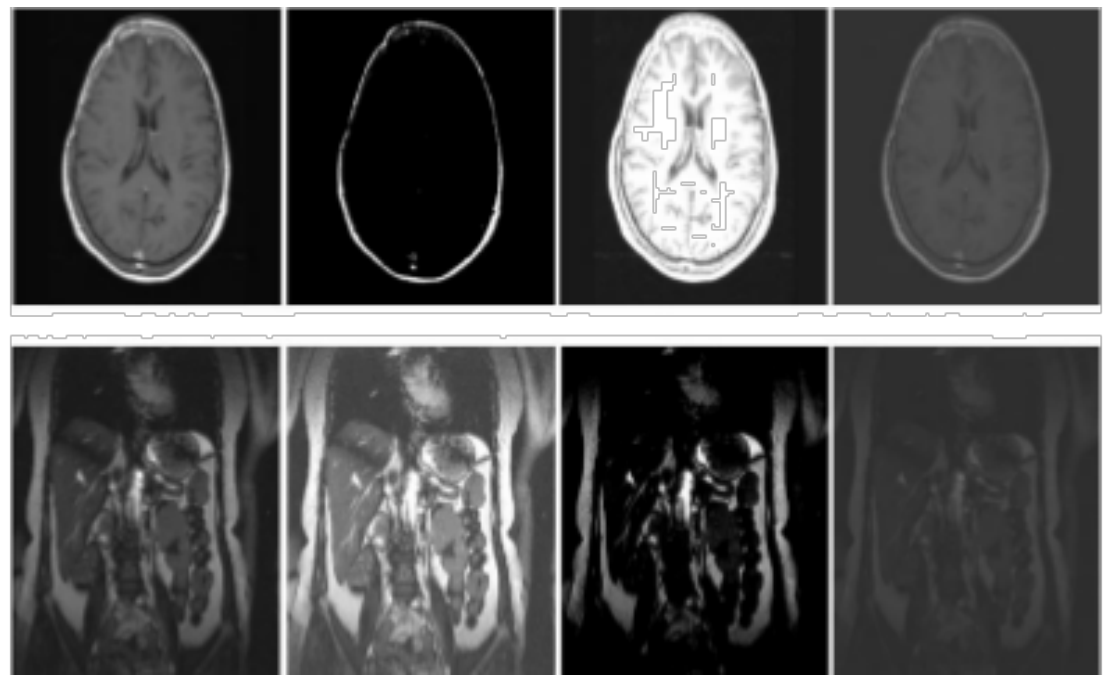

Figura 2.2: Diferentes visualizações de caixa craniana e torácia devido a operações de alargamento de contraste.

A última tag do cabeçalho DICOM faz referência aos pixels da imagem. Normalmente, uma imagem DICOM pode armazenar de 12 a 16 bits por pixel, permitindo a visualização da imagem em alto contraste, o que equivaleria dizer que o profissional de saúde pode ver a imagem sob diversas perspectivas através de uma operação conhecida como alargamento de contraste (Preim e Bartz, 2007) ou "janelamento". Esta operação é uma transformação linear de tonalidade dos pixels ilustrada na Figura 2.2, permitindo a visualização parametrizada para alguns pontos de interesse como ossos, determinados órgãos, água (volume) entre outros. 


\subsection{Extratores de Características}

Independentemente do formato e da tecnica de compactação utilizados, dados complexos tendem a ocupar tamanho relativamente grande em disco (Nixon e Aguado, 2008). Este fator também é um dos contribuintes para a dificultosa tarefa de controle e recuperação por parte dos SGBDR.

Uma das possíveis estratégias usadas nos SGBDR é a criação de índices ordenados para facilitar o acesso e a consulta, aumentando a velocidade da resposta. Na maioria dos casos de dados complexos, como de imagens, essa indexação ordenada dos dados não pode ser feita, pois não existe uma relação semântica de grandeza entre os dados, ou seja, não é possível, por exemplo, afirmar que a imagem A é maior ou menor que a imagem B.

Uma abordagem conhecida na literatura é a utilização de técnicas de extração de características que representem os dados originais e que, muitas vezes, possam utilizar uma estrutura de tamanho várias vezes menor do que o tamanho do dado original (Ciaccia et al., 1997), sendo passível de uma nova forma de indexação. De um modo genérico é possível extrair características dos dados em sua forma original (raw data) (Zhang et al., 2012) e também a partir dos dados originais transformados por funções matemáticas (Graps, 1995).

No caso de imagens, a maioria dos métodos extrai características diretamente dos dados brutos, através dos pixels que representam a imagem. Os métodos de extração de características são baseados em propriedades derivadas diretamente da representação computacional como cor e textura (Gonzalez e Woods, 2006) ou de propriedades subjetivas como forma e direção (Theodoridis e Koutroumbas, 2006).

Já no caso das séries temporais financeiras é possível utilizar características referentes às oscilações do valor da série tais como médias diárias e liquidez (Atsalakis e Valavanis, 2009) gerando valores que possam ser usados diretamente como entradas por técnicas de classificação ou por modelos estocásticos.

Para o domínio de dados de áudio, existem basicamente duas divisões para os métodos de extração de caracteristícas. Na primeira, o arquivo de áudio é dividido em pequenos segmentos no tempo e valores são extraídos para cada grupo. Essa abordagem é representada como uma série temporal de características (Kovačević et al., 2010). Na segunda, é extraído um único conjunto de características para todo o arquivo de áudio (Yang et al., 1999). Cada uma dessas abordagens é recomendada para uma atividade fim como classificação de áudio e recuperação de áudio por conteúdo.

É importante notar que cada domínio de dados complexos possui propriedades intrínsecas utilizadas para sua representação. Para ilustrar essas propriedades devemos considerar cada domínio. Portanto, a seguir, serão apresentados nas próximas subseções conceitos relacionados à extração de características dos dados complexos utilizados neste trabalho: imagens, áudio e séries temporais financeiras. 


\subsubsection{Extratores de Características de Imagens Baseados em Cor}

Utilizar a propriedade da tonalidade de cada pixel constitui a base da maioria das técnicas de extração de características de imagens. Usualmente, cada cor pode ser representada em uma escala de vermelho-verde-azul (RGB) que representam as três cores primárias na teoria de cores de Goethe. Outras representações como matiz-saturação-valor (HSV) podem descrever o sistema de cores de maneira mais intuitiva, segundo alguns pesquisadores (Preim e Bartz, 2007). Os dispositivos eletrônicos e algoritmos podem passar de um sistema a outro através de conversão de espaço de coordenadas.

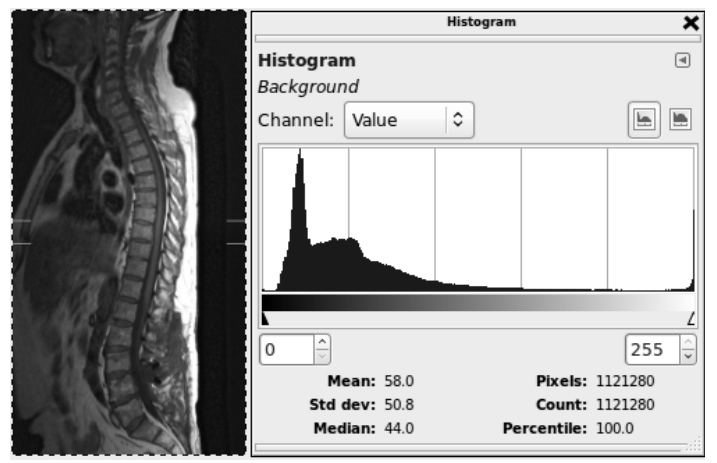

Figura 2.3: Imagem e respectivo histograma em escala de cinza.

Um primeiro extrator de característica que pode ser utilizado para representar uma imagem é o histograma (Figura 2.3). Histograma é o termo estatístico utilizado para representar, através de barras, a contagem de ocorrência de certo acontecimento. Histogramas são simples de se obter computacionalmente e utilizam poucos recursos de hardware, tornando esta técnica uma das mais populares em aplicativos CBIR e de processamento de imagens de tempo real (Traina et al., 2003)(Theodoridis e Koutroumbas, 2006).

O histograma de cores em imagens conta a ocorrência de certa tonalidade em uma imagem (Gonzalez e Woods, 2006). Formalmente, um histograma de uma imagem digital com intensidade de pixels no intervalo $[0, L-1]$, com $L$ sendo limitante da quantidade de tonalidades, é uma função discreta $h\left(r_{k}\right)=n_{k}$, onde $r_{k}$ é o $k$-ésimo valor de intensidade e $n_{k}$ é a quantidade de pixels da imagem de intensidade $r_{k}$.

Em muitos aplicativos, em especial os aplicativos que utilizam imagens de alta definição, é importante normalizar a contagem de pixels para que os valores aparentemente distintos, porém equivalentes após uma operação de escala, não prejudiquem o processamento posterior. A normalização comumente utilizada é redimensionar o intervalo do histograma para $[0,1]$ através de uma função $f\left(r_{k}\right)=n_{k} / m$, onde $m=\max \left(n_{k}\right)$ para $k=0,1, \ldots, L-1$.

Outra importante norma, conhecida como Probabilidade de Intensidade, trata de estimar a probabilidade de ocorrência de uma determinada tonalidade. Dessa forma a 
normalização é dada através da função $p\left(r_{k}\right)=n_{k} / N M$, onde $N$ é a altura da imagem e $M$ a largura. Decorre, então, que $\sum_{k=0}^{L-1} p\left(r_{k}\right)=1$.
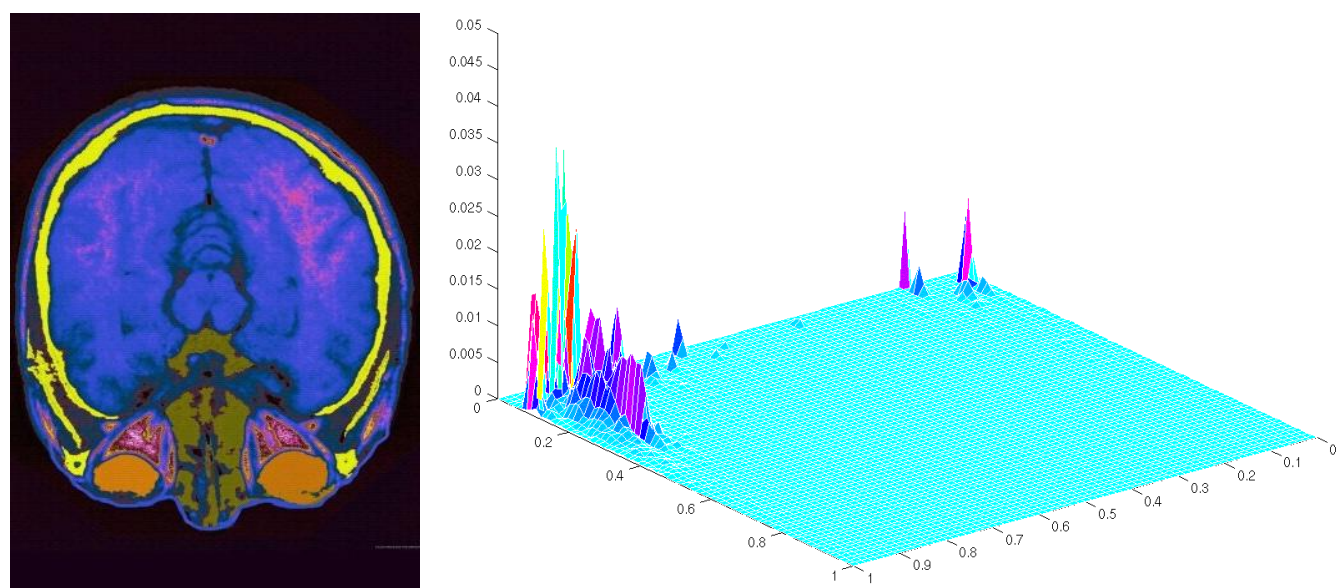

Figura 2.4: Histograma de cores de imagem, em escala RGB.

Embora os histogramas de escala de cinza sejam os mais utilizados é possível obter histogramas de cores (RGB) como o exemplo ilustrado na Figura 2.4. A contagem e normalização dos valores ocorrem para cada um dos componentes resultando em um histograma que pode ser visualizado (Yang et al., 1999). Para os histogramas de cor apenas o conjunto de tonalidades é considerado e não a relação espaço-objeto, fazendo com que imagens com formas distintas possam ser consideradas como similares (Huang et al., 1999).

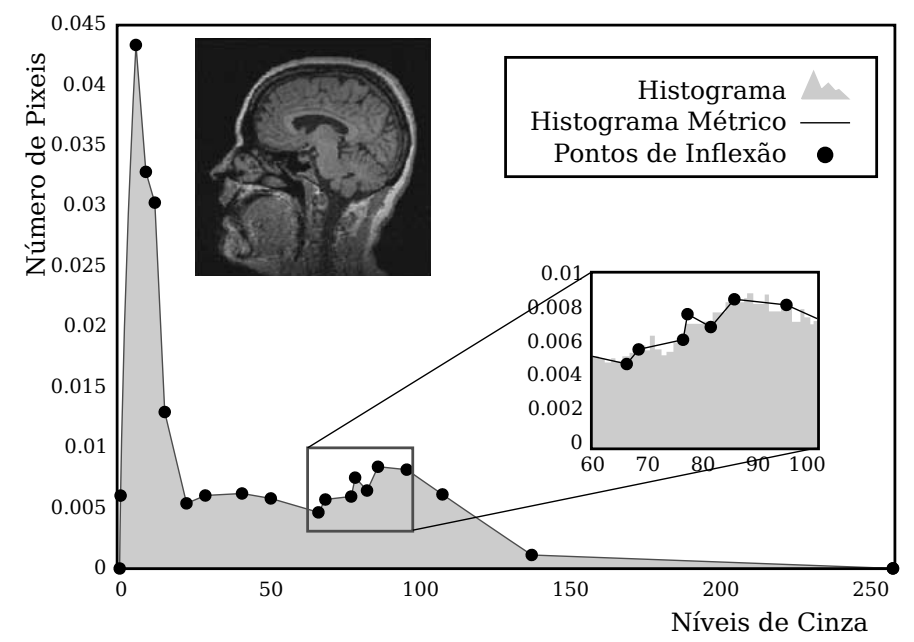

Figura 2.5: Histograma métrico a partir do histograma tradicional. Adaptado de (Traina et al., 2003).

A técnica tradicional do histograma pode ocasionar armazenamento de informações pouco relevantes sobre as características extraídas. Isso ocorre quando a imagem possui pixels de tonalidades muito próximas que podem ser representadas por um único valor. A técnica de Histograma Métrico (Traina et al., 2003) leva em consideração as correlações 
entre as dimensões do histograma que podem ser representadas por pequenas funções de primeiro grau, em intervalos (pontos) definidos, denominados pontos de inflexão ou pontos de máximo e mínimo locais, e que apresentam, com perdas bastante reduzidas, o histograma original.

Esta técnica leva a uma sumarização do histograma que preserva as características de contagem de cores. A figura 2.5 ilustra como o histograma métrico pode representar o histograma original desprezando as informações pouco relevantes obtidas no processo de extração de características.

Além dos histogramas descritos neste capítulo, existem na literatura muitos outros extratores baseados em cores como Color Coherence Vector (Pass e Zabih, 1996), Cell Histograms (Stehling et al., 2003) dentre outros. O Comitê do padrão MPEG-7 também propôs alguns novos extratores baseados em cor com o objetivo de garantir a interoperabilidade entre sistemas que operam com o MPEG-7 (Manjunath et al., 2001).Entre eles se destacam o Color Layout e o TCDescriptor. Outros métodos de extração são descritos em publicações tais como (Krishnamachari et al., 2000) (Sookhanaphibarn e Lursinsap, 2006).

\subsubsection{Extratores de Características Baseados em Textura}

Textura é a característica de rugosidade de uma superfície, facilmente identificada pelo tato, um dos sentidos humanos. Entretanto, quando há referência à textura na literatura de processamento de imagens, não temos uma definição amplamente aceita.

De acordo com (Barioni, 2006), a textura em uma imagem pode ser definida como “(...) um padrão visual no qual há um grande número de elementos arranjados de forma equânime e com densidades variadas". Os métodos numéricos de identificação de representação de textura em imagens podem ser classificados em estatísticos (que realizam contagem de tonalidades dos pixels) ou estruturais (que se baseiam na identificação e classificação prévia de elementos de uma cena). Além disso, podem-se combinar extratores baseados em textura e cor, como as Wavelets (Murphy e Singh, 2010).

\subsubsection{As Características de Haralick}

Um dos extratores de características para textura mais conhecidos da literatura é o padrão de Haralick. Em seu artigo original, Haralick (Haralick et al., 1973) propôs a observância de quatorze padrões numéricos que descrevem texturas de imagens de tons de cinza e atribuiu às mesmas significados semânticos como variância e entropia.

Para obter estes padrões numéricos, Haralick diagramou um processamento prévio de contagem da frequência relativa das cores dos pixels, parametrizados por dois argumentos: distância e ângulo. Assim sendo, para cada distância e ângulo é possível obter uma matriz, denominada por Haralick de matriz de dependência, com as frequências relativas 
de aparições de determinadas tonalidades próximas umas das outras. Fixada a variação dos parâmetros (distância, ângulo), para cada uma das combinações, fica definida a quantidade de matrizes de co-ocorrência.

Tabela 2.1: Descrição de seis das características de Haralick.

\begin{tabular}{|c|c|c|}
\hline Descritor & Equação & Semântica \\
\hline Variância & $\sum_{i} \sum_{j}(i-j)^{2} P(i, j)$ & Nível de contraste da imagem \\
\hline Entropia & $\sum_{i} \sum_{j} P(i, j) \log (P(i, j))$ & Suavidade da imagem \\
\hline Energia & $\sum_{i} \sum_{j} P^{2}(i, j)$ & Uniformidade da imagem \\
\hline Homogeneidade & $\sum_{i} \sum_{j} \frac{P(i, j)}{(1+|i-j|)}$ & Distribuição dos pixels \\
\hline Momento Terceira Ordem & $\sum_{i} \sum_{j}(i-j)^{3} P(i, j)$ & Nível de distorção da imagem \\
\hline Variância Inversa & $\sum_{i} \sum_{j} \frac{P(i, j)}{(i-j)^{2}}$ & Nível inverso de contraste \\
\hline
\end{tabular}

Uma vez calculadas as frequências de aparições dos pixels, Haralick matematicamente formula a descrição das características, que são obtidas por somatórios dos valores contidos nas matrizes de dependência e também detalhou o significado semântico de cada característica. Na Tabela 2.1 são apresentadas as características mais comumente utilizadas (Ponciano-Silva, 2008), onde $P(i, j)$ é o valor do elemento $(i, j)$ na matriz de co-ocorrência.

\subsubsection{Wavelets}

Algumas características de cor e textura podem ser combinadas quando se pretende identificar objetos em imagens. A diferença entre resolução e contraste de objetos é a principal idéia por trás das transformadas wavelets. A idéia de redução gráfica de escala é ilustrada em (Gonzalez e Woods, 2006) por meio das "pirâmides de imagens" (como ilustrado na Figura 2.6. Para cada uma das reduções é possível a utilização de um filtro, como o filtro de passa-baixas de Gauss. Postulado de modo matemático, a teoria das wavelets se baseia na sobreposição de funções (Graps, 1995).

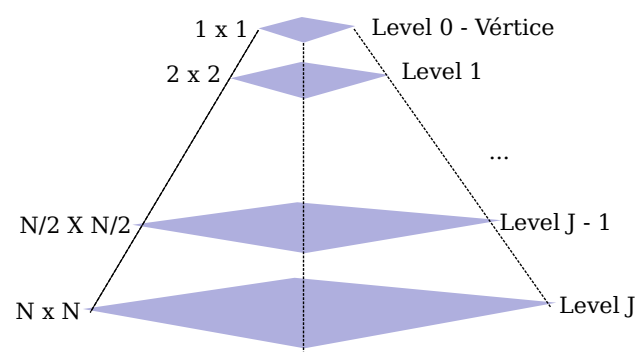

Figura 2.6: Pirâmide de imagens. Adaptado de (Gonzalez e Woods, 2006).

A análise dos processos de wavelets se inicia com a adoção de uma função protótipo, denominada wavelet-mãe que é seguidamente contraída em frequências mais altas para gerar uma representação fiel da wavelet original em um espaço de menor dimensão (Dorini 
e Leite, 2009). Em seu funcionamento discreto, para dados em duas dimensões, pode-se aplicar os seguintes passos: para determinada imagem é procedida uma redução constante, aplicando-se filtros e preservando visualmente as mesmas características.
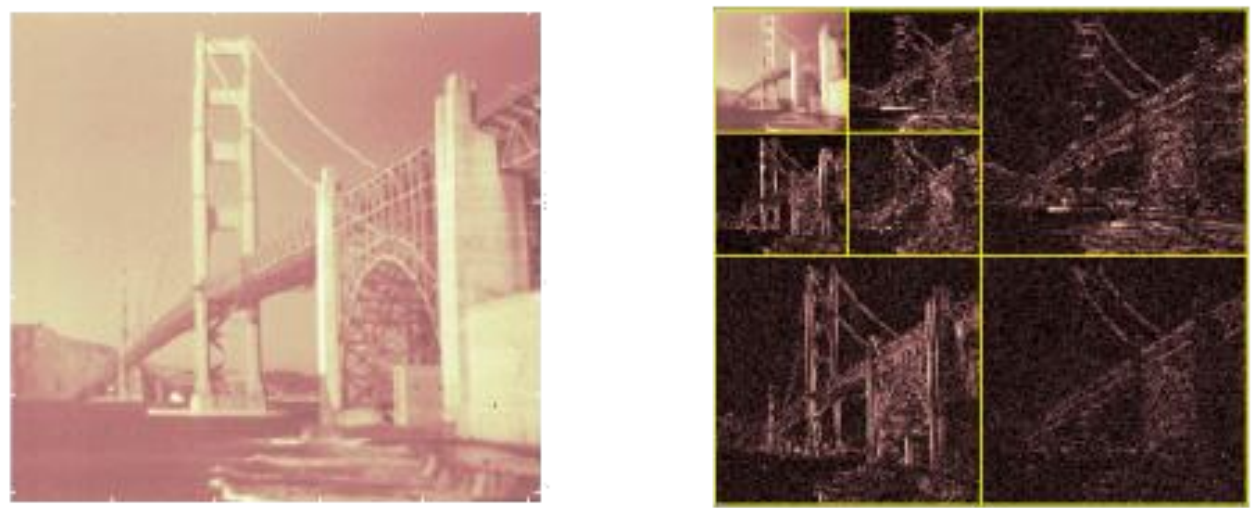

Figura 2.7: Exemplo de redução de escala para transformadas wavelets.

Para cada iteração de redução da imagem na pirâmide pode-se gerar uma imagem estimada da redução usando filtros (Welstead, 1999) e é possível realizar um cálculo de diferenças entre o resultado previsto e o resultado obtido (Gonzalez e Woods, 2006). O resultado de algumas iterações para uma determinada imagem pode ser conferido na Figura 2.7.

As transformações discretas de Haar e Daubechies (Lina, 1997)(Murphy e Singh, 2010) fornecem uma base para decomposição e reconstrução reconhecidamente eficientes em um plano bidimensional. Aplicando-as em imagens, no segundo passo da redução de resolução da imagem, obtem-se as características para a extração desejada.

Suponha que, genericamente, as transformadas possam ser expressas como: $T=$ $H F H^{T}$, onde $\mathrm{F}$ é uma imagem $N X N$, onde $N$ é uma das dimensões da imagem e $H$ é uma matriz de transformação. A principal diferença entre as transformadas de Haar e Daubechies são os valores utilizados para a composição de $H$. Daubechies propõe a utilização de mais algumas informações do sinal da wavelet-mãe, dando um suporte um pouco maior na decomposição da imagem.

Uma análise matemática e aprofundada sobre a teoria das wavelets, filtros de transformações suportados, limitações e uso da técnica para outros dados complexos como áudios podem ser encontrados em (Welstead, 1999).

\subsubsection{Extratores de Características Baseadas em Forma}

Identificar formas de objetos inseridos em uma imagem representa uma grande desafio computacional. Embora muito se tenha caminhado em termos de métodos práticos de descrição de forma, as metodologias utilizadas não possuem aceitação unânime. 
Usualmente, procura-se segmentar a imagem isolando o objeto e realiza-se a extração de características de seu contorno (Felipe, 2005). Nesse paradigma, uma técnica bastante utilizada é a chamada códigos da cadeia (Theodoridis e Koutroumbas, 2006). Esse método aproxima o contorno do objeto por segmentos de reta interconectados onde são explicitados a direção e o comprimento.

Do mesmo modo, a frequência direcional e a curvatura são exemplos de características que podem ser extraídas. Os Momentos Geométricos também são um método bastante tratados na literatura (Sonka et al., 2008). Essa técnica se baseia no somatório dos valores de intensidades dos pixels junto a dois pesos $p$ e $q$ que definem a ordem do Momento. Essa técnica possui uma grande capacidade de representar formas compostas por várias regiões disjuntas. Alguns dos Momentos mais citados na literatura são os Momentos de Hu e Momentos de Zernike (Sonka et al., 2008)(Kim et al., 2000). Existem ainda vários outros extratores baseados em reconhecimento de forma. Uma revisão sobre estes métodos pode ser encontrada em (Liu et al., 2007).

\subsubsection{Extratores de Características para Áudio baseados em Frequência e Tempo}

Uma das primeiras aplicações para o processamento de sinais de áudio e extração de características foi desenvolvida para a representação e o processamento da fala (Kovačević et al., 2010). Na maioria das técnicas desenvolvidas, as características são obtidas da análise do formato espectral da onda representativa do áudio, ou seja, são métodos de análise baseados na análise de <Tempo-Frequência $>$, como a Transformada de Fourier de Curta Duração (STFT) (Paliwal e Alsteris, 2005).

A técnica STFT representa, basicamente, a distribuição de energia de um sinal de áudio em um plano tempo-frequência. Algumas variações deste método podem ser usadas para deteç̧ão de timbres e empregadas na análise de músicas (Kovačević et al., 2006). Esta técnica é baseada no uso discreto do tempo e na descrição matemática formal dada pela Transformada Discreta de Fourier (DFT). A DFT opera em comprimento finito de sequências, enquanto a STFT pode representar sequências de qualquer tamanho quebrando-as em blocos curtos e aplicando a DFT em cada bloco.

A DFT também é a base para outros métodos do tipo Mel Frequency Cepstral Coefficients (MFCC) (Saidi et al., 2010). As características definidas por esse método podem ser utilizadas para descrever aspectos relacionados ao timbre de um sinal de áudio. Existem, também, outros métodos que têm por base a STFT e trazem consigo alguma modificação e vantagem, seja em tempo de processamento, seja na forma de manter a representação dos dados de áudio originais.

Além das técnicas apresentadas, outras foram propostas no sentido de captar características específicas do ambiente musical. Além de informações concernentes ao 
timbre, outras características da teoria musical como ritmo e harmonia podem ser melhor representados e descritos por técnicas como o Beat Histogram (Gruhne et al., 2009) e o Histogramas de Borda de Pitch (Won, 2004), respectivamente.

\subsubsection{Séries-Temporais Financeiras: Estruturas e Indicadores}

Uma série-temporal pode ser representada por um conjunto de observações $X=$ $\left\{x_{t}, x_{t+1}, \ldots, x_{t+n}\right\}$ onde $x_{t}$ é o valor da observação no instante $t$. Séries-temporais podem ter tamanho indefinido, aumentando a medida em que novos dados são coletados (Keogh e Kasetty, 2002). No caso particular de séries-temporais financeiras cada ponto de observação pode incluir um conjunto de valores tais como abertura, fechamento, máxima, mínima e volume. Dada uma determinada janela definida sobre essa classe de series, elas podem visualizadas de acordo com as informações de cada ponto observado.

A Figura 2.8 mostra a visualização de uma mesma série-temporal financeira, em uma mesma janela sobre três diferentes visualizações: Montanha, o modelo gráfico que mostra o valor de uma ação quando do encerramento de um determinado período (por exemplo, dia); Candlestick, uma representação gráfica utilizada para visualização de padrões; AMaMiF, uma representação sintética de linhas que mostra os valores de máxima, miníma, abertura e fechamento.

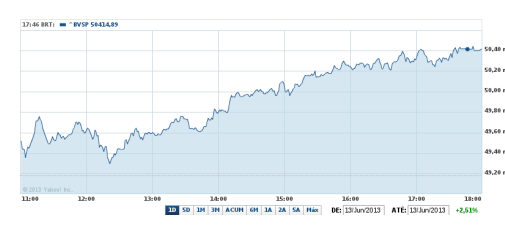

(A)

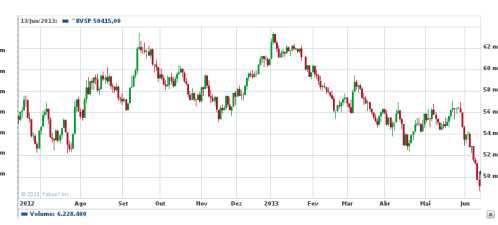

(B)

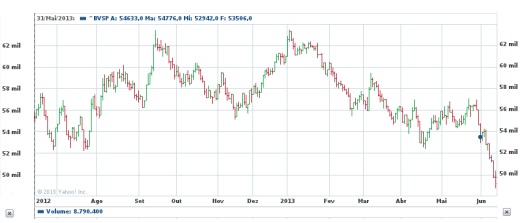

(C)

Figura 2.8: Diversas visualizações gráficas para uma mesma série-temporal financeira. (A) Montanha. (B) Candlestick. (C) AMaMiF.

Existem basicamente duas vertentes para análise de séries-temporais financeiras. A primeira, conhecida como fundamentalista (Mills e Markellos, 2008) (Cios, 2001) afirma que os preços de ações dependem única e exclusivamente do cenário macro-econômico e político, e que dados sobre estes cenários devem ser considerados em ações de forecasting. A segunda vertente, conhecida como análise técnica, afirma que os dados de maior relevância para entendimento do comportamento da série-temporal financeira podem ser encontrados em dados anteriores (Armano et al., 2005) (Martinez et al., 2009).

Ainda de acordo com a vertende de análise técnica (Hamilton, 1994), existem duas abordagens para encontrar informações relevantes em dados anteriores: A análise gráfica, cujo foco é encontrar padrões gráficos e portanto um pouco subjetiva; e a análise de indicadores técnicos por exemplo, dados sobre volume) cuja informação pode ser diretamente utilizada por técnicas de regressão linear (Box e Jenkins, 1990) ou processos 
estocásticos, como a Cadeia de Markov (Bengio et al., 1991) sem proceder a extração de características do dado complexo.

Quando se considera a construção de um sistema de recuperação por conteúdo, pode-se perceber a possibilidade de tratar a série-temporal financeira como um outro dado complexo qualquer, isto é, é possível proceder a extração de características a partir de informações gráficas, realizar a consulta por similaridade sobre os mesmos e então exibir os resultados para o especialista. Essa abordagem também possibilita a realização de forecasting automático (Martinez et al., 2009), sem prejuízo semântico.

\subsubsection{Extração de Características para Séries-Temporais Financeiras}

Muitos sistemas de forecasting empregam extração de características para analisar dados de períodos anteriores. Embora seja possível e comum a utilização dos dados brutos diretamente (Armano et al., 2005), os resultados pouco assertivos indicam que a extração de características é uma etapa que pode ser utilizada para aumentar o grau de confiança destes sistemas.

Alguns dados podem ser extraídos diretamente de cada ponto da série-temporal, como o preço médio (Raposo et al., 2005), a volatilidade de Chainkin (Lee et al., 2012) e distribuição de William (Kumaresan e Tufts, 1982). No entanto, a maioria dos métodos de extração de características são desenvolvidos visando a análise gráfica.

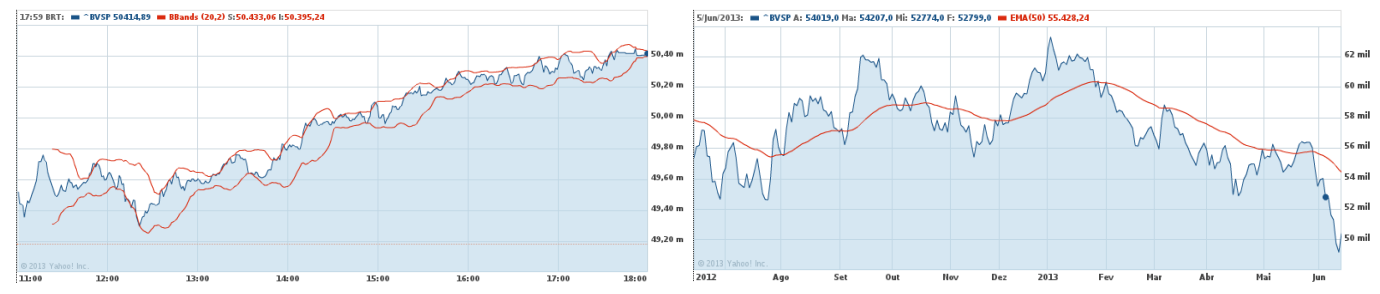

(A)

(B)

Figura 2.9: Extração de características gráficas. (A) Bandas de Bollinger. (B) Média Móvel Exponencial.

A Figura 2.9 ilustra dois extratores de características para gráficos: As bandas de Bollinger e a Média Móvel Exponencial (EMA). A EMA é baseada na média simples, porém enfatiza os dados de preços mais recentes. Matematicamente, a média móvel exponencial é dada por $E M A\left(x_{t}\right)=x_{t} * k+E M A\left(x_{t-1}\right) *(1-k)$, onde $k=2 /(n+1)$, sendo $n$ a quantidade de pontos em análise (Krollner et al., 2010).

As bandas de Bollinger (Butler e Kazakov, 2010) podem ser vistas como curvas desenhadas na estrutura de preços e ao seu redor para definir o máximo e mínimo de forma relativa. A base das bandas é uma média simples. Utiliza-se uma medida de volatilidade, o desvio padrão, para definir a largura das bandas, tornando-as adaptáveis. Os padrões são bandas espalhadas acima e abaixo de uma média simples por dois desvios padrão. 


\subsection{Funções de Distância}

Responder consultas por similaridade passa por mensurar o quão parecidos são dois vetores de características sob uma determinada ótica. Essa quantificação é realizada de acordo com uma função de distância, cujo resultado representa a proximidade entre um par de objetos dado por um valor real indicando a semelhança entre eles. Quanto maior estes valores, mais distantes estarão os objetos. Quanto menor, mais próximos.

Se for retornado o valor zero, significa que os vetores de características comparados são idênticos. As funções de distância utilizadas com a finalidade de recuperação de dados por conteúdo utilizadas na literatura são, em sua maioria, definidas dentro de um espaço métrico (Bugatti et al., 2008). Isso facilita a construção de métodos de acesso que usem estruturas de índices para recuperar os dados.

No caso particular de comparação entre vetores de coordenadas numéricas em um espaço $n$-dimensional com distância métrica definida tem-se um caso conhecido de espaço métrico denominado espaço vetorial de dimensão finita.

Na literatura há uma ampla gama de funções de distância (Felipe, 2005) que obedecem as restrições de espaço métrico, denominadas funções métricas, capazes de medir a similaridade entre dois objetos segundo os critérios de espaço métrico. Uma categoria amplamente utilizada é a família Minkowsky. De modo genérico, pode-se definir a família Minkowsky como:

$$
d(x, y)=\sqrt[p]{\sum_{i=1}^{n}\left|x_{i}-y_{i}\right|^{p}}
$$

Onde $x=x_{1}, x_{2}, \ldots, x_{n}, y=y_{1}, y_{2}, \ldots, y_{n}$ são os vetores a serem comparados e $p$ é um parâmetro que define a função de distância. Para $p=1,2$ e $\infty$ temos as funções de distância City-Block, Euclidiana e Chebyshev, respectivamente. Existem na literatura outras funções de distância da família Minkowsky para outros valores de $p$, bem como modificações onde há a inserção de pesos (fixos ou variáveis) para cada um dos componentes dos vetores de características comparáveis.

Um survey sobre outras funções de distância em espaços vetoriais comuns na literatura como a função Mahalanobis, Camberra e outras pode ser encontrado em (Liu et al., 2007). Em se tratando de espaços não vetoriais, onde as características extraídas dos dados complexos não resultam em dois vetores de características de mesmo tamanho há a necessidade de outras funções de distância que não as fornecidas pela família Minkwosky e derivadas.

A função de distância Ledit (Levenshtein, 1966) é capaz de mensurar a similaridade entre cadeias de caracteres por meio da contagem de operações de inserção, alteração e remoção para transformar uma cadeia na outra. Por exemplo, ('vida', 'viga') resulta em 
uma alteração enquanto ('vida', 'vigario') resulta em uma alteração e três inserções. A função Ledit pode ser empregada na comparação de palavras e cadeias de DNA, entre outras.

A escolha correta da melhor função de distância depende da aplicação fim. Em alguns casos muitas podem, inclusive, mostrar-se pouco aceitáveis para os especialistas do domínio. Essa adequação é objeto de muita discussão, como por exemplo em (Ponciano-Silva, 2008) e (Bugatti et al., 2008).

Em (Smeulders et al., 2000), os autores definem o gap semântico gerado pelas funções de distância em ambientes de recuperação de imagens por conteúdo como a ausência de coincidência entre a informação que pode ser extraída dos dados e a interpretação dos mesmos sob determinado contexto. Uma hierarquia no uso das funções de distância de acordo com o domínio pode ser encontrada em (Vasconcelos e Lippman, 2000).

\subsubsection{A função de Distância Metric Histogram - MHD}

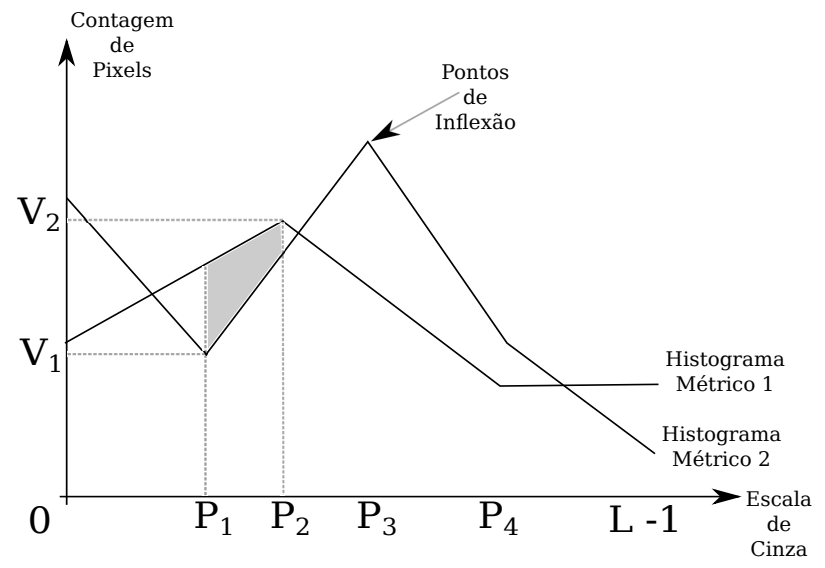

Figura 2.10: Função MHD parcial para a região da figura limitada pelos quatro pontos indicados. Adaptado de (Traina et al., 2003).

As características extraídas pelo método do Histograma Métrico tratado na Seção 2.5 só podem ser comparadas por funções de distância puramente métricas, como a função MHD (Traina et al., 2003). A função Metric Histogram Distance (MHD) considera os dados extraídos na formação de funções lineares e realiza a comparação entre suas respectivas áreas. A Figura 2.10 ilustra o cálculo da distância entre dois histogramas métricos. O cálculo considera a área entre as regiões conexas definidas pelos pontos de inflexão.

\subsubsection{Data Time Warping - Função de Distância Não-Métrica}

Existem, também, outras funções de avaliação de similaridade entre dados complexos que não obedecem as restrições de espaço métrico como a Data Time Warping (DTW) (Santosh et al., 2011)(Vlachos et al., 2006). Essa função é bastante referenciada na 
literatura pela sua eficiência em comparar duas séries temporais (financeiras, por exemplo) e fornecer uma medida de similaridade entre elas. A grande restrição para funções deste tipo é que elas não serão passíveis de indexação, uma vez que não obdecem a propriedade de desigualdade triangular, por exemplo.

Suponha, para efeito de formalização, duas séries temporais $Q=q_{1}, q_{2}, \ldots, q_{m}$ e $C=$ $c_{1}, c_{2}, \ldots, c_{n}$ com $m \neq n$. A DTW irá construir uma matriz $n \times m$ onde cada posição $(i, j)$ representa a distância euclidiana $d\left(q_{i}, c_{j}\right)$, correspondendo ao alinhamento entre os pontos $q_{i}$ e $c_{j}$. Considere, então, $W$ como um caminho contíguo entre $Q$ e $C$. Um elemento $k$ de $W$ é definido como $W_{k}=(i, j)_{k}$. Desta forma:

$$
W=w_{1}, w_{2}, \ldots, w_{n}, \max \{m, n\} \leq k \leq m+n-1
$$

$W$ está sujeito a restrições como: Continuidade, Monoticidade e Condições de Limite como descrito em (Ratanamahatana, 2005). Consideremos agora como resultado da DTW, a seguinte expressão:

$$
D T W(Q, C)=\min \left\{\sum_{i=1}^{k} \frac{w_{i}}{k}\right\},
$$

Onde o valor encontrado em $\operatorname{DTW}(Q, C)$ mensura a distância entre as duas séries temporais.

\subsection{Consultas por Similaridade}

As consultas por similaridade visam recuperar dados complexos similares baseados na relação de proximidade, sob determinada ótica, dentro de um espaço métrico, ou seja, encontrar objetos avaliados com o menor valor quando submetidos a comparação por uma função de distância junto ao objeto de consulta.

Do ponto de vista do usuário, duas consultas por similaridade podem ser realizadas: a consulta por abrangência ou a consulta aos $k$ - vizinhos mais próximos. Elas divergem entre si no tocante aos seus limitadores.

Enquanto a busca aos $k$-vizinhos mais próximos tenta recuperar um número exato de objetos similares (Barioni, 2006), independentemente do seu raio de proximidade do objeto de consulta, a busca por abrangência tem o princípio oposto, isto é, tenta recuperar todos (independente da quantidade) os objetos mais próximos do centro de consulta que estejam dentro de um determinado raio (Bugatti et al., 2008). Uma representação gráfica da diferença entre as duas consultas por similaridade é dada pela Figura 2.11. Postulado de maneira formal, temos:

1. Consulta por Abrangência (Range Query): Dado um objeto de consulta $s_{q} \in S_{1}$ contido em $\mathbb{S}$, uma função de distância métrica $d()$ e uma distância máxima de 
busca $\xi$, a consulta $R_{q}\left(s_{q}, \xi\right)$ recupera todos os objetos de $S_{1}$ que estejam a uma distância de $s_{q}$ de, no máximo, $\xi$. O subconjunto resposta é $\left\{s_{i} \in S_{1} \mid s\left(s_{q}, s_{i}\right) \leq \xi\right\}$.

2. Consulta aos $k$-Vizinhos mais próximos $\left(k\right.$-NN): Dado um objeto de consulta $s_{q} \in S_{1}$ contido em $\mathbb{S}$, uma função de distância métrica $d()$ e um número inteiro $k$, a consulta $k N N_{q}\left(s_{q}, k\right)$ recupera os objetos mais próximos de $s_{q}$ em $S_{1}$. O subconjunto resposta é denotado por $S^{\prime}=\left\{s_{j} \in S_{1}\left\{\left|S^{\prime}\right|=k, \forall s_{r} \in S^{\prime}, \forall s_{j} \in\left\{S_{1}-S^{\prime}\right\}, d\left(s_{q}, s_{r}\right) \leq\right.\right.$ $\left.d\left(s_{q}, s_{j}\right)\right\}$.

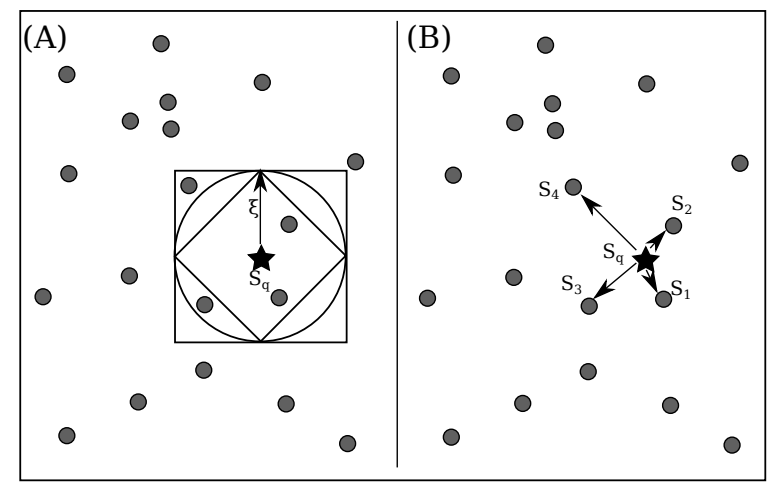

Figura 2.11: (A) Range-Query utilizando a família Minkowsky, para diversos valores de $p=1,2$ e $\infty$ e raio $\xi$. (B) $k$-Vizinhos mais próximos para $k=4$ e $p=2$. Adaptado de (Barioni, 2006).

\subsubsection{Estruturas de Indexação}

A associação entre extrator e função de distância juntamente com o fato da consulta ser por abrangência ou aos $k$-vizinhos mais próximos já permite realizar com sucesso uma busca em uma base de dados complexos. No entanto, mesmo com a habitual sumarização dos dados da base por meio das técnicas de extração de características, os vetores de características resultantes ainda ocupam grande quantidade de memória e a estratégia da realização da consulta por meio de uma busca linear entre eles pode não ser a mais eficiente (Traina et al., 2007).

Assim como para dados escalares (números e strings, por exemplo), existem estruturas de indexação também para dados complexos, que tornam a execução de Range Queries e $k$-NN Queries muito mais ágeis e eficientes (Ciaccia et al., 1997). Essas estruturas diminuem o número de execuções do cálculo de funções de distância e de acessos a disco, o que contribui para uma redução do tempo de processamento da consulta (Carélo et al., 2009).

Quando temos consultas por similaridade em espaços métricos genéricos, pode-se lançar mão das estruturas de indexação conhecidas como Métodos de Acesso Métrico (MAM), que utilizam apenas funções de distância para organizar sua estrutura interna. 
A evolução destas técnicas de indexação pode ser vista no survey de (Skopal, 2010). Vários métodos também podem ser encontrados com detalhes na literatura como a $M$-Tree (Ciaccia et al., 1997), a Família Omni-Tree (Traina et al., 2007), a Onion-Tree (Carélo et al., 2009) e a Slim-Tree (Traina et al., 2002).

\subsubsection{O Método de Acesso Métrico Slim-Tree}

A Slim-Tree (Traina et al., 2002) é uma técnica de indexação para espaços métricos genéricos. Internamente, ela utiliza uma estrutura de dados balanceada e dinâmica que suporta a inserção e remoção de novos elementos a qualquer tempo.

Este MAM utiliza a mesma estratégia de construção de outras árvores balanceadas por construção, como a M-Tree (Traina et al., 2007) escolhendo um elemento central como representante do nó e utilizando as funções de distância para dividir o restante dos objetos do espaço em subgrupos, repetindo o procedimento recursivamente.

A abordagem de construção é bottom-up, assim como a B-Tree (Codd, 1970) (das folhas para o nó raiz), sendo que os objetos são todos armazenados nas folhas e estas, por sua vez, em páginas de tamanho fixo.

Estruturalmente, cada nó não-folha, denominados nós-indíces, possui um objeto como elemento central e um determinado raio de cobertura. Apenas os objetos cobertos por esse raio podem ser elementos deste nó.

Para cada novo objeto a ser inserido, o algoritmo de inserção percorre a árvore a partir do nó raiz até encontrar um nó folha cujo raio de cobertura possa incluir o novo objeto. Caso esta decisão seja aplicável a mais de um nó-candidato uma política de escolha é aplicada (escolha de sub-árvore). Se nenhum nó atende a esse requisito, o nó mais próximo é escolhido para ter seu raio aumentado para englobar o novo objeto.

Esse procedimento é repetido recursivamente até a inserção efetiva do novo objeto. A escolha da política de expansão da árvore é fundamental no que tange aos aspectos de ocupação e taxas de sobreposição dos nós. As possíveis políticas para a escolha das sub-árvores são:

- Aleatório: Apenas seleciona aleatoriamente um dos nós aplicáveis;

- Distância Mínima: Escolhe o novo nó baseado na distância do elemento representante e o novo objeto;

- Ocupação Mínima: Calcula a média de ocupação de cada nó elegível candidato e escolhe aquele que possui a menor taxa de ocupação. Essa é a política padrão.

Conforme os espaços disponíveis no raio de cobertura do nó vão se preenchendo o algoritmo aplica uma política de redistribuição dos nós, sendo, a política padrão, uma distribuição que minimiza a sobreposição dos nós, por meio do cálculo da distância entre os 
representantes dos nós. Além destas, existe, assim como no caso da escolha da sub-árvore, outras duas políticas que incluem a escolha aleatória e a minimização do raio de cobertura entre os nós representantes.

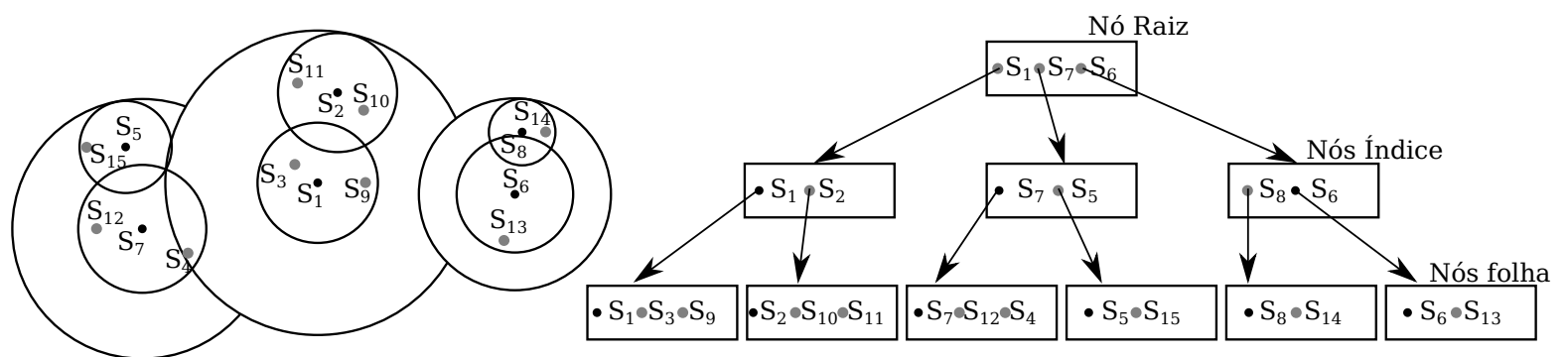

(A)

(B)

Figura 2.12: Slim-Tree com 15 elementos e capacidade $=3$. (A) Estrutura lógica (B) Representação hierárquica. Adaptado de (Barioni, 2006).

As estratégias de expansão do índice, bem como os algoritmos de minimização da sobreposição dos nós estão detalhados em (Traina et al., 2002). A Figura 2.12, representa a Slim-Tree com quinze elementos internos, sendo que cada nó tem capacidade para três.

Um problema comum aos métodos MAM está relacionado a sobreposição dos nós. À medida que aumenta a sobreposição diminui a eficiência da estrutura. A Slim-Tree foi proposta com o intuito de diminuir a quantidade de sobreposição de métodos MAM, mensurando o grau de sobreposição entre os nós (Fat Factor) e escolhendo automaticamente políticas eficientes para o gerenciamento de inserções/remoções do índice.

\subsubsection{Linguagens de Sistemas de Recuperação por Conteúdo}

A esmagadora maioria dos SGBDR relacionais e não relacionais utiliza a linguagem estruturada de consultas (SQL). Já foram feitas algumas extensões de SQL para dados complexos como proposto por (Carey e Kossmann, 1997) e (Barioni et al., 2006) com a inserção de comandos STOP AFTER e CREATE METRIC respectivamente.

Como é cada vez mais comum a necessidade da realização das consultas por similaridade, a Organização Internacional de Padrões (International Organization for Standardization - ISO) sugeriu uma extensão padronizada da linguagem conhecida como SQL/MM (Melton e Eisenberg, 2001) que suporta a manipulação de vários dados multimídia usando tipos de dados e funções definidos pelo usuário (UDT e UDF, respectivamente).

O padrão proposto, no entanto, não permite a utilização de algoritmos otimizados para operações de busca por similaridade nem a integração desses operadores com os operadores utilizados em consultas tradicionais. 


\subsubsection{Sistemas}

Existem alguns sistemas disponíveis para a operação com dados complexos. Com o advento do SQL/MM vários SGBDR passaram a integrar suas funcionalidades como o DB2 ${ }^{\circledR}$ e o Oracle ${ }^{\circledR}$. Nestes ambientes, apenas a recuperação de imagens por conteúdo é possível, sendo que para outros dados complexos, como áudio e séries temporais, podem ser feitas realizando-se consultas sobre meta-dados.

Um sistema proposto por (Barioni et al., 2006) conhecido como SIREN (Similarity Retrieval Engine) é capaz de operar com imagens (através de histogramas de tons de cinza e caracteristícas de Zernike) e áudio (através de STFT), bem como permitir ao usuário alternar entre as funções de distância $L_{1}, L_{2}$ e $L_{\infty}$ e formular a consulta através de uma consulta por SQL estendido. Uma versão web do sistema pode ser obtida em: http://gbdi.icmc.usp.br/siren.

Outro sistema baseado em SQL estendido é o proposto por (Kaster et al., 2009), FMi-SiR que é integrado ao SGBDR Oracle $\AA$, oferecendo suporte a consultas por similaridade para imagens médicas e, em particular, para imagens DICOM. Uma tabela comparativa entre as funcionalidades dos sistemas SIREN e FMi-SiR, pode ser vista abaixo.

$\begin{array}{lll}\text { Característica } & \text { SIREN } & \text { FMi-SiR } \\ \text { Suporte a SQL estendido } & \operatorname{sim} & \operatorname{sim} \\ \text { Suporte a imagens DICOM } & \text { não } & \operatorname{sim} \\ \text { Três ou mais extratores de características } & \text { não } & \operatorname{sim} \\ \text { Duas ou mais funções de distância } & \operatorname{sim} & \operatorname{sim} \\ \text { Suporte a Métodos de Acesso Métrico } & \operatorname{sim} & \operatorname{sim} \\ \text { Suporte a mp3 } & \operatorname{sim} & \text { não } \\ \text { Operadores de similaridade agregada } & \operatorname{sim} & \text { não } \\ \text { Junção por similaridade } & \operatorname{sim} & \operatorname{sim}\end{array}$

Tabela 2.2: Tabela comparativa SIREN e FMi-SiR.

\subsection{Considerações Finais}

Esta seção apresentou um breve resumo sobre as principais técnicas e conceitos necessários à área de pesquisa de recuperação por conteúdo. Somente a integração de todos estes métodos e técnicas permite desenvolver um framework capaz de fornecer todas as funcionalidades e otimizações atingidas em anos de pesquisa.

Como foi observado, permitir ao especialista do domínio dos dados complexos escolher a sua combinação extrator e função de distância adequada para sua aplicação é fundamental, para a diminuição do gap semântico, facilitando a construção de aplicativos 
que se beneficiem da busca por similaridade e permitir um tratamento adequado a consultas sobre dados complexos.

Aumentar a gama de extratores e funções de distância disponíveis ao usuário é de primordial importância para aumentar a aceitação e a qualidade dos sistemas de recuperação por conteúdo. Os sistemas disponíveis, mesmo os que trabalham no espaço métrico como o SIREN, não são capazes de fornecer essa dinamicidade na escolha dos componentes da consulta por similaridade, ou seja, apenas um conjunto limitado e pré-fixado de dados complexos, funções de distância, extratores e estruturas de indexação estão disponíveis e não necessariamente modularizados. 


\section{Recuperação de Dados por Conteúdo em SGBDR}

\subsection{Introdução}

Nos capítulos anteriores foram mostrados alguns dos pontos importantes para a realização de consultas por similaridade sobre dados complexos em ambientes computacionais. As consultas por similaridade tem por objetivo encontrar um objeto, representado por seu vetor de características dentro do espaço métrico cuja distância atenda aos critérios de busca definidos pelo usuário.

Nestes últimos anos (Silva e Aref, 2009) (Wu et al., 2011), muitas tem sido as pesquisas para otimizar o desempenho das consultas por similaridade, em particular aquelas que visam o desenvolvimento de novos Métodos de Acesso Métrico, capazes de acelerar a realização de comparações envolvendo distância. O último item (Ares et al., 2009) para o desenvolvimento de aplicativos de recuperação por conteúdo seria a interface final com o usuário.

Dados complexos possuem significado próprio e podem ser modelados como atributos dentro do modelo Entidade-Relacionamento. Desta feita, torna-se natural que os analistas de bases de dados e DBA's modelem seus bancos de dados para SGBDR seguindo esse paradigma. Assim sendo, deve existir uma linguagem equivalente para que tais operações possam ser efetivadas pelo usuários. Obviamente, estando disponíveis dentro de um SGBDR, a modelagem de aplicações em qualquer linguagem torna-se bastante facilitada, sem mencionar o aspecto da portabilidade.

A linguagem SQL (Structured Query Language) é a linguagem padrão para a maioria dos SGBDR. Algumas iniciativas pioneiras que visam propor uma extensão robusta da 
linguagem SQL, própria a ser integrada em um SGBDR (Guliato et al., 2009). Uma das propostas que se destacam é o SIREN, cuja arquitetura geral está ilustrada na Figura 3.1.

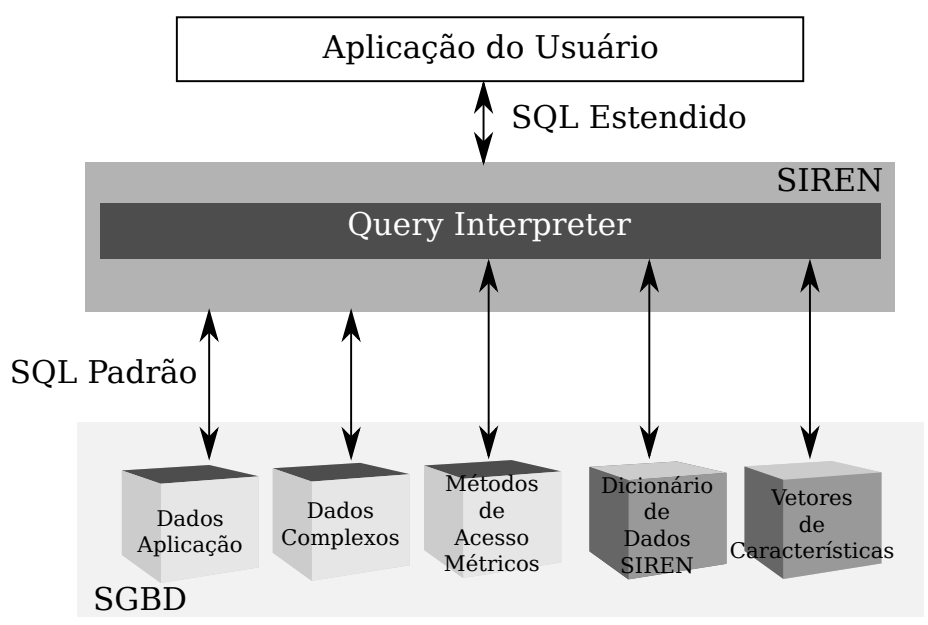

Figura 3.1: Módulos para recuperação por conteúdo.

Neste capítulo far-se-ão as definições sobre a proposta de extensão do SQL, bem como as propostas de sintaxe para a DDL, DML e DCL, considerando o suporte a dados complexos: imagem, áudio e séries-temporais financeiras.

\subsection{Adicionando Suporte a Consultas por Similaridade em SQL}

As consultas por similaridade comparam um objeto de referência com uma coleção de objetos (Müller et al., 2004) previamente armazenados na base de dados. Essas operações foram mostradas no capítulo anterior e definidas como Range Query e k-Nearest Neighbor Query. Estas operações são equivalentes às operações de seleção com predicado $\left(\sigma_{\text {predicado }}\right)$ do SQL tradicional.

Também é possível, comparar pares de objetos de duas relações, em uma operação similar a operação de junção do SQL tradicional $(\stackrel{\text { predicado }}{\bowtie})$. Para dados complexos, é possível empreender junção por abrangência (Silva e Aref, 2009), junção aos $k$-vizinhos mais próximos e aos $k$ pares de vizinhos mais próximos. A partir dessas operações, foi definida a seleção por similaridade de grupo, que permite obter objetos de uma coleção que se assemelham a um ou mais centros de referência.

Formalizando, considere o predicado por similaridade $P<d(), \mathbb{S}, \lim >$. O predicado P utiliza uma função de distância $d()$, em particular as funções de distância definidas no capítulo anterior, definida sobre um domínio de dados complexos $\mathbb{S}$ para coletar uma determinada quantidade de objetos similares lim. No caso das consultas por abrangência e aos vizinhos mais próximos lim, assume os valores do raio ou do número de vizinhos $l i m=\{\xi, k\}$. 
Estes predicados podem ser tanto unários quanto binários. Os predicados unários são as seleções por similaridade. As seleções por similaridade comparam os objetos de um conjunto $S \subseteq \mathbb{S}$ com um ou mais objetos de referência (centros de consulta) $s_{q} \in \mathbb{Q}$. No caso do centro de consulta ser composto por um único elemento temos o caso particular das consultas Range Query e $k$-Nearest Neighbor Query, definidas no capítulo anterior.

Formalmente, uma seleção por similaridade sobre o atributo $S$ da relação $T_{1}$ pode ser representada como $\hat{\sigma}_{(S: P<d(), \mathbb{Q}, l i m>)} T_{1}$. No caso de uma consulta Range Query $\hat{\sigma}_{\left(S: P<d(),\left\{s_{q}\right\}, \xi>\right)} T_{1}$. Já para uma consulta $k$-Nearest Neighbor Query, tem-se $\hat{\sigma}_{\left(S: P<d(),\left\{s_{q}\right\}, k>\right)} T_{1}$.

Quando o conjunto de centros de consulta possui mais de um objeto, $|\mathbb{Q}|>1$, as distâncias de cada centro $s_{q}$ precisam ser calculadas para cada objeto $s_{i}$ do conjunto a ser consultado. Existem várias medidas de similaridade $m_{i}$ propostas na literatura (Barioni, 2006) para conseguir essa agregação em grupo. A equação abaixo, apresenta a proposta: $\left(m_{p}\right)$ o padrão de agregação para múltiplos centros de consulta (considerando $x_{1}$ e $y_{i}$ os elementos que compõem os vetores de características representantes dos dados originais):

$$
m_{p}=\sqrt[p]{\sum_{i=1}^{n}\left|x_{i}-y_{i}\right|^{p}}
$$

Para $\mathrm{p}=1$, a consulta minimiza o somatório das distâncias de cada objeto até os centros, enquanto para $\mathrm{p}=2$, temos uma minimização dos quadrados das distâncias e $\mathrm{p}$ $=\infty$ há uma minimização das distâncias máximas do objeto até os centros de consulta.

Finalmente, os predicados binários são correspondentes às operações de junção por similaridade. Uma junção por similaridade sobre um atributo $S$ de uma relação $T_{1}$ e o atributo $R$ de uma relação $T_{2}$ pode ser descrita como $T_{1} \stackrel{S, R: P<d(), l i m>}{\bowtie} T_{2}$. A resposta de uma junção por similaridade são pares de elementos $s_{i}$ concatenados com elementos $r_{i}$ de acordo com o predicado de junção. O limitante lim define os dois tipos de junção por similaridade: Junção por abrangência (Aggarwal, 2009) e Junção aos k-vizinhos mais próximos (Silva et al., 2010).

\subsection{SQL Estendido para SGBDR}

No processamento de consultas por similaridade sobre dados complexos em um SGBDR faz-se necessária a definição primária de como se dará o armazenamento interno de tais dados. Os padrões de armazenamento sugeridos estão contidos na ISO SQL/MM (Melton e Eisenberg, 2001). Como exemplificação de dados complexos, neste projeto, são tratados imagens, sons e séries temporais financeiras.

Dentro da proposta SQL/MM o tipo STILLIMAGE é destinado a imagens, enquanto o tipo AUDIO é destinado a diversos tipos de áudio. STILLIMAGE encapsula a imagem 
binária, um pequeno conjunto de operações sobre processamento de imagens e outros tipos de metadados.

No entanto, este padrão não possui nenhuma especificação para o armazenamento e representação de dados necessários às consultas por similaridade como extratores e funções de distância. Por este mesmo motivo, cada SGBDR apresenta suas próprias alternativas proprietárias. Um dos primeiros sistemas a apresentar uma alternativa para complementar as definições do SQL/MM foi o IBM DB2. A recuperação de dados por conteúdo é provida pelo sistema QBIC (Ashley et al., 1995) e tanto as consultas por abrangência $\left(R_{q}\right)$ e aos $k$-vizinhos mais próximos são possíveis, com número restrito de extratores e funções de distância.

Assim como o IBM DB2, vários outros módulos foram apresentados como o Informix Excalibur Image Data Blade (Berthold e Meyer-Wegener, 2001) e o Oracle interMedia (Carrer et al., 1999) com o mesmo propósito. No entanto, estes módulos são comerciais e de código fechado não possibilitando melhorias e nem a inclusão de novas características. Além disso, a especificação SQL/MM e os módulos desenvolvidos a partir dela realizam apenas a definição de operações de manipulação dos elementos de dados nos respectivos formatos, não dispondo de operações de comparação entre elementos, nem a especificação de consultas por conteúdo, e especificamente não existe nenhuma menção a consultas por similaridade.

Uma representação alternativa que respeita as definições do SQL/MM é proposta em (Barioni, 2006). Neste sistema, dados simples e complexos podem ser armazenados juntos, sendo que os dados complexos são referenciados na forma de BLOBs ou dados monolíticos. O termo monolítico é usado para evidenciar que o atributo é indivisível para efeito de reconhecimento do SGBDR e o SIREN o referencia como um dado MONOLITHIC.

Existem outros tabalhos (Guliato et al., 2009) para o tratamento de dados multimídia dentro de um SGBDR referenciando os dados complexos a partir de palavras chaves. A proposta deste trabalho flexibiliza a estrutura do SIREN ao ponto de podermos incorporar novos tipos de dados, sem prejuízo da sintaxe do SQL estendido proposto, cuja sintaxe é especificada na Forma de Backus-Naur e cuja semântica já estava validada (Barioni, 2006).

A partir da declaração de novos dados complexos, é possível desenvolver novos comandos para que o usuário possa declarar e criar tabelas e indíces, associando dado complexo/extrator/função de distância da maneira que mais convier ao domínio de dados de sua aplicação.

\subsection{Novas Estruturas de Dados para SQL Estendido}

Quando se trata de executar consultas por similaridade internas a um SGBDR, devemos considerar que o DBA ou o desenvolvedor da aplicação precisa definir novas estruturas 
de dados que definam claramente o que se está buscando para a aplicação. Por exemplo, para um aplicativo que vise recuperar imagens genéricas similares, o DBA poderia criar uma estrutura que definisse previamente que o extrator de características histograma está associado a função de distância euclidiana, sob um determinado identificador (alias). Uma definição dessa associação via SQL estendido pode ser feita por meio de uma estrutura conhecida como métrica.

A partir das métricas, os dados complexos poderiam ser declarados nas definições de tabelas do banco, fazendo referência a essa definição. No comando de criação de tabela, portanto, deve constar após o dado complexo qual (ou quais) associações < extrator, função de distância > são válidas para as consultas por similaridade que serão realizadas sobre o mesmo, com significado particular para a aplicação. Embora não se altere a sintaxe e a parte declarativa do comando de criação de tabelas, é necessária uma nova estrutura capaz de armazenar e identificar essa associação final entre o atributo complexo da relação, o(s) extrator(es) de características e função(es) de distância.

Uma última estrutura de dados importante, deste ponto de vista, são os índices capazes de lidar com dados complexos. No caso dos indíces, podemos lançar mão dos Métodos de Acesso Métricos, gerando estruturas de indexação capazes de responder às consultas por similaridade com maior rapidez. Nas próximas seções far-se-á uma revisão da conjuntura de comandos em SQL estendidos disponibilizados pela primeira versão no SIREN.

\subsection{Definindo Métricas em SQL}

No SQL tradicional não existem operadores de comparação por similaridade. Considerando que os extratores de características e funções de distâncias podem ser rotuladas e armazenadas no dicionário de dados do SGBDR, o conceito de métrica e sua definição (Barioni, 2006) permite que associemos o par < extrator, função de distância >, na forma de uma nova estrutura de dados, sob um comando estendido da DDL.

Para que o uso dessa nova estrutura seja de mais fácil adaptação por parte de desenvolvedores e DBA's, os comandos de criação, remoção e alteração de estruturas devem ser respeitados, definindo, então, os comandos: CREATE METRIC, ALTER METRIC e DROP METRIC.

Seguindo a abordagem tradicional de consultas por similaridade (Silva e Aref, 2009), os dados complexos precisam ser representados no espaço métrico, pois a partir destes torna-se possível a utilização de uma função de distância métrica para mensurar a semelhança entre eles e o uso de métodos de acesso métrico para agilizar a busca nos conjuntos de dados. Os métodos que realizam essas transformações (extratores de características/descritores) podem ser implementados como procedimentos armazenados (stored procedures) que tratam internamente ao SGBDR o dado complexo ou, de forma 
simplificada, podem ser externos aos SGBDR, sendo que o dado complexo é apenas inserido com seu vetor de características correspondente.

A sintaxe do comando CREATE METRIC possui a seguinte estrutura:

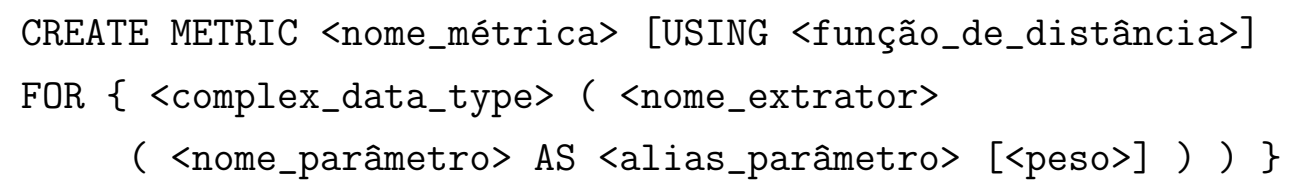

Onde é opcional indicar a função de distância, em omitindo-a utiliza-se a função euclidiana, correspondente ao senso comum de distância (Müller et al., 2004). Para os tipos de dados complexos pode-se utilizar as definições do SQL/MM para imagens e áudio, ainda que a estrutura do comando possa interpretar outros dados complexos (por exemplo, séries-temporais financeiras) e dados complexos definidos sobre dados simples (por exemplo, dados do tipo PARTICULATE).

No caso da sintaxe acima, pode-se também, opcionalmente associar um ou mais extratores a função de distância, diminuindo o gap semântico para a aplicação a medida que o usuário melhor conceber a aplicação. Por exemplo, suponha que o objetivo seja associar o extrator histograma de tons de cinza para imagens com a função de distância euclidiana. A sintaxe ficaria da seguinte forma:

\section{CREATE METRIC histograma FOR STILLIMAGE}

( histogramext ( histogram AS hist) ) ;

No caso de querermos combinar extratores, atribuindo pesos a cada um deles poderíamos usar a mesma construção. Por exemplo, suponha que seja desejável associar o extrator histograma e o extrator wavelets de Haar para imagens, com a função de distância euclidiana. Suponha ainda, que seja importante que a função de distância considere 2 vezes mais o valor extraído pelo histograma do que pelas wavelets. Dessa forma teríamos:

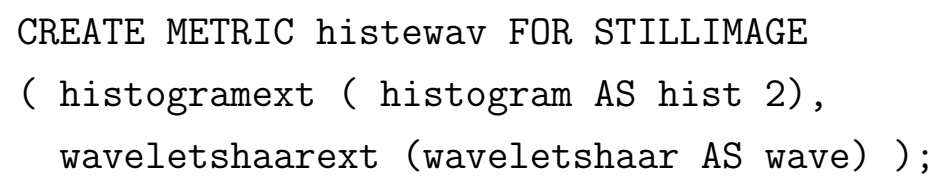

\subsection{Criação de Tabelas com Dados Complexos}

O suporte a dados complexos dentro de tabelas de SGBDR precisa considerar quais são as possíveis consultas por similaridade sobre os mesmos e quais tipos de indexação podem ser efetuadas. A definição de métricas, como visto na seção anterior, possibilita que o DBA faça a ligação explícita entre o dado complexo e o tipo de consulta por similaridade esperada. Para tanto, basta que na declaração DDL de construção de tabela conste uma referência constraint à métrica que deve ser utilizada. 
Assim, torna-se viável e factível a elaboração de um comando da DDL equivalente para criação de tabelas, no qual se acrescente apenas a possibilidade de se declarar uma nova restrição referencial de integridade. Por exemplo, considere uma tabela que armazene exames de mamografia. Um exame de mamografia consiste basicamente de dois cortes para cada mama: cranio caudal e oblíqua-médio lateral. Uma possibilidade de declaração de tabela para o banco de dados poderia ser:

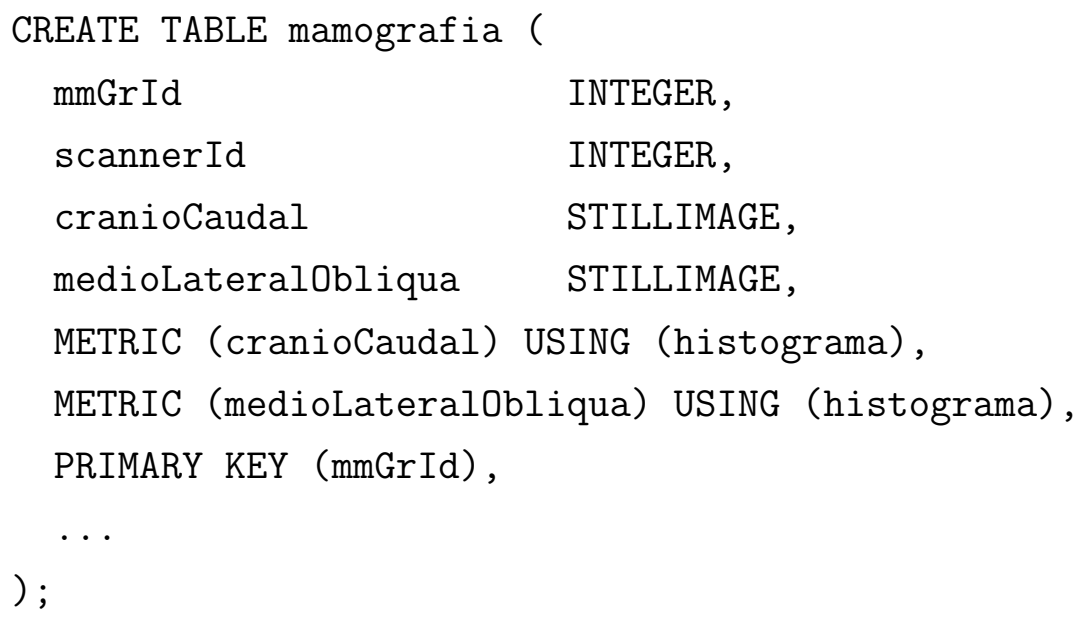

Na declaração da criação de tabela também é possível associar várias opções para comparação na consulta por similaridade. Um usuário, por exemplo, pode estar interessado em realizar consultas por similaridade considerando um histograma, enquanto outro pode estar interessado em utilizar as características extraídas pelo método de wavelets de Haar. Nesse caso, poderia-se declarar a referência a métrica da forma abaixo. Associa-se o dado complexo as métricas histograma e wavelets, usando-se a palavra reservada DEFAULT para ilustrar uma situação de prioridade.

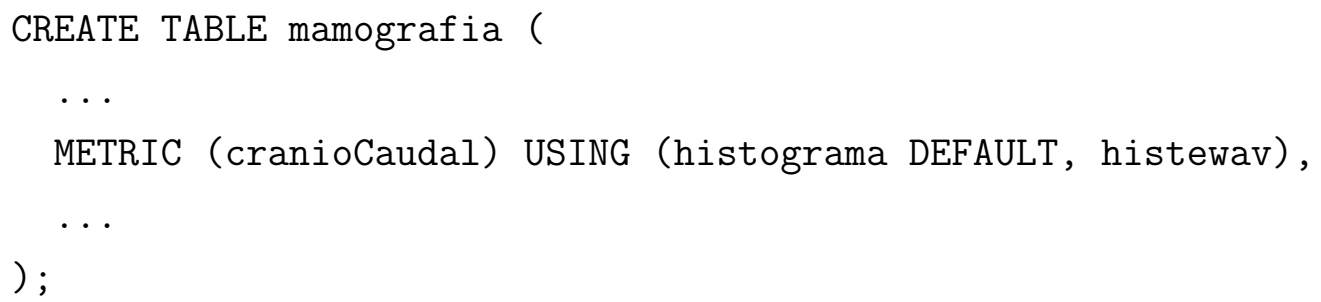

\subsection{Criação de Índices envolvendo Dados Complexos}

Assim como para com as consultas tradicionais, índices são estruturas que aceleram o tempo de resposta quando buscando por uma determinada chave, em determinada ordem. No caso de dados complexos, os Métodos de Acesso Métrico, como Slim-Tree (Traina et al., 2002), M-Tree (Ciaccia et al., 1997) e outros podem reduzir em várias vezes o tempo de resposta do SGBDR quando realizando consultas por similaridade.

Do ponto de vista das estruturas de dados relacionadas neste capítulo, os indíces também permitem que as métricas sejam associadas aos dados complexos, independemente 
da sua declaração no momento de criação de tabelas. Por exemplo, para a declaração da tabela anterior é possível definir o seguinte índice:

CREATE INDEX idxMamografia ON mamografia (cranioCaudal)

USING (histewav);

\subsection{Predicados de Seleção por Similaridade}

Como visto neste capítulo, as seleções por similaridade são expressas em SQL após a clausula WHERE, considerando que as outras classes de operação por similaridade também podem ser expressas em SQL de outras formas. Para uma seleção tradicional, temos a definição em SQL que atributo $\theta$ valor, onde $\theta$ é um operador que se enquadra nas propriedades ROT. Para manter o mesmo padrão, uma seleção por similaridade, pode ser também expressa pela forma atributo $\theta$ valor, agora $\theta$ é um operador de consulta por similaridade (Silva e Aref, 2009), de acordo com a sintaxe:

<atributo> operador <centro_consulta> [STOP AFTER <k>] [RANGE <raio>]

Barioni (Barioni, 2006) propõe dois operadores de similaridade: NEAR e FAR para recuperar objetos que devem estar próximos e distantes. Por exemplo, suponha os seguinte comandos:

(1) SELECT imgId, scannerId FROM mamografia WHERE cranioCaudal NEAR ( SELECT cranioCaudal FROM mamografia WHERE imgId = '1') by histograma RANGE 0.2 ;

(2) SELECT imgId, scannerId FROM mamografia WHERE medioLateralObliqua NEAR ( SELECT medioLateralObliqua FROM mamografia WHERE imgId = '1') by histograma STOP AFTER 3;

O comando descrito em (1) recupera todas as imagens de corte Cranio Caudal da tabela que estão a distância 0.2 da imagem centro de consulta (cujo identificador é igual 1), considerando a representação no espaço métrico via a métrica histograma, que por sua vez, associa a representação dada pelo extrator histograma e a função de distância euclidiana. Já o comando descrito em (2) recupera as 3 imagens Medio Laterais Obliquas mais similares ao centro de consulta, com as mesmas considerações de (1).

Repare que o centro de consulta pode ser expresso como o resultado de um comando SELECT e como tal é um conjunto com qualquer número de linhas (tuplas). Caso esse conjunto possua mais de um elemento podemos realizar uma consulta tendo em conta uma similaridade de grupo. Como visto no começo deste capítulo é possível utilizar uma função de agregação para a realização dessas operações. Neste caso, para cada centro 


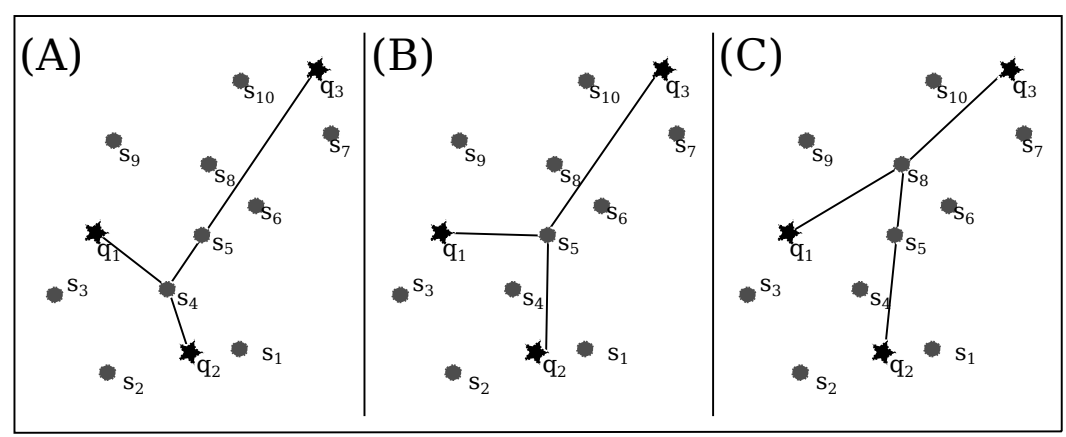

Figura 3.2: Funções de agregação para múltiplos centros de consulta, utilizando-se padrão de agregação $m_{p}$ como função avaliadora. Em (A) O primeiro objeto selecionado a partir de $p=1$. Em (B) O primeiro objeto selecionado tendo-se em $p=2$ e, em (C) O primeiro objeto selecionado considerando-se $p=\infty$.

de consulta é computada a distância pré-estabelecida e então o conjunto de dados que responda a consulta é recuperado.

A Figura 3.2 ilustra como o resultado da agregação para responder à consulta por similaridade com múltiplos centros varia de acordo com a função de distância escolhida. Naturalmente, esse conceito pode ser generalizado para qualquer classe de funções de distância de acordo com o que o desenvolvedor/DBA/especialista julgue o mais adequado para a aplicação.

\subsubsection{Variações de Seleção por Similaridade em SQL}

Embora o predicado mais referenciado seja o dos objetos mais próximos, muitas vezes o que se busca é justamente o oposto (Guld et al., 2007). O uso de consultas com o predicado FAR visa recuperar os objetos com maior dissimilaridade do centro de consulta.

Por exemplo, suponha que tenha-se uma imagem em cores (cujo identificador igual a 1) e o objetivo seja obter as imagens coloridas cujas tonalidades não aparecem na imagem colocada como centro de consulta (negativas). Através de um histograma de cores poderíamos solicitar:

SELECT imagem FROM tabelaImagens WHERE imagem FAR (SELECT imagem FROM tabelaImagens WHERE id = '1') by histograma STOP AFTER 3;

Também é possível, sendo foco de diversos trabalhos (Gupta et al., 2011) (Ballesteros et al., 2011) mesclar consultas por similaridade com consultas tradicionais através de operadores de seleção. Essa classe de consultas aumenta consideravelmente a semântica dos resultados, além de permitir cortes nos resultados, aumentando a capacidade de resolução de problemas via SGBDR. Por exemplo, para mamografias temos um padrão 
de descrição e classificação utilizada pelos especialistas ao laudar um exame, conhecida como BI-RADS (ACR, 2003).

Suponha que na tabela onde são armazenadas as imagens do exame exista também dois campos, onde o médico radiologista insira o diagnóstico (sendo valores pré-definido como, por exemplo, massa ou calcificação) e a descrição BI-RADS do diagnóstico. Assim, uma ferramenta CBMIR poderia, através do SGBDR, responder questões como: "O especialista gostaria de ver as 5 imagens cranio-caudal mais similares a do atual paciente, considerando o diagnóstico de massa e um grau BI-RADS de certeza superior a 2". De acordo, com a disposição das tabelas a consulta poderia ser traduzida como:

SELECT cranioCaudal FROM mamografia WHERE UPPER(diagnostico) = 'MASSA'

AND biRads > 2 AND cranioCaudal NEAR

(SELECT cranioCaudal FROM mamografia WHERE imgId $=$ ' 1 ')

by histograma STOP AFTER 3;

Outra utilização das consultas por similaridade, em particular em domínios médicos é sua a utilização para realizar classificações automáticas por aplicativos CAD (Tang et al., 2009). Por exemplo, suponha, considerando o parágrafo anterior, que gostaríamos de realizar uma classificação automática da imagem em análise (i.e. "massa" ou "calcificação"). Usando o SQL estendido, o seguinte comando pode ser emitido, usando a idéia de "votação" pelos vizinhos mais próximos:

SELECT COUNT(diagnostico), diagnostico AS classificacao FROM mamografia WHERE cranioCaudal NEAR

(SELECT cranioCaudal FROM mamografia WHERE imgId = '1')

by histograma STOP AFTER 3

GROUP BY diagnostico

HAVING COUNT(diagnostico) > 1 ;

Uma última consideração importante sobre consultas que envolvem buscas aos $k$-vizinhos mais próximos é com relação a existência de empates (o conjunto resposta pode ter vários elementos com distâncias iguais à distância máxima). Barioni (Barioni, 2006) propõe o uso da clausula WITH TIE LIST ao final da consulta SQL para determinar o comportamento de recuperar todos os elementos, inclusive empatados no conjunto resposta.

A combinação das cláusulas STOP AFTER e RANGE podem ser combinadas em um único comando para gerar uma consulta $k$ and Range Query. Neste caso a resposta não conterá mais do que $k$ elementos ou que estejam mais distantes do que o raio $\xi$ especificado. Por exemplo, considere o comando: 
(SELECT cranioCaudal FROM mamografia WHERE imgId = '1')

by histograma STOP AFTER 3 RANGE 0.2;

O comando acima recuperará até três elementos cuja distância ao centro não seja maior do que 0.2 , considerando a métrica histograma.

\subsection{Junção por Similaridade em SQL}

Outra operação comum aos dados tradicionais e complexos é a operação de junção. No caso de junção por similaridade, como visto na primeira parte deste trabalho, podemos ter a ocorrência de junção por abrangência, junção aos $k$-vizinhos mais próximos ou aos $k$-pares de vizinhos mais próximos.

Barioni (Barioni, 2006) propôs uma sintaxe que contemplasse a realização dessas junções, especificadas após a clausula FROM do comando SQL, expressa da seguinte maneira:

SELECT . . FROM < tabela1 >

\{RANGE | NEAREST | CLOSEST \} JOIN

< tabela 2 > ON < coluna_dado_complexo1 >

\{NEAR | FAR\} < coluna_dado_complexo2 >

[STOP AFTER <k>] [RANGE <raio>];

\subsection{As Propriedades dos Operadores de Consulta por Similaridade}

Os operadores de consulta por similaridade podem ser combinados com operadores tradicionais para melhorar a semântica e o resultado das consultas em SQL (Silva e Aref, 2009). Internamente, cabe ao SGBDR definir a ordem de execução de cada um dos operadores sobre os dados, podendo utilizar heurísticas que estimam qual o melhor plano de consulta para cada execução.

Podemos visualizar um plano de consulta, como uma "árvore de comandos" como a da Figura 3.3. Nesse sentido, para estimarmos qual o melhor tempo de execução, precisamos considerar a precedência dos operadores, tanto os tradicionais quanto os de similaridade.

Propriedades particularmente interessantes são as propriedades de comutatividade e distributividade. Os predicados por limitados por $\xi$ apresentam também a propriedade

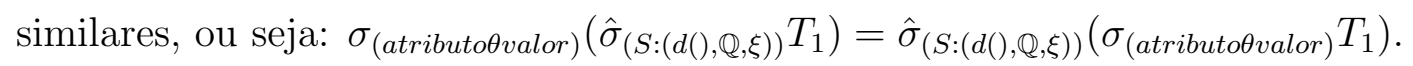

No entanto, para os predicados que utilizam busca aos $k$-vizinhos mais próximos ou aos $k$-pares de vizinhos mais próximos a propriedade de comutatividade não é válida. Essa limitação impede a comutatividade de conjuntos conectados pelos predicados AND 


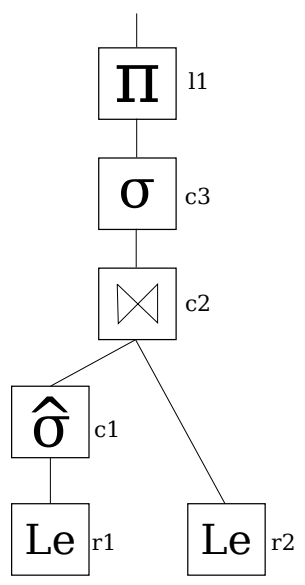

Figura 3.3: Árvore de comandos (bottom-up) que representa a ordem de execução de uma consulta SQL envolvendo operadores por similaridade e tradicionais.

e OR da linguagem SQL, algo que inviabiliza e dificulta a execução de heurísticas para determinar o plano ótimo de consulta. Por exemplo, suponha que a Figura 3.3 represente um plano canônico de execução, as operações de seleção e junção por similaridade só poderiam ser trocadas, na busca pelo plano de execução ótimo, se todas elas fossem operações de Range Query.

Uma das soluções para este impasse de ambiguidade, em se tratando de predicados limitados por $k$, é a definição de regras como: Predicados por similaridade devem ser sempre executados antes dos predicados tradicionais; os predicados limitados por $k$ devem ser executados antes dos predicados Range e; dois ou mais predicados limitados por $k$ devem ser executados independementente e sobre seu conjunto-solução deve ser aplicado uma intersecção/união. Utilizar essas regras, no entanto, pode levar a uma execução lenta e bastante distante dos plano de consultas ideais.

O estudo das propriedades entre os operadores relacionais tradicionais e os operadores por similaridade é alvo de diversas pesquisas (Lange e Naumann, 2013) cujo objetivo final é encontrar novas heurísticas que, respeitando as propriedades tácitas dos operadores de similaridade, sejam capazes de encontrar o plano de consulta ótimo, dentro dos requisitos estabelecidos.

\subsection{Considerações Finais}

Nesse capítulo e no anterior vimos que a literatura nos apresenta um sólido arcabouço para que o conceito de consultas por similaridade seja incorporado aos SGBDR comerciais. Isso, por sua vez, popularizaria e facilitaria o desenvolvimento de aplicações de recuperação por conteúdo, tão necessarias em um ambiente onde os dados multimídia crescem a uma taxa exponencial. 
Agregar todos estes conceitos em um protótipo/framework, no entanto, ainda representa um grande desafio. Mais do que isso, planejar uma arquitetura onde os dados complexos possam co-existir sem que o DBA ou o usuário final precisem realizar pessoalmente as operações e dar suporte a novos dados complexos, a medida em que forem sendo definidos por pesquisas desenvolvidas representa um desafio ainda maior.

A representação do dado complexo no espaço métrico através de um extrator de características e sua comparação através de uma função de distância é apontado como o maior desafio (Müller et al., 2004) para se diminuir o gap semântico entre os aplicativos de recuperação de dados complexos por conteúdo e domínios específicos, como medicina e mercado de ações. Construir novos extratores de características e novas funções de distância também é o objetivo de diversos trabalhos (Kao et al., 2013) (Nixon e Aguado, 2008).

Alguns sistemas, como o FMi-SiR (Kaster et al., 2010) e o SIREN (Barioni, 2006) merecem citação especial, por implementarem protótipos de interpretadores de extensões da linguagem da linguagem SQL, respeitando as definições citadas ao longo dos dois últimos capítulos. Em particular, o SIREN, diferentemente do FMi-SiR que está acoplado ao SGBDR Oracle $\AA$, apresenta uma sintaxe bem definida de SQL estendido que suporta:

- Expressar consultas por similaridade, representando um baixo impacto na linguagem SQL padrão;

- Expressar uma associação inicial entre <extrator, função de distância > para que possam ser efetuadas as comparações entre imagens e dados PARTICULATE (definidos sobre dados simples).

- Expressar a definição de clusters para a definição de agrupamento de dados.

Nos próximos capítulos veremos como, com os conceitos definidos nas últimas seções e partindo-se do interpretador de SQL estendido da versão original do SIREN, pode-se desenvolver um framework onde torna-se possível integrar novos dados complexos, extratores de características, funções de distância, métodos de acesso métrico ao interpretador de consultas, bem como definir novas palavras reservadas (dicionário de dados) para o tratamento dos mesmos, ampliando o conceito do SIREN de mero aplicativo a um framework de recursos capaz de lidar com as diversas consultas por similaridade.

Para validar essa nova abordagem foi construído um aplicativo shell (similar aos disponibilizados pelos SGBDR proprietários) onde é possível inserir os comandos em SQL estendido, interpretá-los e executá-los em três SGBDR distintos.

Além disso, os novos recursos adicionados ao SIREN permitem que se utilize como base as consultas por similaridade via SQL estendido para a criação de aplicativos de recuperação de dados por conteúdo. Em particular é apresentado como exemplo o aplicativo Higiia, para a recuperação de imagens de mamografias por conteúdo, 
desenvolvido sob a nova arquitetura do SIREN e testado em um domínio real, o Hospital das Clinícas de Ribeirão Preto. 


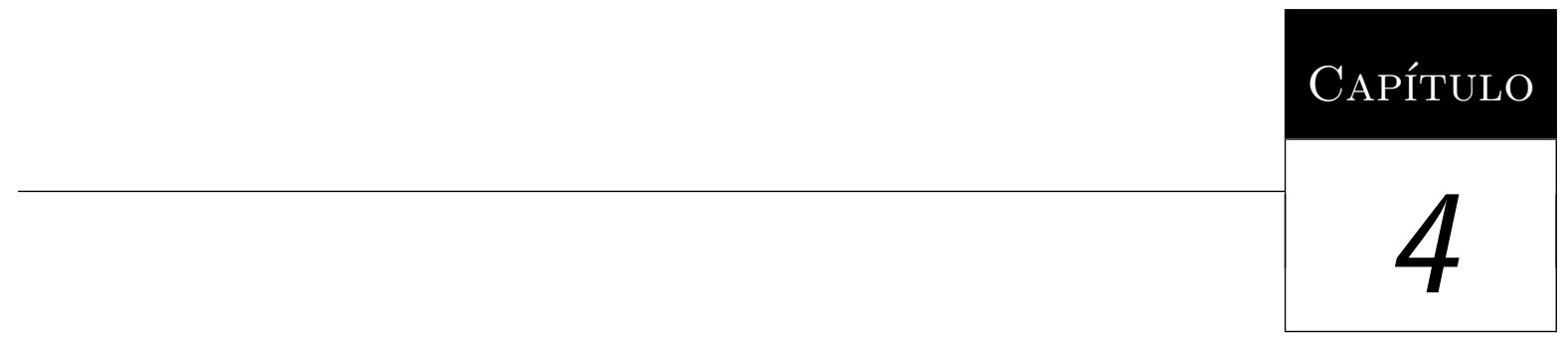

\section{Metodologia}

A nova arquitetura e os novos recursos para o SIREN, requereu que fosse feita uma nova implementação de um shell, similar aos diponibilizados pelos SGBDR comerciais para a validação da proposta deste trabalho. Além disso, para validar a flexibilidade da arquitetura desenvolvida, que deve contemplar suporte a novos dados complexos, foi implementada uma biblioteca de séries-temporais financeiras e criado um novo extrator de característica para este tipo de dados, ao final integrados ao shell. Ainda para validar a arquitetura, foi proposto e implementado um sistema de recuperação de imagens médicas por conteúdo, específico para imagens de mamografia, que utiliza os recursos propostos e implementados neste trabalho, para auxiliar médicos radiologistas em um ambiente real de aplicação. Esses módulos de software são apresentados neste caopítulo.

\subsection{Equipamentos e Detalhes de Implementação}

Todos os recursos (do agora framework) SIREN, incluindo bibliotecas, foram codificado em $\mathrm{C}++$, seguindo a proposta da STL. Para resolver um dos problemas enfrentados pela versão inicial, foi utilizado a plataforma cruzada Qt ßque possibilita que as bibliotecas desenvolvidas funcionem tanto para Windows, quanto Linux e MAC OS. Os drivers para conexão aos bancos utilizados são os disponibilizados pela Nokia @ e Trolltech @ para Qt e permitem conexão aos SGBDR Oracle ( ), PostGres @e MySQL @.

Nessa versão, foram incorporadas as seguintes bibliotecas: Artemis, Apolo, Midas, Hermes, Arboretum e Agathon. Artemis é (Bedo e Traina, 2010b) uma biblioteca para o tratamento de imagens que dá suporte aos formatos jpg, bmp, png, krl e DICOM e possui os seguintes métodos extratores de características: Histograma de tons de cinza, Histograma de Cores, Histograma Métrico (Traina et al., 2003), MPEG Color Layout 
(Ivanova et al., 2010), Haralick (Haralick et al., 1973), Wavelets de Haar (Graps, 1995), Wavelets de Daubechies (Kao et al., 2013) e características de Zernike (Hasan e Shaker, 2012); Apollo (Bedo e Traina, 2010a) é uma biblioteca para tratamento de áudio que trabalha com arquivos no formato wav e tem os extratores de característica PCA e STFT; a biblioteca Midas dá suporte a séries-temporais financeiras no formato xls, csv e txt, e inclui o extrator de características GapExtractor (Bedo et al., 2013b); a biblioteca de funções de distância Hermes (Bedo e Traina, 2011) implementa as funções de distância: Ledit (Levenshtein, 1966), família Minkowsky (Zezula et al., 2010), Metric Histogram Distance (Traina et al., 2003) e DTW (Ratanamahatana, 2005); a biblioteca Arboretum dá suporte aos Métodos de Acesso Métrico Slim Tree (Traina et al., 2002), M-Tree (Ciaccia et al., 1997) e Omni-Tree (Traina et al., 2007). Por fim a biblioteca Agathon, baseado na implementação original do SIREN, é responsável pela interpretação do comando e possui classes e métodos que definem um interpretador de comandos de SQL estendido.

\subsection{Dicionário de Dados do Interpretador}

O dicionário de dados necessário para o interpretador de consultas, armazena dinamicamente os relacionamentos entre $<$ dado complexo, extrator, função de distância $>$. Os dados armazenados a partir das especificaçoes que podem ser fornecidas pelos comandos da DDL são inseridos em relações de trabalho específicas do shell, que são criadas na base como se fossem parte da "meta-base de dados" do interpretador, que posteriormente são utilizadas para validar novos comandos e compor a tradução do SQL complexo para SQL regular, seguindo a orientação de ser um meta-modelo das estruturas de dados em SGBDR (Barioni, 2006).

Foi especificado, nessa nova versão do dicionário de dados, um tratamento específico para o armazenamento de funções de distância, bem como a definição estrutural de restrição de integridade entre dados complexos e extratores de características (qual extrator pode ser aplicado sobre qual dado). A visualização das tabelas e colunas que compõe o dicionário de dados é mostrado na Figura 4.1.

\subsection{Arquitetura da Solução}

Como parte deste projeto de mestrado foi implementado um shell para validar a proposta de trabalhar com diversos tipos de dados complexos, uma ampla gama de funções de distância e extratores de características. O shell é basicamente uma interface que replica o interpretador da linguagem SQL de um SGBD. Ele é baseado no processamento por linha de comando, onde o usuário/DBA insere o comando em SQL estendido e obtém sua resposta, como se estivesse em contato direto com o SGBDR. 


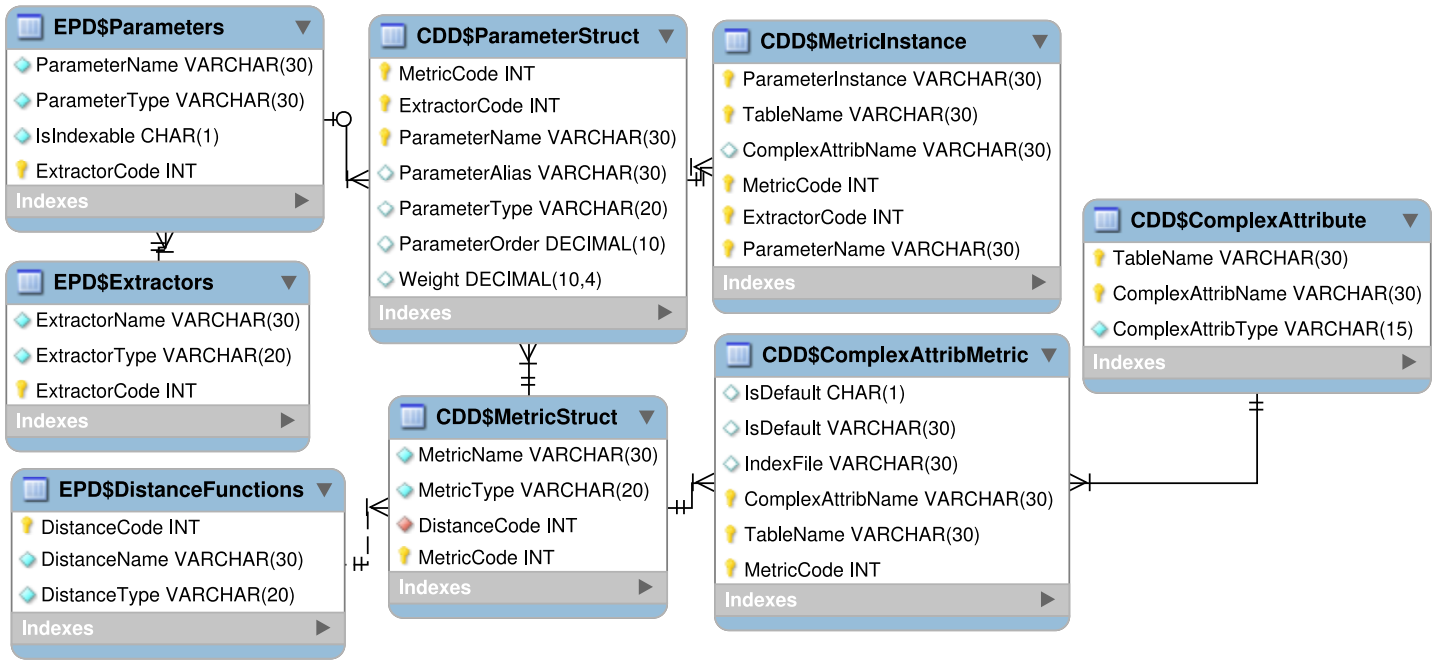

Figura 4.1: Tabelas que definem o dicionário de dados do interpretador de comandos.

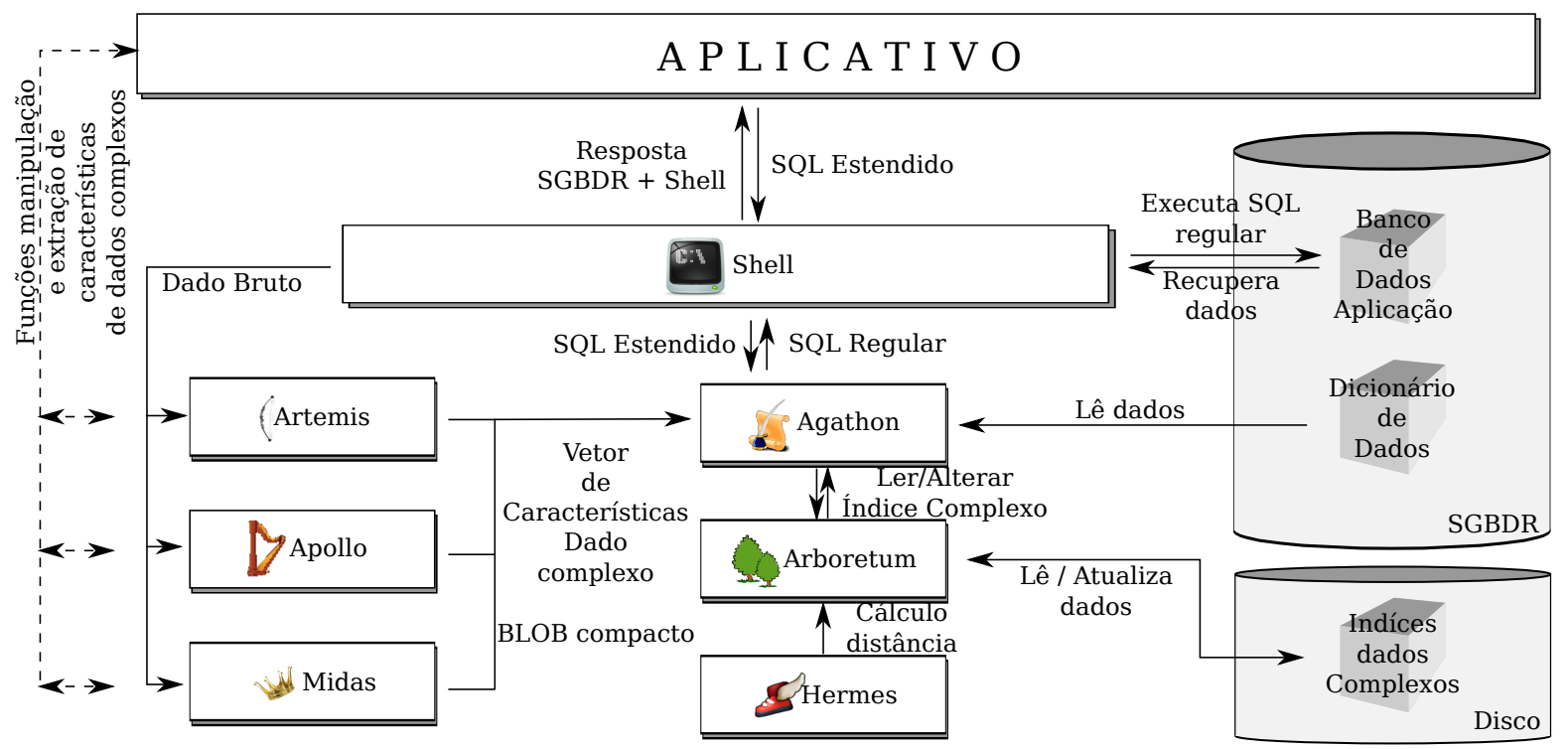

Figura 4.2: Arquitetura do shell.

A Figura 4.2 mostra a arquitetura do novo shell capaz de operar com SQL estendido. Os módulos que se conectam ao shell compõem o framework SIREN e podem ser usados em separado, à medida que o programador de aplicativos achar conveniente. Quando um novo extrator ou uma nova função de distância é integrado às bibliotecas que tratam dos dados complexos, é preciso atualizar o dicionário de dados do SIREN (efetivamente armazenado no SGBDR) para que as declarações posteriores possam contemplar o uso dos novos recursos. É importante destacar que os comandos da linguagem DDL estendida permitem ao programador de aplicativos criar a descrição dos seus dados, incluindo as associações dos tipos e funções de distância disponíveis. No entanto, quando novos tipos de dados complexos, novos extratores de características e novas funções de distância são criadas, sua incorporação ao SIREN é feita pela inclusão dos códigos compilados nas bibliotecas adequadas e pela inclusão de suas descrições no dicionário do SIREN. Essa 
inclusão deve ser feita pelo programador das novas funcionalidades usando comandos de atualização normais do SQL.

\subsubsection{Estruturas de Tabelas de Dados Complexos em SGBDR}

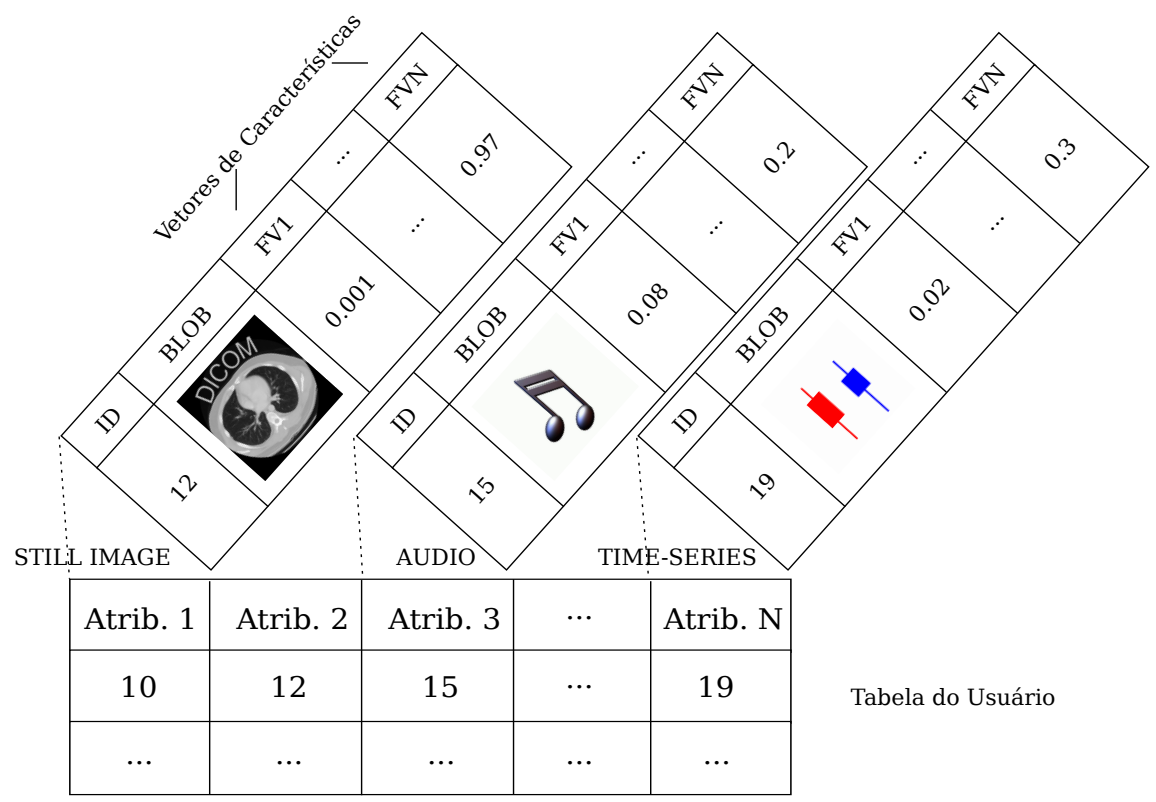

Figura 4.3: Estrutura de tabelas do sistema SIREN. Adaptado de (Barioni et al., 2006).

Em se tratando de dados complexos armazenados como dados monolíticos, uma tabela auxiliar pode ser criada como ilustrada na Figura 4.3. Juntamente com o dado integral armazenado como um BLOB, algumas outras informações importantes podem ser adicionadas. Essa abordagem, faz com que para cada dado complexo declarado no momento de criação de tabelas seja criada uma nova tabela auxiliar correspondente.

Por exemplo, para um campo STILLIMAGE declarado é criada uma nova tabela da forma IPV\$nometabelaoriginal_nomeatributo. A sigla IPV\$ identifica o dado complexo como imagem e o valor do parâmetro (Image Parameter Value no original, em inglês). Quando, por exemplo, quisermos inserir uma série-temporal financeira será criada uma tabela auxiliar FPV\$nometabelaoriginal_nomeatributo que armazenará a série-temporal em sua forma original.

Todas as tabelas PV\$ têm a seguinte estrutura: BLOB do dado original, chave de ligação com o valor do atributo e todas as características extraídas. No momento de inserção, as bibliotecas fornecem a representação de características que é armazenada como um campo da tabela auxiliar. A extração de características é computacionalmente cara (Aslandogan e Yu, 1999) e, portanto, seu armazenamento evita a repetição exaustiva desse procedimento quando do executar de uma consulta. Armazenar as características extraídas significa que o processo de extração só precisa ser realizado uma vez, no momento da inserção dos dados. Essa providência também permite a indexação contínua dos dados. 


\subsubsection{Armazenamento de Dados Complexos e Vetores de Carac- terísticas em SGBDR}

Neste trabalho, foi utilizada a seguinte abordagem (que é válida tanto para o dado complexo bruto quanto para os vetores de características extraídos a partir dos mesmos): (1) serializa-se o dado complexo (de acordo com as definições das bibliotecas de manipulação); (2) o vetor de bytes resultante é transformado em uma longa string de valores hexadecimais. A partir desse ponto já é possível visualizar e executar a instrução INSERT INTO, e o dado já é portável para qualquer SGBDR (e qualquer linguagem de desenvolvimento de aplicação), bastando que ao recuperá-lo se realize o processo inverso para obter o dado bruto novamente.

O armazenamento de BLOB's (e variantes) influencia muito no tempo efetivo de recuperação de dados por conteúdo. Normalmente, se executa uma serialização dos dados complexos em bytes e este são inseridos diretamente na base de dados. Internamente, esse objetos são tratados de forma diferente por cada SGBDR (Chen et al., 2010). Outros problemas, como a diferença de codificação interna (unicode, ascii) adotada por cada SGBDR tornam essa abordagem não-portável para diferentes sistemas e impedem que se trabalhe com dados complexos como, por exemplo, o tipo FULLTEXT (Eisenberg et al., 2004).

Mais do que isso, ao termos a string em hexadecimal, é possível (3) efetuar uma compressão da mesma e (4) adicionar as medidas de segurança e criptografia necessárias, sem que o dado deixe de ser portável aos SGBDR e reduzindo o espaço efetivo usado em disco. A utilização dos passos (3) e (4) dependem dos requisitos levantados para cada aplicação (em termos de urgência de recuperação efetiva do dado). Essa alternativa é bastante viável e prática podendo ser combinada com outras estratégias de paginação de BLOB's, armazenamento de BLOB's em páginas separadas do restante do registro (Chen et al., 2010) entre outras, que otimizam ainda mais a relação espaço em disco versus tempo de resposta do sistema.

\subsection{Adicionando Suporte a Novos Tipos de Dados Com- plexos e Novos Extratores de Características.}

Para dar suporte a um novo tipo de dado complexo via consulta por similaridade com SQL estendido (ilustrado na Figura 4.2), o primeiro passo é a implementação de uma biblioteca específica para manipulação do novo tipo. As bibliotecas implementadas durante o projeto de mestrado levam em consideração que os dados complexos possuem diversas origens e, muitas vezes, diversos padrões. Esses dados precisam ser representados perante o sistema como um tipo único de dados. Além disso, as bibliotecas devem encapsular os métodos 
de extração de características, obedecendo também a uma interface comum. Desta forma, é possível definir uma sequência de ações para o tratamento do dado complexo e sua representação no espaço métrico.

O segundo passo é informar ao dicionário de dados quais são os novos métodos de extração de características e por quais dados complexos os mesmos podem ser utilizados. Finalmente, como último passo, é necessário definir as palavras reservadas para o tratamento deste dado complexo no módulo de interpretação do SQL estendido bem como suas implicações e restrições. As características extraídas e o dado complexo, serão armazenados conforme a descrição da seção anterior. Deve-se utilizar a biblioteca desenvolvida para o tratamento do dado complexo para recuperar o dado original a partir da resposta de consultas por similaridade realizadas via shell e a partir daí convertê-los aos formatos desejados pelos programadores/usuários.

\subsubsection{Definição de uma Biblioteca para Séries-Temporais Financeiras}

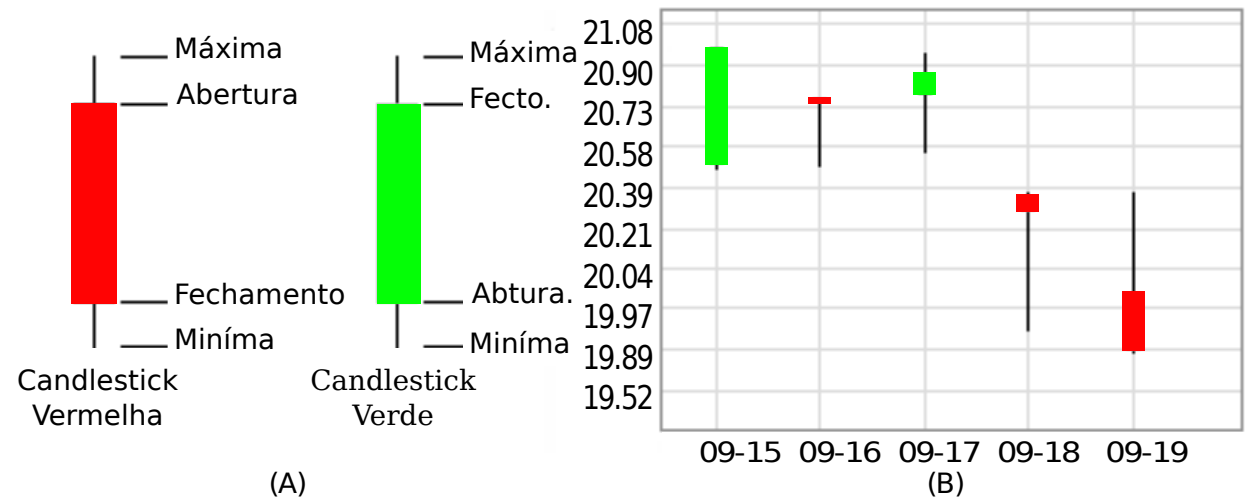

Figura 4.4: (A) Representação visual diária de uma série-temporal financeira via candlestick. (B) Representação de uma semana via candlestick iniciando em $15 / 09$.

A análise gráfica de séries-temporais financeiras (Lee e Jo, 1999) é um grande desafio para os analistas, pois esta análise é inicialmente subjetiva e sujeita a diversas interpretações. No entanto, oferece diversas características visuais que podem ser extraídas sem perda de significado semântico. Por exemplo, a Figura 4.4 (B) mostra um gráfico baseado na representação diária de candlesticks. No dia 16/09 podemos observar o fenômeno gráfico conhecido como "prego" enquanto o dia 19/09 nos mostra outro fenômeno conhecido como "martelo". A representação via candlesticks evidencia as diferenças entre as correlações entre os valores diários (média, variância, etc.).

Note-se que o valor de fechamento de uma ação, não é necessariamente o mesmo da abertura do dia seguinte, gerando uma espécie de "buraco" no gráfico. Esses comportamentos estão relacionados a diversos fatores que influenciam a confiança do investidor. Dessa forma, as oscilações podem ser bem representadas. 
Durante esse trabalho de mestrado, foi proposto um extrator de características baseado na representação via candlestick. O extrator proposto considera exclusivamente as características visuais, não considerando variáveis externas, como liquidez, que podem ser utilizadas como pesos em uma eventual comparação via função de distância. Foram definidas quatro características para realizar a geração dos vetores de características para as mesmas. As quatro características (Bedo et al., 2013b) obedecem as seguintes formulações (considerando as funções open $(x)$ como abertura do dia atual, $\operatorname{close}(x)$ fechamento do mesmo, low $(x)$ o valor mínimo do preço no dia e $h i g h(x)$ o máximo valor atingido pela ação no dia):

1. [Relação Body-Shadow] A relação proposta é uma função linear expressa pelos valores diários da candlestick. O significado desta relação pode ser visto na Figura 4.5(A) e é expressa pela seguinte expresão:

$$
f(x)= \begin{cases}\frac{(\operatorname{open}(x)+\operatorname{close}(x)) / 2-\operatorname{low}(x)}{\operatorname{high}(x)-\operatorname{low}(x)} & \text { se high }(x)-\operatorname{low}(x) \neq 0 \\ 0 & \text { caso contrário }\end{cases}
$$

2. [Relação Amplitude] A relação proposta é uma função linear expressa pelos valores diários da candlestick. O significado desta relação pode ser visto na Figura 4.5(B). Essa característica descreve os fenômenos "prego" e "martelo", por exemplo. Essa formulação é expressa pela seguinte expresão:

$$
f(x)= \begin{cases}\frac{\operatorname{open}(x)-\operatorname{close}(x)}{\operatorname{high}(x)-\operatorname{low}(x)} & \text { se high }(x)-\operatorname{low}(x) \neq 0 \\ 0 & \text { caso contrário }\end{cases}
$$

3. [Relação Gap] A relação gap é uma função linear entre dois dias consecutivos da série-temporal financeira. Essa relação captura a variação não contínuas de preços, como ilustrado na Figura 4.5 (C). O valor de fechamento é sempre maior que 0, para companhias ativas.

$$
f(x)=\frac{\operatorname{open}(x)-\operatorname{close}(x-1)}{\operatorname{close}(x-1)} .
$$

4. [Relação de Projeção] A relação de projeção é uma função que descreve a média da amplitude projetada sobre a média do dia, como visualizado na Figura 4.5 (D) e é expressa pela seguinte expresão:

$$
f(x)= \begin{cases}f(x)=\frac{(\operatorname{open}(x)+\operatorname{close}(x)) / 2-\operatorname{low}(x)}{\operatorname{open}(x)-\operatorname{close}(x)} & \text { se open }(x)-\operatorname{close}(x) \neq 0 \\ 0 & \text { caso contrário }\end{cases}
$$


O método de extração de características pode ser realizado automaticamente. O menor tamanho da janela para extração de características é 2, por causa da Relação Gap, que relaciona ao menos 2 unidades por vez. Uma vez extraídas as características, podemos proceder a consultas por similaridade, ou tirar proveito dos classificadores baseados em $k$-NN para aplicações de forecasting e clusterização. Todas as funções de distância da família Minkowsky podem ser utilizadas para comparação dos vetores de características extraídos.

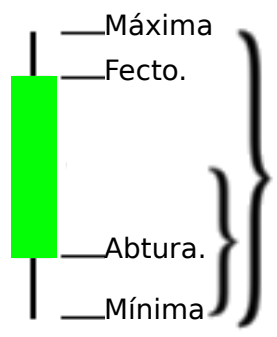

(A)

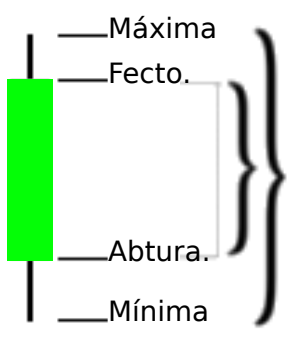

(B)

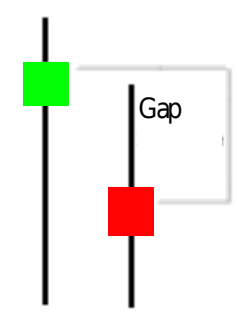

(C)

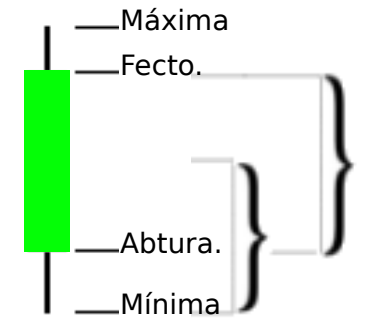

(D)

Figura 4.5: Representação visual das características extraídas: (A) Relação Body-Shadow (B) Relação de Amplitude (C) Relação Gap e (D) Relação de Projeção.

\subsection{Adicionando novas Funções de Distância}

Para se adicionar novas funções de distância, deve-se proceder à codificação individual da nova função de distância proposta, de acordo com a interface disponibilizada pela biblioteca de funções de distância (Hermes). Uma vez definida a nova função de distância, também é necessário informar ao dicionário de dados a nova função de distância e suas atribuições, inserindo os dados adequados nas relações do dicionário de dados.

\subsection{Definição de um Sistema de Recuperação de Imagens por Conteúdo sobre a Solução}

Como uma ferramenta para a validação da arquitetura da solução foi definido e implementado um sistema de recuperação de imagens médicas por conteúdo para mamografias (Bedo et al., 2013a), baseado na sequência de passos:

- Modelagem da aplicação incluindo dados do paciente, radiologistas, laudos e relatórios seguindo orientação dos radiologistas especialistas;

- Definição das métricas utilizadas, nesse caso a métrica definida como padrão associa o histograma com a função de distância euclidiana; 


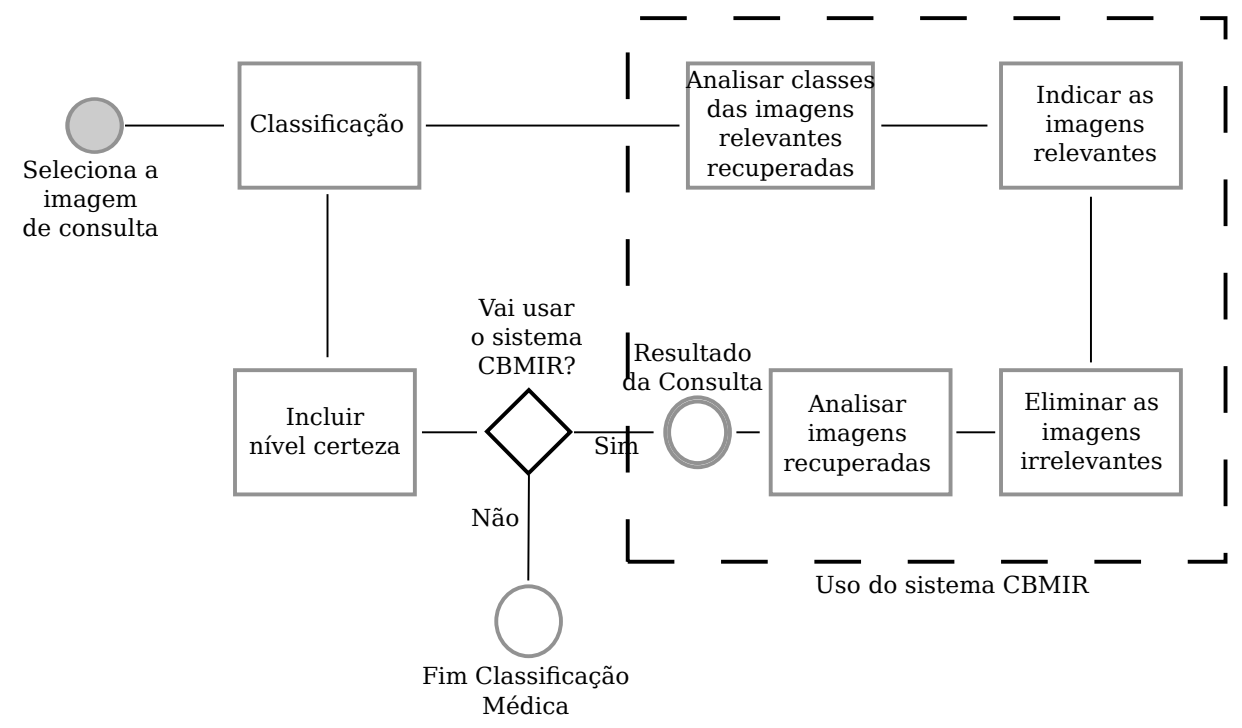

Figura 4.6: Workflow do sistema CBMIR para mamografias.

- Definição da base de dados (esquema do banco de dados) para que sejam armazenadas as imagens de mamografia em formato krl ou DICOM;

- Realização das consultas por similaridade de apoio a profissionais, seguindo os passos propostos na Figura 4.6.

O sistema CBMIR possui uma interface para coletar as informações solicitadas pelo especialista (Ponciano-Silva et al., 2013). Uma vez que estas estão definidas, ele submete uma consulta com SQL estendido para o shell, que então retorna com o conjunto solução. A partir daí a aplicação exibe os resultados e continua seu ciclo de iterações.

\subsection{Considerações Finais}

A metodologia deste trabalho de mestrado foi definida de modo a integrar diversas técnicas utilizadas para o processamento de consultas por similaridade, tomando-se por base a iniciativa SIREN. Durante a elaboração da nova arquitetura foi definida e implementada uma biblioteca para processamento de séries-temporais financeiras e proposto um novo extrator de características que pode ser utilizado tanto para consultas por similaridade quanto para forecasting.

As bibliotecas para dados complexos, foram integradas a um interpretador de SQL estendido, e assim foi possível implementar (1) um aplicativo shell capaz de realizar consultas por similaridade e (2) um aplicativo CBMIR que utiliza os recursos propostos para funcionar em um ambiente clínico.

Os experimentos realizados são referentes à:

1. Validação da arquitetura e das bibliotecas propostas, através dos seguintes passos: 
- Modelar os dados de uma aplicação para recuperação de imagens de mama por conteúdo, sendo as imagens recuperadas de mamografias de alta resolução;

- Modelar a base de dados respectiva para a aplicação utilizando os recursos (framework) disponibilizados neste projeto de mestrado;

- Definir e implementar uma interface capaz de interagir com o usuário e realizar as consultas por similaridade, auxiliando o diagnóstico;

- Verificar a qualidade das respostas das consultas e validade desta abordagem para este domínio.

2. Validação da biblioteca de séries-temporais financeiras, através dos seguintes passos:

- Extração de características de ações da BM\&FBovespa;

- Extração de características de indíces de bolsas de valores;

- Classificação utilizando uma abordagem melhorada do classificador Instance-Based Learn (IBL) (Aha e Kibler, 1991).

- Comparação dos resultados com demais abordagens de forecasting quanto a (1) acurácia (através d teste estatístico do Wilcoxon (Wilcoxon, 1945)) e (2) velocidade da predição;

- Integração da biblioteca aos demais módulos.

3. Desenvolvimento de um shell capaz de interpretar comandos SQL estendidos e realizar consultas em SGBDR Oracle @, PostGres @e MySQL @, validado através da criação uma base de dados de imagens para mamografia e de consultas SQL onde é possível:

- Definir associações entre o par < extrator de característica, função de distância >;

- Realizar consultas por similaridade a partir de imagem salva em disco;

- Realizar consulta por similaridade junto a consultas por dados tradicionais;

- Mensurar o tempo de resposta para a resolução das consultas e criação das estruturas (coletar estatísticas);

- Recuperar os dados complexos cifrados em hexadecimal para a aplicação. 


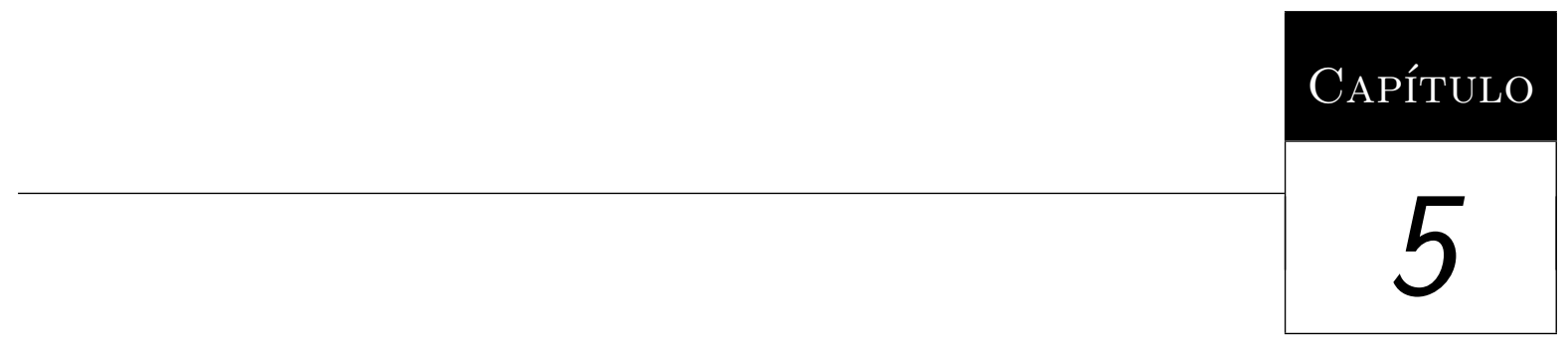

\section{Resultados e Discussão}

Neste capítulo é feita a apresentação das implementações dos softwares desenvolvidos neste projeto de mestrado. Primeiramente, são apresentados os resultados referente a acurácia e desempenho da abordagem de forecasting de séries-temporais financeiras por similaridade, e discute-se como a inclusão da solução pode ser integrada ao framework graças a definição de novas palavras reservadas e da arquitetura modular proposta.

Em seguida é apresentado um caso de uso da ferramenta shell desenvolvida, que integra todos os módulos propostos nesta trabalho. Neste caso de teste, foi modelado um banco capaz de dar suporte a consultas por similaridade em mamografias (desde a criação das tabelas com dados complexos, até a execução das consultas por SQL estendido). Os novos recursos disponibilizados pelo framework são comparados com as implementações anteriores e com outros sistemas.

Como última parte dos resultados é mostrado um aplicativo, denominado Higiia, que utiliza como base os comandos de consulta em SQL estendido para servir como recuperação de imagens médicas por conteúdo, adicionando características importantes para este domínio, como a realimentação de relevância e auxílio ao diagnóstico. São descritas as funcionalidades do aplicativo, sua arquitetura (como ele depende de outras estruturas construídas ao largo deste projeto) e a viabilidade prática da realização de consultas por similaridade em um ambiente real.

\subsection{Uma Ferramenta para Séries-Temporais Financeiras}

A extração de características de séries-temporais financeiras resulta em um vetor de características, representando a mesma no espaço métrico. A partir desse ponto, podemos proceder a classificação, agrupamento (clusterização) ou consulta por similaridade sobre 
o mesmo (Figura 5.1). As seções seguintes discutem a acurácia da abordagem por similaridade ( $<$ extrator proposto, função euclidiana $>$ ) através de um classificador IBL acelerado por Métodos de Acesso Métrico (Aha e Kibler, 1991).

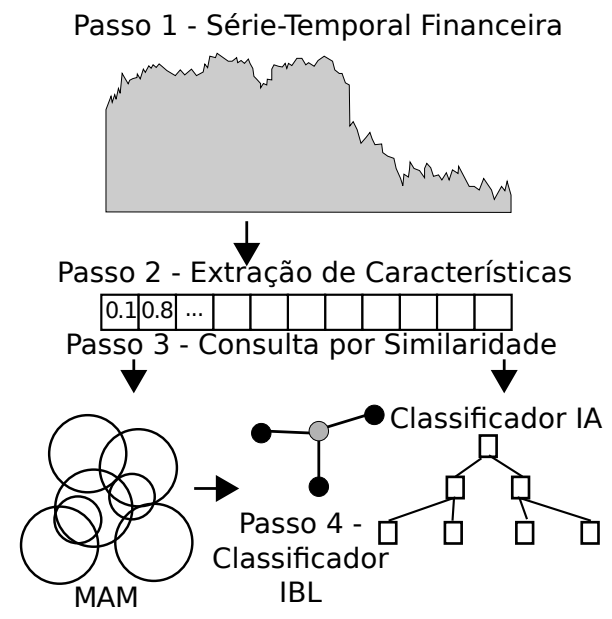

Figura 5.1: Workflow do possível tratamento a séries temporais financeiras.

\subsubsection{Configurações do Experimento}

Para validar a acurácia e a resposta ágil do sistema foram realizados dois experimentos:

1. Para comparar a abordagem por similaridade proposta, comparando com as classificações feitas por métodos de regressão linear e redes neurais;

2. Para mostrar que o método é escalável para um grande volume de dados, e que a classificação é mais rápida que a feita por outros classificadores a medida em que cresce a base de dados.

Para a realização dos experimentos foram utilizados duas bases de dados reais. O primeiro conjunto de dados, denominado BM\&FBOVESPA_SHARES, é composto pelas 33 maiores companhias desta Bolsa (em termos de volume e liquidez) no ano de 2009. Os dados iniciam em 01/01/2005 e terminam em 01/01/2010. Yahoo Finances! ${ }^{1}$ possui um banco de dados aberto e livre que disponibiliza essas séries temporais para acesso ao publico em geral. A motivação para uso desses dados é o crescimento expressivo dessa bolsa nos últimos anos, além da falta de estudos sobre o comportamento dessa Bolsa de Valores (Martinez et al., 2009).

O segundo dataset denominado WORLD_STOCKINDEXES, é composto por séries-temporais dos seguintes indíces de Bolsas de Valores: Dow Jones (New York), FTSE (London), BM\&FBOVESPA (São Paulo), Nikkei (Tokyo), SSMI (Bern), Euronext (Paris) e SSEC (Shanghai). Cada série-temporal inicia da fundação de cada Bolsa de Valor em particular e termina em 01/01/2010.

\footnotetext{
${ }^{1}$ http://finance.yahoo.com
} 


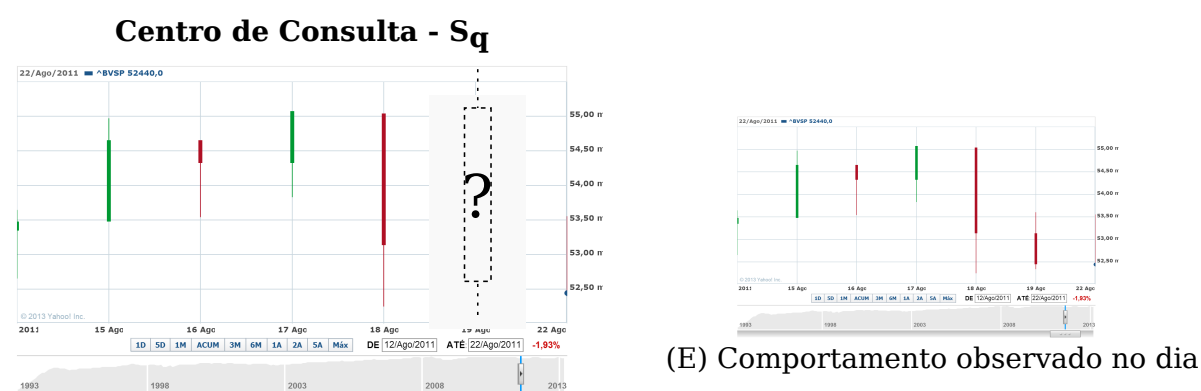

(A) Alta do último dia da semana para previsão

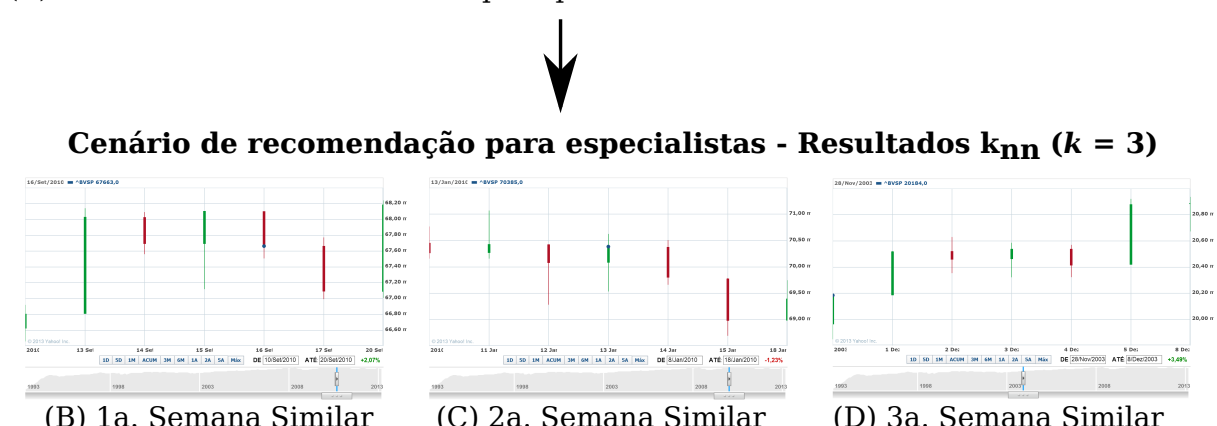

Figura 5.2: A abordagem por similaridade: dado um centro de consulta (A), o especialista pode visualizar os $k=3$ fragmentos mais similares à série-temporal (B), (C) e (D) ou solicitar diretamente o forecast baseado na classe majoritária das mais similares. A imagem (E) mostra o comportamento real do centro de consulta ao final da sexta-feira.

As características foram extraídas considerando a janela temporal de uma semana, o que nos permitiria responder questões como: "Para uma determinada companhia Y conhecemos os valores que sua ação assumiu na segunda, terça, quarta e quinta-feira. Ao iniciar o dia na sexta-feira sabemos que a ação tem valor de abertura X. Devemos investir em Y esperando ganhar mais de 1\%?". A Figura 5.2 ilustra o que corresponderia essa pergunta em um gráfico de candlesticks.

Após a extração de características os vetores foram indexados no Método de Acesso Métrico Slim-Tree (Traina et al., 2002), sob o qual foi possível realizar consultas por similaridade e então, através das prerrogativas do classificador IBL, catalogar um novo centro de consulta. Foi realizada uma comparação da abordagem por similaridade proposta com uma classificação feita pelo método de regressão linear ARIMA (Box e Jenkins, 1990) e com uma abordagem mais comum na literatura utilizando redes-neurais (ANN-MLP) (Martinez et al., 2009). O sucesso de cada um dos métodos é a entrada para o método de comparação estatística de Wilcoxon (Wilcoxon, 1945).

Indexar os vetores de características em uma estrutura de Método de Acesso Métrico também permitiu que a classificação ficasse mais ágil e escalável para grandes volumes de dados. Foi feita uma comparação de escalabilidade e desempenho entre a classificação melhorada versus classificação comum e de desempenho com relação aos demais métodos de classificação. 


\subsubsection{Da Acurácia do forecasting via Consultas por Similaridade.}

Foram medidas as taxas de sucesso (Tabela 5.1) da abordagem ao responder a pergunta mencionada na seção anterior. Também foram medidas as taxas de sucesso da previsão ARIMA e utilizando-se um ANN-MLP como classificador. Em seguida, as taxas de sucesso foram colocadas em um rank, de acordo com os critérios postulados por Wilcoxon $\left(\left|d_{i j}\right|,\left|d_{i k}\right|\right.$, rank $_{i j}$, rank $_{i k}$, onde $i$ é a abordagem proposta, $j$ é abordagem por regressão linear e $k$ é a abordagem via ANN-MLP, $|d|$ é o módulo da diferença da taxa de sucesso entre dois métodos e rank é a posição atribuída ao módulo da diferença dentre todo o conjunto) (Wilcoxon, 1945)

Tabela 5.1: Taxa de acerto sobre o dataset BM\&FBOVESPA_SHARES.

\begin{tabular}{|c|c|c|c|c|c|c|c|c|}
\hline Share & Our Met. & ARIMA & ANN-MLP & ZeroR & $\left|d_{i j}\right|$ & $\left|d_{i k}\right|$ & $\operatorname{rank}_{i j}$ & rank $_{i k}$ \\
\hline BOBR4 & 65.7038 & 57.00 & 66.6823 & 51.2077 & 8.6038 & 0.9785 & 32 & 10 \\
\hline CRUZ3 & 65.0713 & 61.50 & 62.8940 & 56.0386 & 3.5713 & 2.1772 & 16 & 25 \\
\hline AMBV4 & 64.495 & 57.86 & 62.5633 & 52.0202 & 6.635 & 1.932 & 30 & 24 \\
\hline PETR4 & 64.9155 & 60.57 & 62.2290 & 54.3269 & 4.3455 & 2.6865 & 20 & 29 \\
\hline BRAP4 & 62.6696 & 58.55 & 61.0671 & 50.2703 & 4.1196 & 1.6025 & 19 & 19 \\
\hline CCRO3 & 57.5423 & 61.27 & 57.0450 & 52.973 & 3.7277 & 0.4973 & 17 & 5 \\
\hline PSSA3 & 56.5169 & 48.10 & 58.0987 & 53.1401 & 8.4169 & 1.5818 & 31 & 18 \\
\hline EMBR3 & 60.6664 & 54.33 & 61.3840 & 50 & 6.3364 & 0.7176 & 28 & 7 \\
\hline VALE5 & 58.7958 & 53.55 & 58.5430 & 55.5556 & 5.2458 & 0.2528 & 24 & 3 \\
\hline TMAR5 & 56.3266 & 56.31 & 57.6486 & 50.7246 & 0.0166 & 1.3220 & 1 & 17 \\
\hline ELET6 & 63.6079 & 58.98 & 62.4890 & 56.5217 & 4.6279 & 1.1189 & 22 & 13 \\
\hline BBDC4 & 56.7801 & 55.81 & 58.6534 & 51.3889 & 0.9701 & 1.8733 & 4 & 23 \\
\hline TNLP4 & 55.3423 & 53.87 & 55.2211 & 57.971 & 1.4723 & 0.1212 & 6 & 2 \\
\hline USIM5 & 59.5722 & 53.14 & 57.1590 & 50.9615 & 6.4322 & 2.4132 & 29 & 26 \\
\hline TLPP4 & 61.3458 & 56.21 & 58.5647 & 51.3514 & 5.1358 & 2.7811 & 23 & 31 \\
\hline CMIG4 & 60.7181 & 61.45 & 58.9773 & 53.1401 & 0.7319 & 1.7408 & 3 & 20 \\
\hline LAME4 & 56.8193 & 54.28 & 57.9146 & 50.2415 & 2.5393 & 1.0953 & 10 & 12 \\
\hline TAMM4 & 61.1337 & 55.38 & 62.3780 & 56.0386 & 5.7537 & 1.2443 & 26 & 15 \\
\hline ITSA4 & 55.8233 & 55.26 & 55.2455 & 51.3514 & 0.2633 & 0.5778 & 2 & 6 \\
\hline $\begin{array}{l}\text { ELPL4 } \\
\end{array}$ & 60.8649 & 58.21 & 58.4333 & 51.0067 & 2.6549 & 2.4316 & 11 & 27 \\
\hline LIGT3 & 56.9298 & 54.87 & 54.2333 & 51.2077 & 2.0598 & 2.6965 & 8 & 30 \\
\hline GOLL4 & 58.2230 & 54.37 & 57.3221 & 50.8108 & 3.853 & 0.9009 & 18 & 9 \\
\hline DASA3 & 59.1217 & 56.45 & 59.0145 & 55.157 & 2.6717 & 0.1072 & 12 & 1 \\
\hline NATU3 & 55.7391 & 54.46 & 53.9903 & 52.4324 & 1.2791 & 1.7488 & 5 & 21 \\
\hline CSNA3 & 52.479 & 49.07 & 54.3245 & 50.7246 & 3.409 & 1.8455 & 14 & 22 \\
\hline BBAS4 & 60.7447 & 55.45 & 59.8670 & 54.29 & 5.2947 & 0.8687 & 25 & 8 \\
\hline LREN3 & 50 & 54.47 & 52.6793 & 51.6908 & 4.47 & 2.6793 & 21 & 28 \\
\hline PDGR3 & 55.9602 & 53.46 & 56.2560 & 55.2632 & 2.5002 & 0.2858 & 9 & 4 \\
\hline GGBR4 & 57.996 & 55.25 & 54.9099 & 59.9099 & 2.746 & 3.0861 & 13 & 32 \\
\hline RSID3 & 46.1132 & 57.86 & 47.2890 & 56.5217 & 11.7468 & 1.1758 & 33 & 14 \\
\hline BRKM5 & 57.656 & 59.31 & 56.5678 & 51.6584 & 1.654 & 1.0882 & 7 & 11 \\
\hline BRFS4 & 49.3213 & 52.76 & 44.2595 & 61.7117 & 3.4387 & 5.0617 & 15 & 33 \\
\hline EBTP3 & 47.2426 & 53.55 & 48.5002 & 63.1068 & 6.3074 & 1.2576 & 27 & 16 \\
\hline
\end{tabular}




\section{Comparação da Nossa Abordagem versus Abordagem por Regressão Linear}

Para comparar as previsões da abordagem proposta versus ARIMA, podemos realizar o teste estatístico de Wilcoxon. Seja B a taxa de acerto da abordagem por similaridade e $\mathrm{C}$ a taxa de acerto pelo método de regressão linear. Nesse caso:

1. Seja $H_{0}: C=B$ a hipótese nula, o que significa que utilizar o método $\mathrm{B}$ ou o método $\mathrm{C}$ nos dá uma taxa média de acerto similar;

2. Seja $H_{1}: B>C$ a hipótese alternativa, o que significa que utilizar o método $\mathrm{B}$ produz uma taxa média de acerto maior que a utilização do método C.

Fixado o nível de confiança $\alpha=0.1$. Os valores de Wilcoxon (Wilcoxon, 1945) para $R+$ e $R$ - são 438 e 123, respectivamente, o que implica em $z=-2.793414$. De acordo com a tabela de distribuição normal, $P(X<-2.793414)<0.05$. Então, rejeita-se $H_{0}$ e aceita-se $H_{1}$, o que significa que nossa abordagem tem maior acurácia que a abordagem por regressão linear.

\section{Comparação da Nossa Abordagem versus ANN-MLP}

Outra vez podemos recorrer ao teste de Wilcoxon. Seja B a taxa de acerto da nossa proposta e A a taxa de acerto da abordagem via ANN-MLP. Dessa forma:

1. Seja $H_{0}: A=B$ a hipótese nula, o que significa que utilizar $\mathrm{A}$ ou $\mathrm{B}$ produz resultados similares;

2. Seja $H_{1}: A<B$ a hipótese alternativa o que significa que o método $\mathrm{B}$ é mais eficiente que o método A para o forecasting.

Fixado o nível de confiança $\alpha=0.1$. Os valores de Wilcoxon para $R+$ e $R-$ são: $R+=375$ e $R-=186$. Então,temos $z=-1.67604836$. De acordo com a tabela da distribuição Normal temos $P(X<-1.67604836)<0.1$. Então, devemos rejeitar $H_{0}$ e aceitar $H_{1}$, o que significa que a abordagem proposta tem maior acurácia que o método comparado. A rede neural MLP tem três camadas clássicas e um neurônio de saída, a taxa de aprendizado utilizada foi 0.01, e o algoritmo de back-propagation utilizou o momentum de 0.7.

\subsubsection{Escalabilidade}

Além da acurácia, o tempo de execução necessária para o forecasting é um ponto importante a ser considerado. Para analizá-lo foi utilizado o conjunto WORLD_STOCKINDEXES, cujas taxas de sucesso ao fazer predições dos comportamentos semanais dos indíces são mostrados na Tabela 5.2. Para os testes, consideramos duas versões da abordagem proposta: (1) A classificação através do classificador tradicional IBL (Aha e Kibler, 1991) e (2) Utilizando o método de acesso métrico Slim-Tree para 
acelerar a consulta por similaridade e a classificação (denominamos essa abordagem "IBL impulsionado").

Tabela 5.2: Taxa de acurácia referente ao forecasting de índices.

\begin{tabular}{|c|c|c|c|c|c|}
\hline Índice & Acrônimo & Proposta \% & ARIMA \% & ANN-MLP & ZeroR \% \\
\hline Dow Jones I A & ${ }^{\wedge}$ DIJ & 81.76 & 68.27 & 78.54 & 50.76 \\
\hline London - FTSE & ${ }^{\wedge}$ FTSE & 79.10 & 66.23 & 79.00 & 51.89 \\
\hline Tokyo & ${ }^{`}$ NIKKEI & 75.91 & 66.17 & 73.23 & 54.17 \\
\hline Swiss Market & ${ }^{`}$ SSMI & 71.23 & 62.25 & 72.37 & 50.42 \\
\hline Euronext Paris & ${ }^{\circ}$ FHCI & 70.38 & 66.35 & 70.05 & 52.25 \\
\hline BM\&FBovespa & ${ }^{\wedge}$ BVSP & 63.61 & 57.17 & 60.23 & 52.16 \\
\hline Shangai S E & ${ }^{\wedge}$ SSEC & 61.63 & 56.32 & 59.47 & 51.18 \\
\hline
\end{tabular}

Utilizando uma base de dados de domínio real, considere o indíce Dow Jones index (`DIJ) (a maior série-temporal, começando em 1928). Nesse caso, Figura 5.3 (A) mostra a quantidade de tempo total necessária para cada um dos métodos para realizar a previsão a medida em que a série ^DIJ series aumenta. Uma vez efetuada a fase de treinamento, a classificação via ANN-MLP é o método mais rápido. No entanto, seu treinamento leva um tempo expressivo e realizar um novo treinamento conforme a base de dados aumenta pode ser necessário. O método IBL impulsionado foi o segundo mais rápido, sendo $130 \%$ mais rápido que a abordagem tradicional do IBL e $720 \%$ mais rápido que o método ARIMA.

Consideramos que a estrutura de dados Slim-Tree já estava criada no início do teste, assim como a ANN-MLP já estava treinada. Criar a Slim-Tree demorou 190 segundos, em média, enquanto o treinamento da rede neural ultrapassou 360 segundos, em média. Em um cenário dinâmico, em que novos dados são inseridos a cada dia, aumentando o tamanho da base, a atualização da estrutura versus o retreinamento periódico mostra que essa relação fica ainda mais desbalanceada: inserir um conjunto de elementos na estrutura leva menos da metade do tempo necessário que retreinar a rede neural. Ainda com relação ao tempo de construção das estruturas o método ARIMA é o mais rápido, pois ele não precisa de estrutura auxiliar. A melhora de velocidade do IBL impulsionado é devido à redução do número de cálculos de distâncias (redução de 20\%), mostrado na Figura 5.3 (B) e no número de acessos a discos (redução de 70\%), mostrado na Figura 5.3 (C).

Em uma relação "custo-benefício" (tempo para criação de estruturas versus tempo necessário para classificação), nossa abordagem apresenta a melhor performance de acerto as custas de manter uma estrutura de dados cujo tempo gasto para criação e manutenção é inferior a ANN-MLP. Além disso, por já ser uma abordagem focada para grandes bases de dados utilizando como estrutura interna um método de acesso métrico, obtém-se a escalabilidade e a robustez para trabalhar com um largo volume de dados ideal para este cenário, onde os dados aumentam diariamente. 


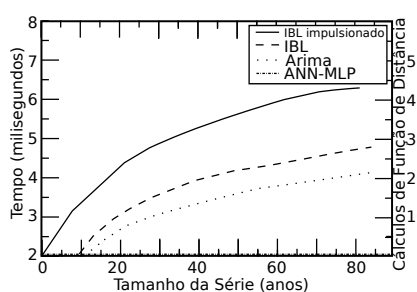

(A)

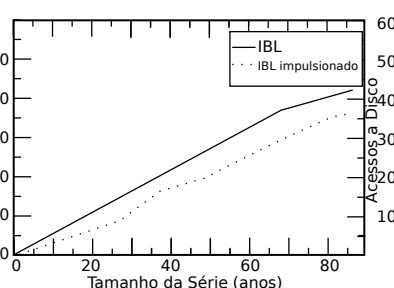

(B)

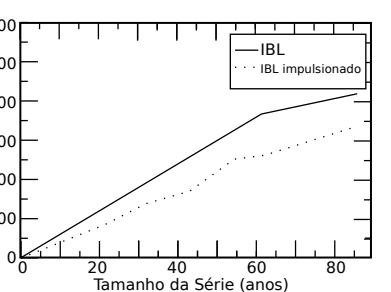

(C)

Figura 5.3: Comparação de tempos de respostas de abordagens de forecasting. (A) Tempo total. (B) Quantidade de cálculos de distância. (C) Quantidade de acessos a disco.

\subsubsection{Discussões Parciais}

O tratamento de séries-temporais financeiras é bastante complicado devido a natureza caótica e irregular dos dados. Utilizar a abordagem de consultas por similaridade (Silva e Aref, 2009), através da extração de características significa um processamento "caixa-branca" que possibilita um forecasting com semântica gráfica adequada.

O extrator de características identifica correlações entre fragmentos da série-temporal financeira através da representação gráfica. Com este tratamento pode-se lidar com um largo volume de dados através da indexação dos dados em um método de acesso métrico. Após a indexação, é possível utilizar a abordagem $k$-NN para a realização de predições.

\subsection{Um Exemplo de Caso de Uso da Ferramenta Shell}

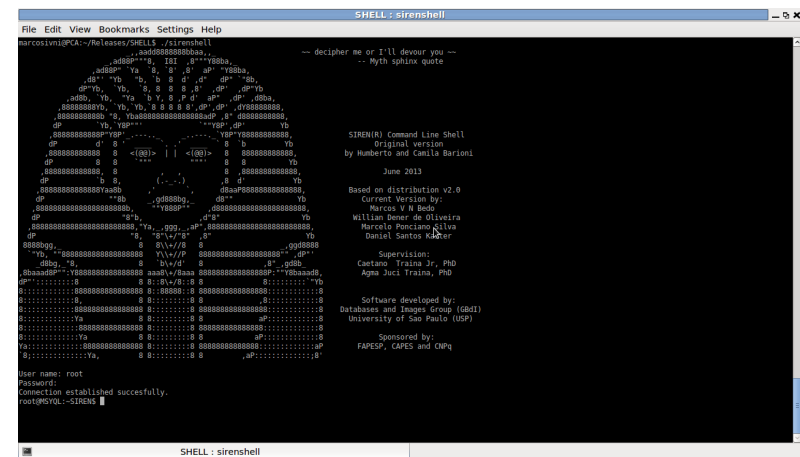

(A)

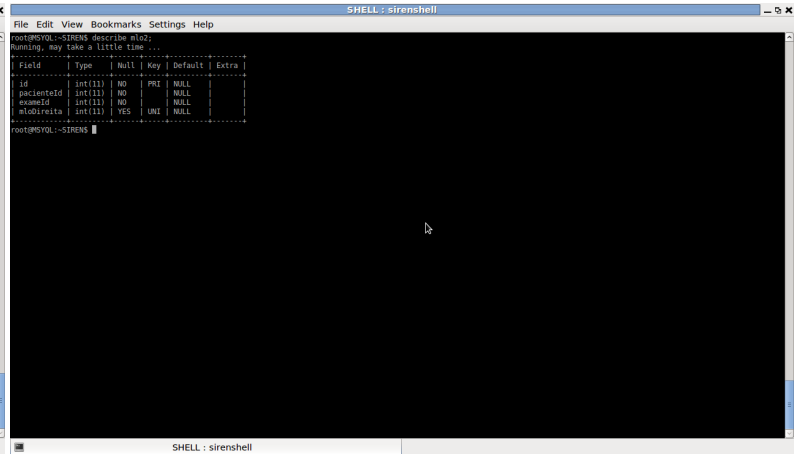

(B)

Figura 5.4: Shell para consultas por similaridade. (A) Interface para usuário / senha / SGBDR. (B) Visualização de resultado do comando DCL DESCRIBE $<$ table $>$.

A ferramente shell (Figura 5.4) desenvolvida integra, efetivamente, todos os recursos do framework proposto neste trabalho. A arquitetura do aplicativo pode ser vista na Figura 4.2. O aplicativo fornece suporte a SQL estendido. Nesta seção é apresentado um exemplo de utilização do sistema para modelar um banco de dados A imagens médicas 
de regiões de interesse de mamografias, utilizado posteriormente por um aplicativo de recuperação de imagens médicas por conteúdo.

\subsubsection{Interpretação das Consultas por Similaridade}

Primeiramente, para cada dado complexo inserido, o sistema extrai automaticamente as características e armazena na tabela auxiliar (IPV\$, APV \$, etc.) respectiva, de acordo com as métricas previamente declaradas para cada tipo de dado complexo, indexando o vetor de característica correspondente em uma Slim-Tree armazenada em disco. Quando é feita a consulta por similaridade, o estado em que o sistema se encontra depende das estruturas citadas neste parágrafo. Por exemplo, considere o seguinte comando com a finalidade de analisar o processamento realizado pelo shell:

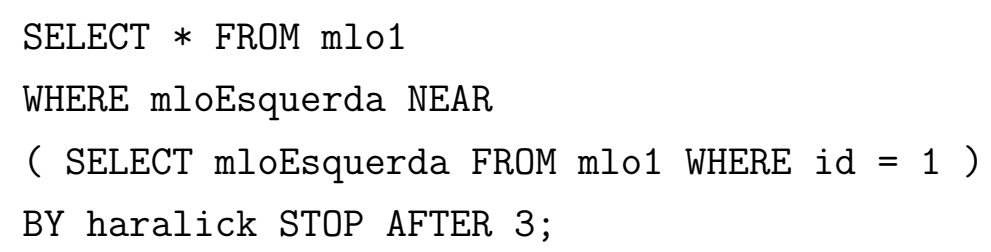

Considerando que "haralick" é uma métrica previamente declarada e que os atributos previstos na projeção são válidos para a consulta. O shell realiza os seguintes passos para processar a consulta:

1. Conecta-se ao SGBDR especificado pelo usuário;

2. O aplicativo fica permanentemente esperando a entrada em SQL estendido, ou algum comando da aplicação como "EXIT" (encerra a aplicação) ou "CLEAR" (para a limpeza de tela);

3. Transforma o comando em listas de tokens válidos (acessando o dicionário de dados para validar palavras reservadas e metadados), classificados de acordo com sua ordem de execução. Caso seja encontrado algum token inválido ou erro de sintaxe, retorna a lista dos erros, encontrados durante o processamento léxico e sintático;

4. Transforma a lista de tokens, adicionando as junções com a tabela interna necessária para processar o dado complexo;

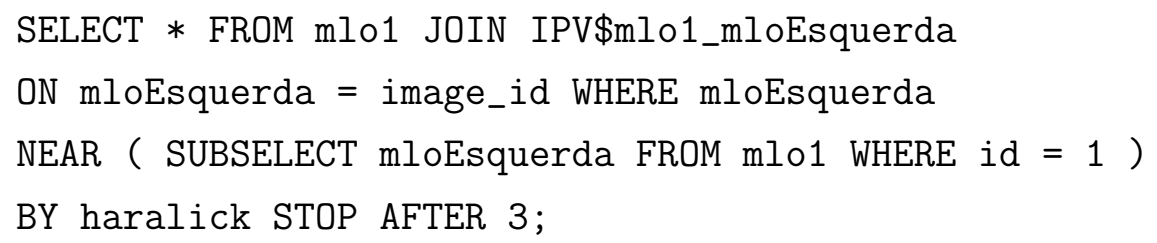

5. Transforma as listas de tokens, definindo quais serão os atributos realmente projetados ao final da consulta; 
SELECT id, ..., IPV\$mlo1_mloEsquerda.image AS mloEsquerda

FROM mlo1 JOIN IPV\$mlo1_mloEsquerda

ON mloEsquerda = image_id WHERE mloEsquerda

NEAR ( SUBSELECT mloEsquerda FROM mlo1 WHERE id = 1 )

BY haralick STOP AFTER 3;

6. Identifica o dado complexo da consulta ( SELECT mloEsquerda FROM mlo1 WHERE id = 1 );

7. Carrega o dado complexo (BLOB cifrado em hexadecimal) da base para a memória;

8. Identifica o extrator de característica e a função de distância a partir da métrica especificada;

9. Extrai a(s) característica(s) do dado complexo;

10. Abre o índice referente ao dado complexo e realiza a consulta por similaridade para as características do passo anterior;

11. Retorna os identificadores referentes a consulta por similaridade;

12. Transforma a lista de tokens, adicionando a clausula IN contendo os identificadores do passo anterior;

SELECT id, .., IPV\$mlo1_mloEsquerda.image AS mloEsquerda

FROM mlo1 JOIN IPV\$mlo1_mloEsquerda

ON mloEsquerda = image_id WHERE mloEsquerda

IN $(271,17,143)$;

13. Transforma a lista de tokens a uma string de SQL regular;

14. Envia o SQL regular ao SGBDR;

15. Exibe o resultado da consulta na tela para o usuário, com o dado complexo cifrado em hexadecimal.

\section{Dados de mamografia}

No caso do banco de imagens de mamografia, os dados inseridos são referentes a um conjunto de regiões de interesse derivado do dataset MAMA_CHICAGO, uma base de dados real de domínio público ${ }^{2}$. A base de dados já traz as classificações entre (1) massa e (2) calcificação, além das classificações BI-RADS (Ponciano-Silva et al., 2013) de composição e malignidade. O conjunto resultante consiste de 2892 imagens.

\footnotetext{
${ }^{2}$ http://marathon.csee.usf.edu/Mammography/Database.html.
} 
Primeiramente foi definida uma métrica: histograma, que associa o extrator histograma de niveis de cinza normalizado, disponível na biblioteca Artemis (Bedo e Traina, 2010b), a função de distância euclidiana, definida na biblioteca Hermes (Bedo e Traina, 2011). Em seguida, foram criadas as tabelas Paciente, Logon, Radiologista, e as tabelas cc1, cc2, mlo1, mlo2 que armazenam as projeções de mamografia cranio-caudal esquerda, cranio-caudal direita, médio-lateral oblíqua esquerda e médio-lateral direita.

Os comandos respectivos são (os atributos CREATE TABLE são similares para cc1, cc2, mlo1, mlo2, visto que estas tabelas são especializações que armazenam uma projeção específica):

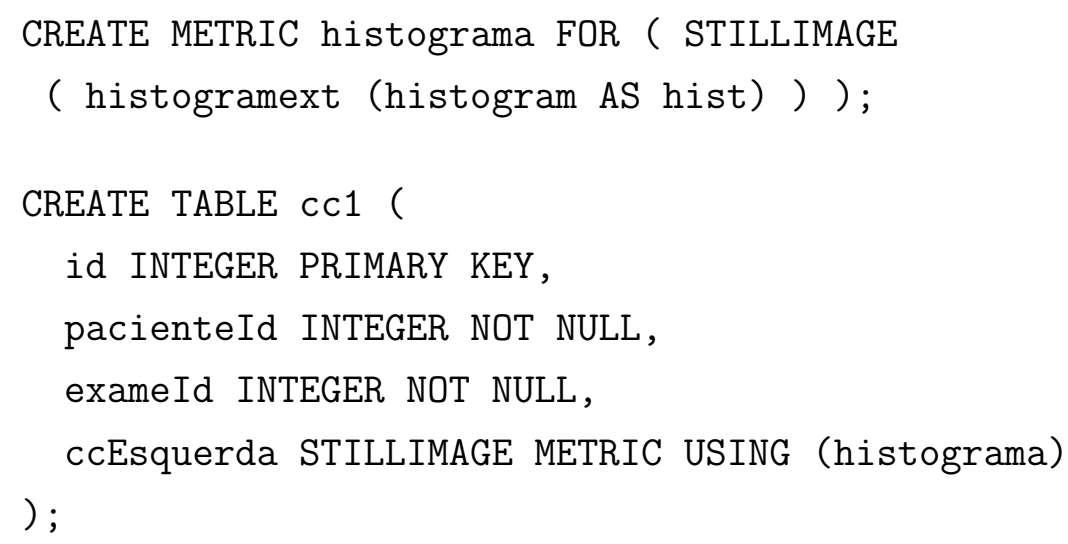

Exemplos de comandos SELECT são mostrados nas Figuras 5.5 e 5.6. A figura 5.5 mostra a execução de uma consulta por similaridade, através do predicado NEAR que visa recuperar as duas imagens cranio-caudal mais similares à imagem centro de consulta. Já a Figura 5.6 exibe o resultado de uma consulta por abrângencia de imagens médio-lateral oblíqua.

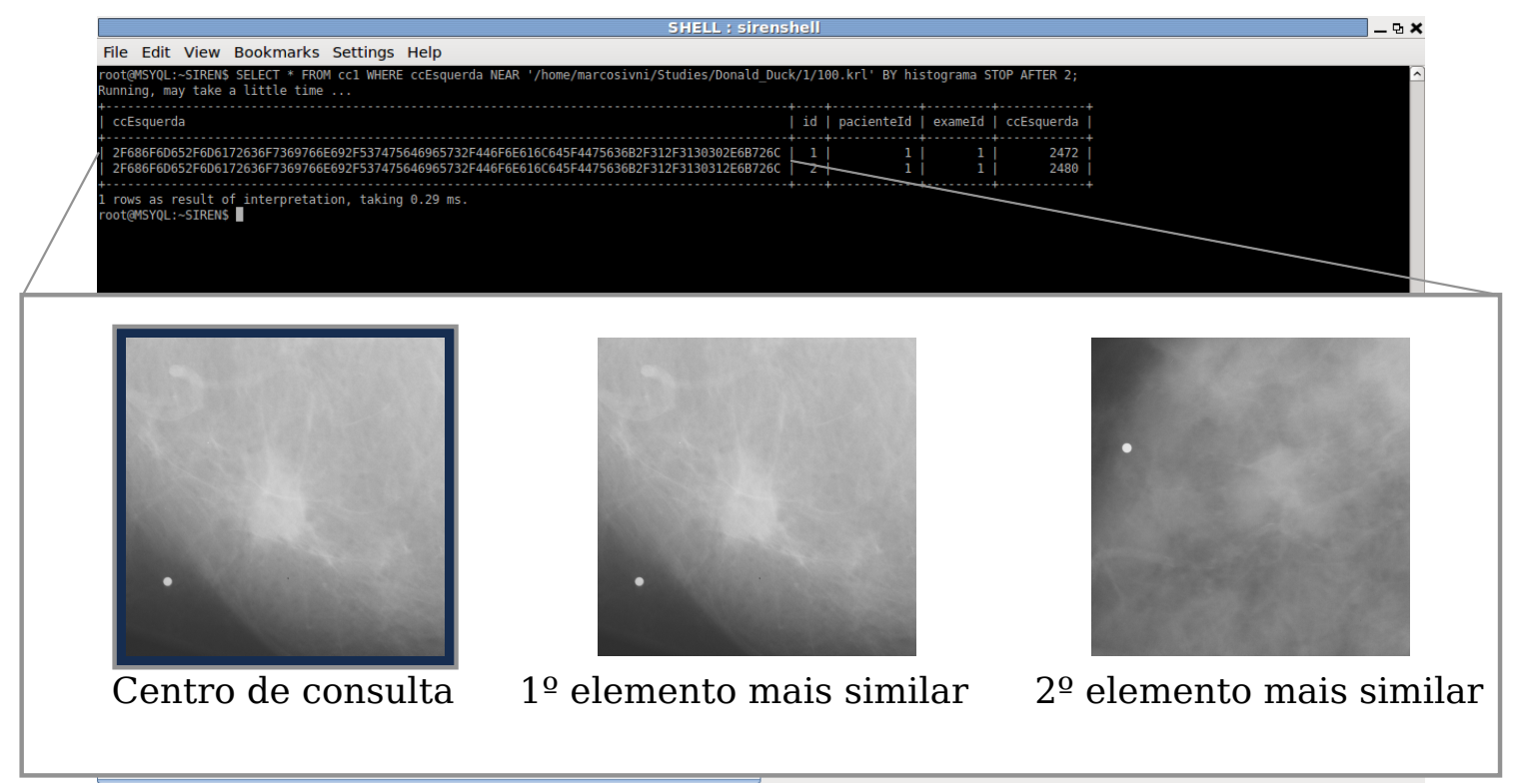

Figura 5.5: Consulta por similaridade, para $k=2$. 
Em ambos os casos, a métrica considerada e utilizada é aquela previamente definida como histograma. Note-se que em ambos os casos a própria imagem de consulta é retornada como parte do resultado, uma vez que essa imagem já está armazenada na base de dados.

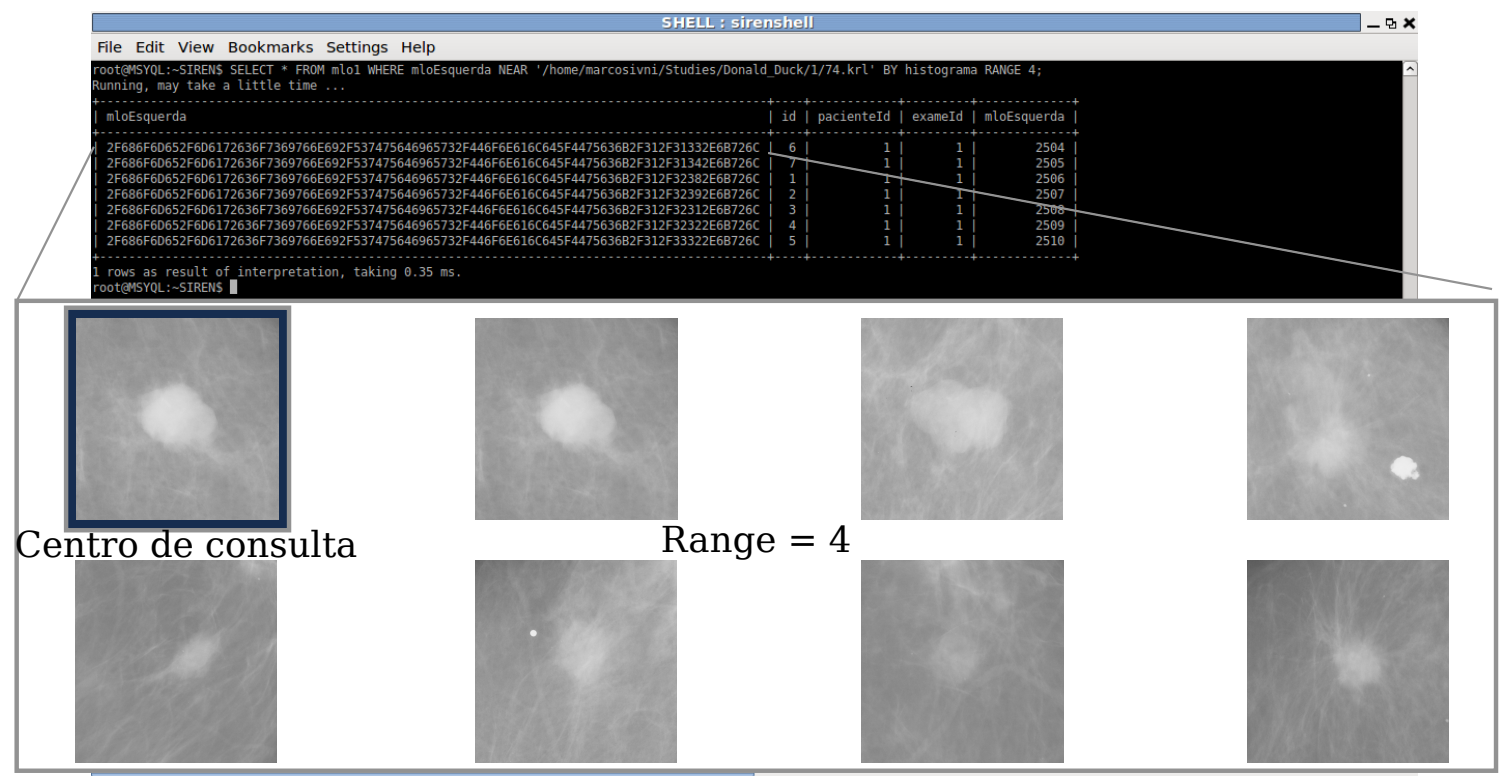

Figura 5.6: Consulta por abrangência.

\section{Trabalhando com diversas métricas}

Considere-se agora um segundo exemplo utilizando o dataset EXAME (Barioni et al., 2006). O conjunto de dados é formado por 800 imagens de exames de tomografia computadorizada (CT) divididas em quatro classes com 200 imagens cada: crânio axial, crânio coronal, crânio sagital e espinha sagital. Para testar este conjunto de dados foi definida, além da métrica histograma, uma segunda métrica adicional denominada textura, com a seguinte declaração:

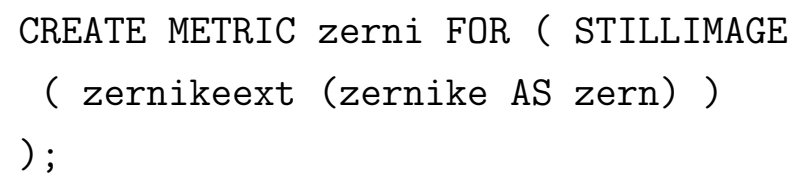

Na definição da tabela que armazenará as imagens em formato jpg do dataset, temos:

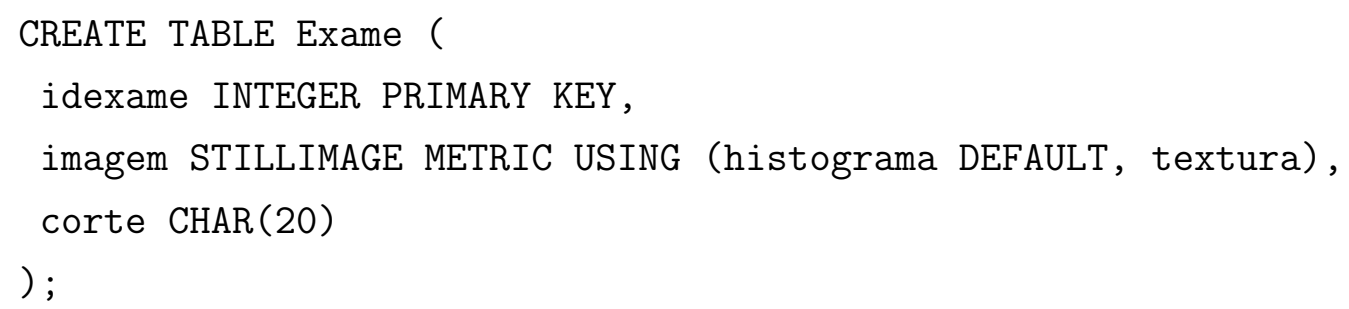




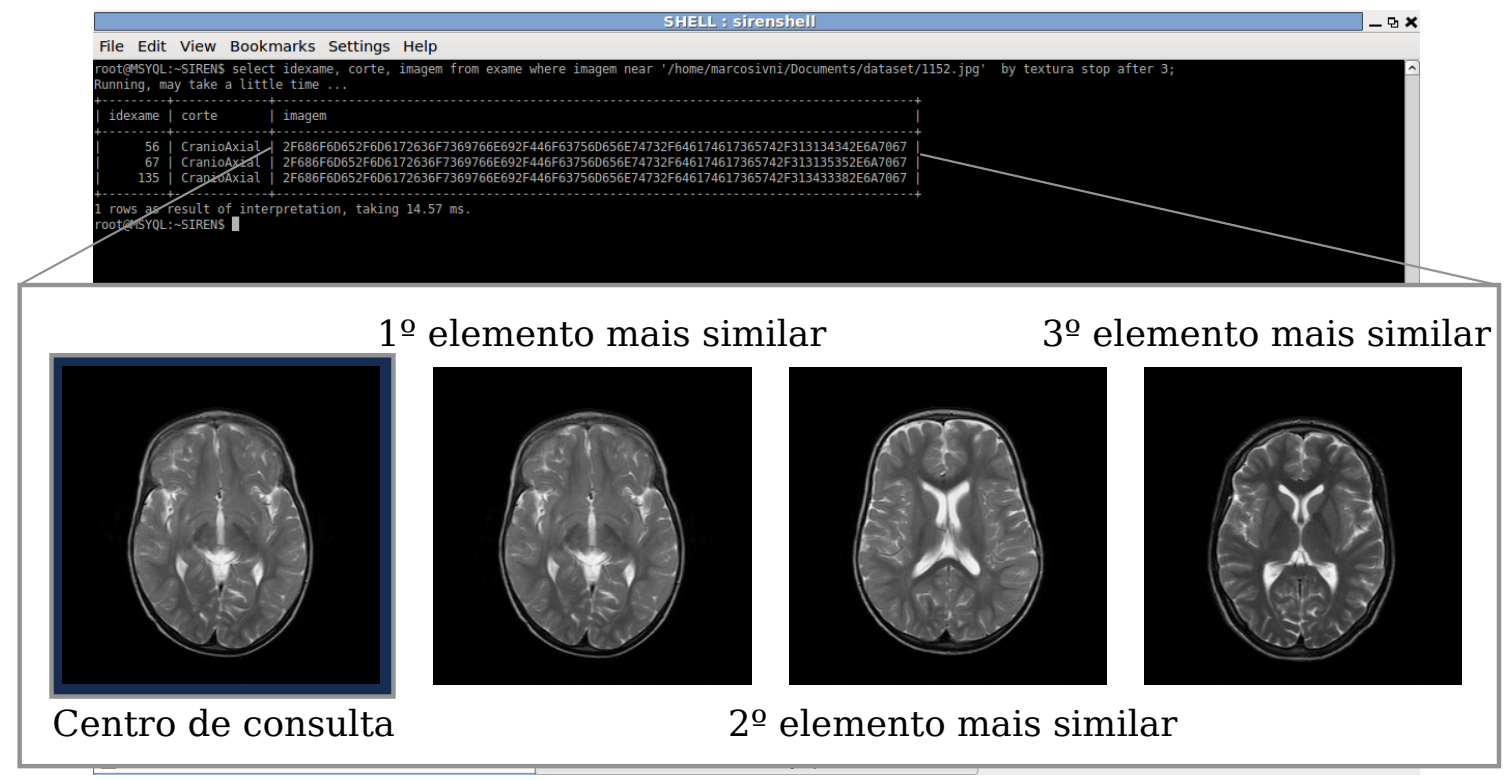

Figura 5.7: Consulta por similiaridade aos 3 elementos mais similares, tendo como centro de consulta uma imagem em disco, por meio da métrica textura.

A Figura 5.7 utiliza a métrica textura para realizar uma consulta aos $k=3$ elementos mais similares. Após cada comando executado, o tempo total de tradução somado à execução do comando (incluindo o acesso aos indíces tradicionais e aos métodos de acesso métricos) é mostrado em milisegundos. As seleções com um único centro de consulta podem ser feitas por meio do MAM Slim-Tree, o que permite acelerar o tempo de resposta em várias vezes (Kaster et al., 2010), enquanto a seleção com múltiplos centros e junções por similaridade são realizadas sem o uso de MAM, pois ainda não existe a implementação destes recursos dentro da estrutura proposta.

\subsubsection{Dos Novos Recursos: Extratores de Características e Funções de Distância}

Quando se compara o shell implementado com o protótipo inicial, verificamos que a estrutura modular proposta na seção anterior possibilita que novos recursos e novos tipos de dados podem ser incorporados, com facilidade bem maior do que anteriormente. Além disso, na implementação do protótipo deste trabalho foram adicionados novos extratores de características e funções de distância, bem como suporte a séries-temporais financeiras, como descritos no capítulo 4. A comparação desses recursos pode ser vista na Tabela 5.3.

\subsubsection{Discussões Parciais}

A ferramenta desenvolvida integra os recursos mostrados na Tabela 5.3 para dar suporte à consultas por similarida via SQL estendido. É possível inserir comandos DDL (criação de tabelas modelando dados complexos para a base, criação de métricas que definem a 
Tabela 5.3: Comparativo de recursos: Shell versus primeira implementação versus FMi-SiR.

\begin{tabular}{|c|c|c|c|c|c|}
\hline Recurso & Extrator & FD & Shell & 1a. Versão & FMi-SiR \\
\hline Histograma de Cinza & $\bullet$ & & $\mathrm{X}$ & $\mathrm{X}$ & $\mathrm{X}$ \\
\hline Histograma de Cores & $\bullet$ & & $\mathrm{X}$ & & \\
\hline Histograma Métrico & $\bullet$ & & $\mathrm{X}$ & & $\mathrm{X}$ \\
\hline MPEG Color Layout & $\bullet$ & & $\mathrm{X}$ & & \\
\hline Zernike & $\bullet$ & & $\mathrm{X}$ & $\mathrm{X}$ & \\
\hline Textura & $\bullet$ & & & $\mathrm{X}$ & \\
\hline Haralick & $\bullet$ & & $\mathrm{X}$ & & $\mathrm{X}$ \\
\hline Wavelets Haar & $\bullet$ & & $\mathrm{X}$ & & \\
\hline Wavelets Daubechies & $\bullet$ & & $\mathrm{X}$ & & $\mathrm{X}$ \\
\hline Gap Extractor & $\bullet$ & & $\mathrm{X}$ & & $\mathrm{X}$ \\
\hline STFT & $\bullet$ & & $\mathrm{X}$ & $\mathrm{X}$ & \\
\hline Sound Texture & $\bullet$ & & & $\mathrm{X}$ & $\mathrm{X}$ \\
\hline City-Block & & $\bullet$ & $\mathrm{X}$ & $\mathrm{X}$ & $\mathrm{X}$ \\
\hline Euclidiana & & $\bullet$ & $\mathrm{X}$ & $\mathrm{X}$ & $\mathrm{X}$ \\
\hline Chebyshev & & $\bullet$ & $\mathrm{X}$ & $\mathrm{X}$ & $\mathrm{X}$ \\
\hline MHD & & $\bullet$ & $\mathrm{X}$ & & $\mathrm{X}$ \\
\hline LEdit & & $\bullet$ & $\mathrm{X}$ & & $\mathrm{X}$ \\
\hline STILLIMAGE & & & $\mathrm{X}$ & $\mathrm{X}$ & $\mathrm{X}$ \\
\hline AUDIO & & & $\mathrm{X}$ & & \\
\hline TIMESERIES & & & $\mathrm{X}$ & & \\
\hline
\end{tabular}

associação < extrator, função de distância > e indíces para dados complexos que melhoram a performance das consultas por similaridade), comandos DCL (exibir informações sobre os esquemas das tabelas e das bases de dados) e comandos DML (comandos de inserção, e de consultas: com um único centro de consulta e com múltiplos centros de consulta).

A medida em que o programador de aplicativos for desenvolvendo novos recursos, a arquitetura modular das biliotecas e do sistema, permite que os mesmos possam ir sendo anexados conforme necessário. Além disso, a estrutura modular adotada no desenvolvimento da ferramenta facilita que ela possa continuar sendo expandida. Em particular, foi contemplado em seu projeto o fato de que a continuação de seu desenvolvimento deve possibilitar o suporte a novos tipos de consultas, similaridades por grupo e suporte a operadores de junção de dados complexos, a medida em que os novos métodos correspondentes forem sendo propostos e implementados de acordo com as especificações definidas e com a continuidade dos demais projetos de pesquisa em andamento no GBdI. 


\subsection{Do SQL Estendido para Apoio a um Aplicativo CBMIR}

Aplicativos de recuperação de imagens médicas por conteúdo (CBMIR) são utilizados para auxiliar os especialistas (médicos radiologistas) no paradigma da medicina baseada em casos, que utiliza laudos antigos para a auxiliar a interpretação das imagens e a preparação de um novo. Os sistemas CBMIR podem responder a perguntas tais como: "Quais são os estudos de pacientes que contém imagens de raios $\mathrm{X}$ similares a uma dada imagem não diagnosticada?". Obviamente, essas questões podem ser expressas em consultas via SQL estendido, conforme visto ao longo deste capítulo.

A literatura aponta como principais desafios para o desenvolvimento de CBMIR (Müller et al., 2004): (1) diminuição do gap semântico entre o domínio e a metodologia dos sistemas e (2) suporte a grande volume de dados. Como contribuição, este trabalho de mestrado implementou o núcleo de um sistema CBMIR para exames de mamografia, denominado Higiia, que aproveita a arquitetura proposta para, através da criação de métricas que associam pares <extratores, funções de distância>, diminuir os gaps semânticos e os métodos de acesso métrico para reduzir o desafio de aproveitar a grande quantidade de exames que vêm sendo acumulados nos centros de saúde, em complexidade e volume cada vez maiores.

O sistema Higiia (Bedo et al., 2013a) é capaz de trabalhar com imagens médicas de alta resolução e contraste, transportando a complexidade de se processar a consulta por similaridade para fora do aplicativo, no caso para o o shell implementado neste trabalho ou o FMi-SiR (Kaster et al., 2009). A arquitetura do sistema pode ser vista na Figura 5.8. O sistema Higiia recebe uma imagem de mamografia para ser laudada de acordo com o tipo de lesão (massa ou calcificação) e sua composição e classificação BI-RADS. O método de realimentação de relevância implementado no CBMIR é o método de Rocchio (Yang et al., 2012).

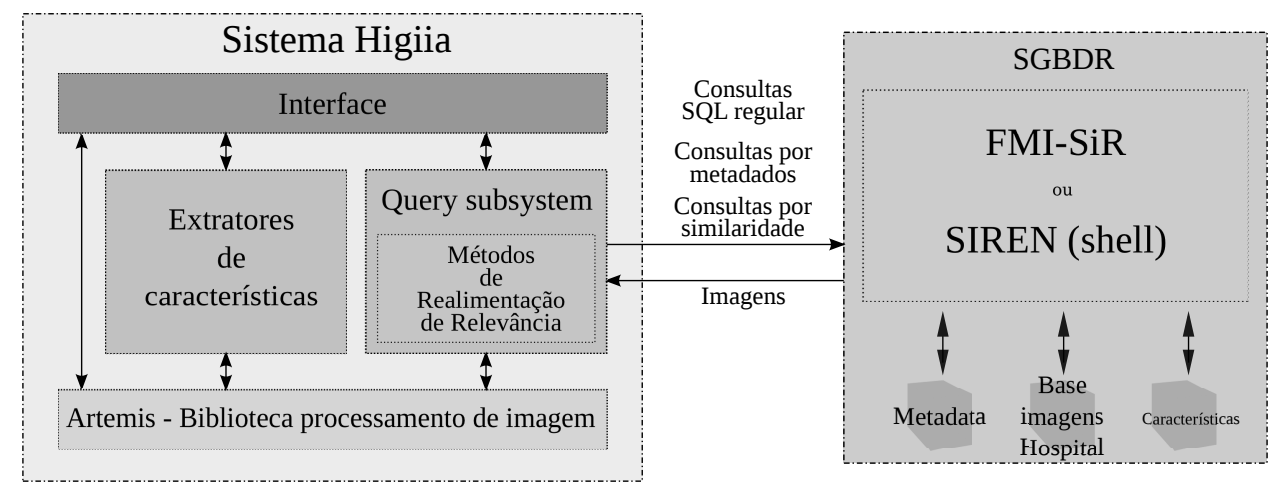

Figura 5.8: Arquitetura interna do CBMIR Higiia. 
Conforme visto na Seção 4.6, a arquitetura compreende a definição da base de dados da aplicação. Cada imagem é armazenada como um BLOB e associada com um bloco de

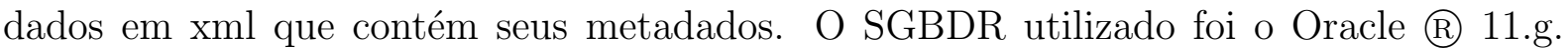
O sistema interno de consultas (query subsystem) recebe a consulta de acordo com os parâmetros definidos pelo usuário via interface do aplicativo, define quais são os parâmetros corretos e escolhe a consulta a ser executada representada em SQL (estendido, regular, por metadados dicom) e envia ao interpretador para executá-lo.

O sistema de execução de consultas inclui métodos de realimentação de relevância que, permite ao profissional de saúde refinar as consultas por similiaridade de acordo com a percepção do usuário, a partir do processo de interação com o sistema, em que o profissional seleciona as imagens mais similares e as menos similares. Todas as informações das iterações de realimentação de relevância são armazenadas pelo sistema. Para a realização de uma consulta por similaridade, o sistema interno pode preparar um SQL estendido nos moldes definidos no Capítulo 3, caso esteja operando com o shell, ou enviar um comando de comandos nos seguintes moldes, caso esteja operando com o FMi-SiR:

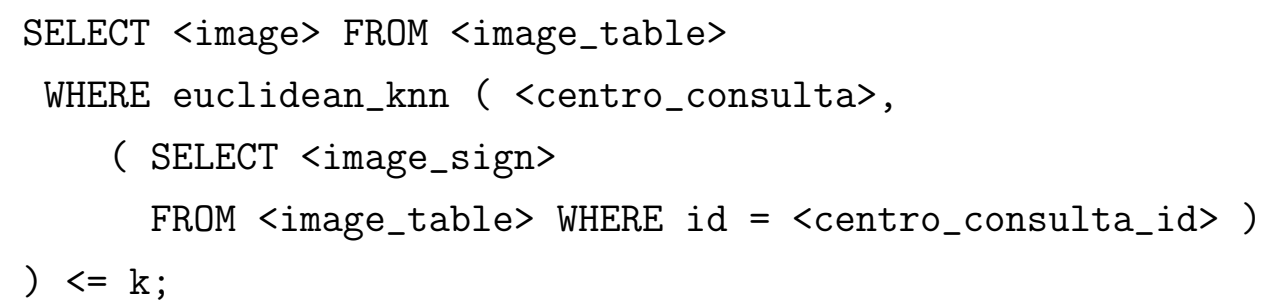

Note-se que, no caso do FMi-SiR, não há a definição prévia de métrica o que implica que seja utilizada uma função (no caso acima a euclidean_knn()) que associa o extrator e a função de distância.

\subsection{0 aplicativo Higiia}

O objetivo do desenvolvimento do aplicativo é trazer mais informações que permitam compreender melhor questões como:

1. Um sistema CBMIR realmente auxilia o profissional ao diagnóstico em um ambiente clínico?

2. A realimentação de relevância conduz o usuário a um diagnóstico com maior nível de certeza?

Para responder essas perguntas, foi efetuada uma avaliação onde o usuário deveria utilizar o sistema seguindo os passos da Figura 4.6, através da interface do sistema, a qual é mostrada na Figura 5.9.

Seguindo os passo na ordem indicada na Figura 5.9, o usuário registra-se no sistema (passo 1) e seleciona o banco de dados e tabelas que deseja trabalhar (passo 2), 


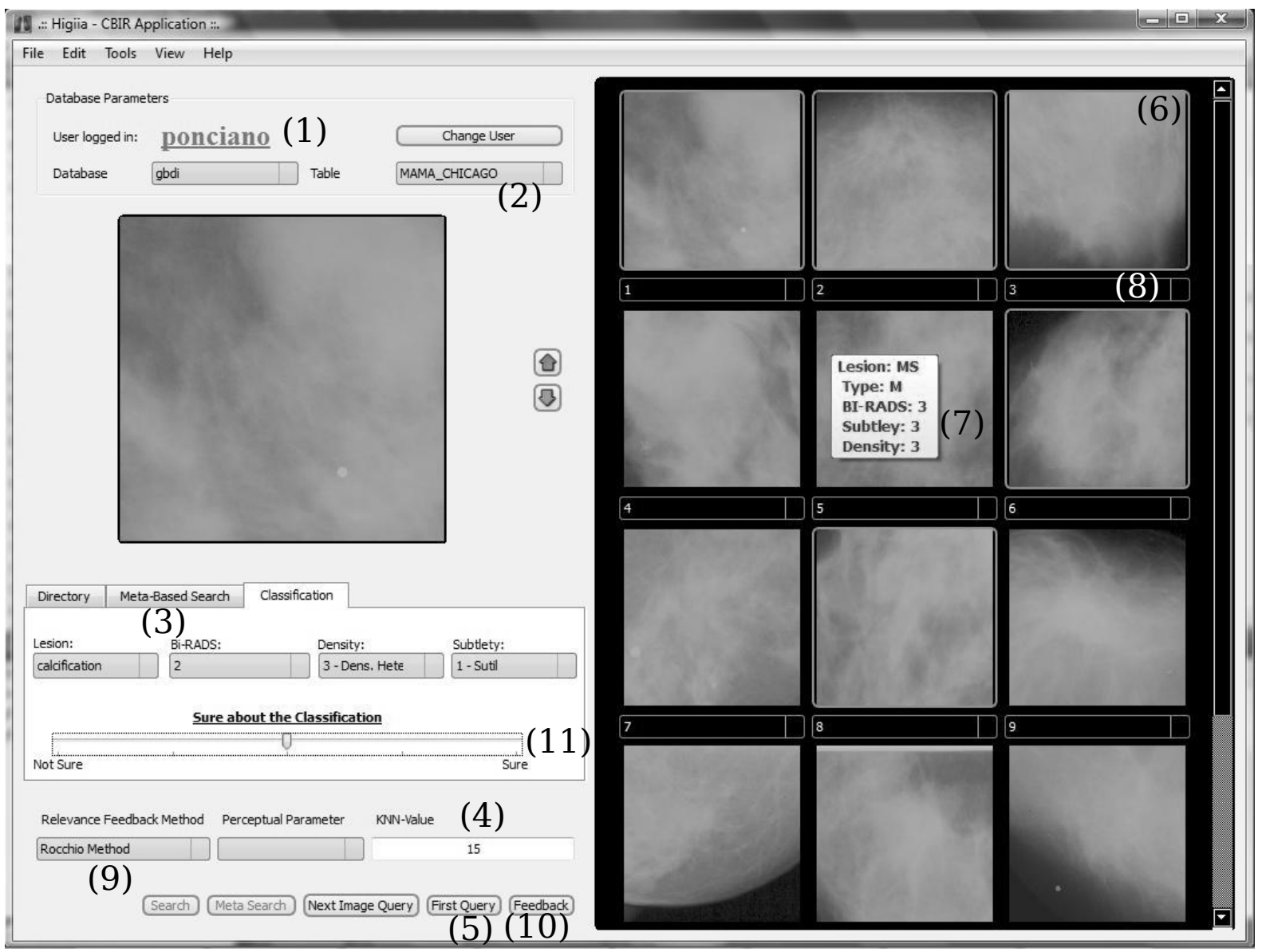

Figura 5.9: Interface do sistema Higiia.

especificando o contexto de busca. Uma vez registrado, o usuário escolhe uma imagem não laudada e executa sua classificação (passo 3). A imagem selecionada é mostrada do lado esquerdo. Nesse ponto é possível proceder a consulta por similaridade, através da definição dos parâmetros de uma busca $k$-NN, incluindo parâmetros de percepção (Ponciano-Silva, 2008) (passo 4) e a demanda (passo 5). Se o usuário omitir algum destes parâmetros o sistema utilizará valores padrão.

O resultado é mostrado com as miniaturas das imagens similares do lado direito da tela, de acordo com a ordem decrescente de similaridade (passo 6). Posicionando o mouse sobre as miniaturas, o usuário pode visualizar a classificação das imagens do banco de dados (passo 7). Os usuários podem esconder imagens que considere irrelevantes clicando sobre elas com o botão direito (um requisito solicitado pelos médicos radiologistas para diminuir o ruído das consultas). O usuário então pode refinar sua busca através da realimentação de relevância, indicando o grau de relevância de cada uma delas (passo 8). A seguir, o usuário escolhe o método de realimentação de relevância (passo 9) e dispara a reavaliação da consulta (passo 10). Os usuários podem realizar quantos ciclos de realimentação de relevância necessários, armazenando os resultados prévios de classificação (passo 11). 
O aplicativo foi utilizado por 10 médicos (radiologistas e médicos residentes) da Faculdade de Medicina de Ribeirão Preto (HCFMRP-USP) para classificar 30 diferentes centros de consultas (imagens) distintas, objetivando responder às questões formuladas no início dessa seção. Ainda nesse sentido, para o experimento foi escolhido como extrator de características o histograma de níveis de cinza associado à função de distância euclidiana para validar o uso desse tipo de aplicativo em um ambiente cliníco.

\subsubsection{Resultados Preliminares do Uso do Sistema}

Cada um dos 10 médicos analisou em média 6 das 30 imagens e cada imagem foi analisada por dois médicos diferentes, totalizando 60 classificações. Para o experimento os especialistas preferiram configurar o aplicativo para consultas $k=15$, isto é, recuperar as 15 imagens mais similares.

Tabela 5.4: Comparação entre a taxa de acerto médicos residentes e a precisão do sistema.

\begin{tabular}{lccclcccc}
\multicolumn{3}{c}{ Calcificação } & & & \multicolumn{3}{c}{ Massa } \\
Iteração & $\mathbf{1 a}$ & $\mathbf{2 a}$ & $\mathbf{3 a}$ & Iteração & $\mathbf{1 a}$ & $\mathbf{2 a}$ & 3a. \\
Acurácia médica & $47 \%$ & $31 \%$ & $27 \%$ & Acurácia médica & $89 \%$ & $93 \%$ & $93 \%$ \\
Precisão do sistema & - & $39 \%$ & $41 \%$ & Precisão do sistema & - & $61 \%$ & $62 \%$
\end{tabular}

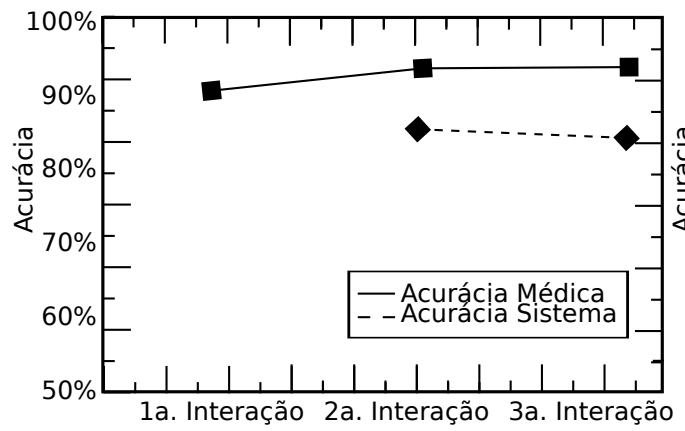

(A)

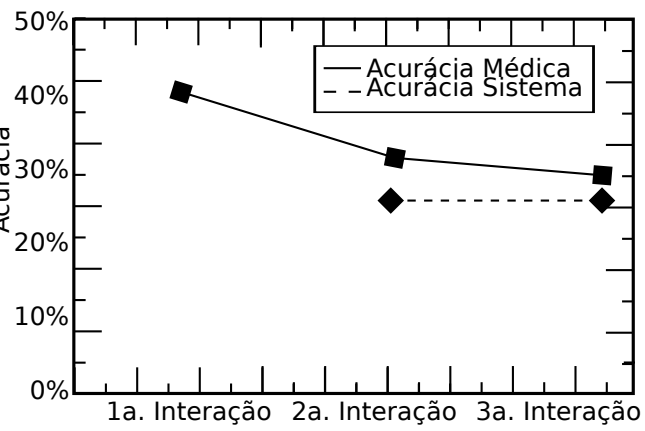

(B)

Figura 5.10: Comparativo da taxa de acerto da classificação feita por radiologistas sobre as classes (A) Massa e (B) Calcificação.

A precisão do sistema é relativa à quantidade total de imagens que são marcadas como relevantes ao final de cada passo se execução de consultas por similaridade. A acurácia médica é a taxa de acertos feita pelos médicos ao laudar uma imagem (considerando como correta a classificação existente no banco de dados original). A Tabela 5.4 mostra os valores obtidos para imagens das classes (1) calcificação e (2) massa. Nota-se que o uso do sistema e da realimentação de relevância impacta na classificação final da imagem pelo especialista. 
No caso da classe de calcificação, o sistema apresentou uma precisão inicial de $39 \%$ e impactou negativamente nas decisões de classificação do especialista. Isso aconteceu devido ao fato que a associação <histograma, euclidiana> não representa um bom parâmetro de percepção para a representação de calcificação. Já para a classe de massa o sistema impactou positivamente na classificação tanto dos médicos residentes (Tabela 5.4) quanto dos radiologistas (Figura 5.10). Esse comportamento era o esperado, e ele é importante para validar a viabilidade do aplicativo em um ambiente clínico real.

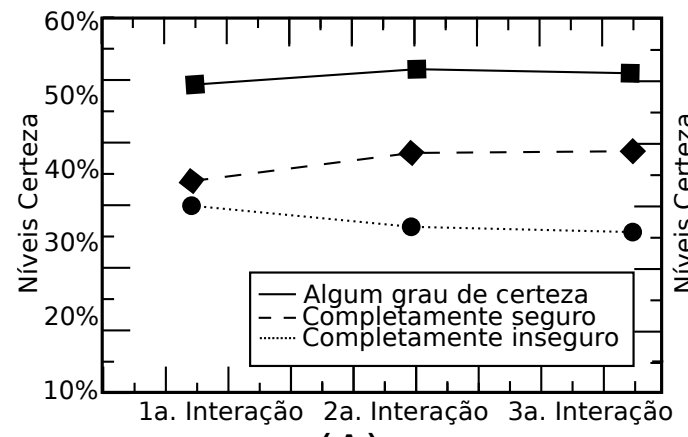

(A)

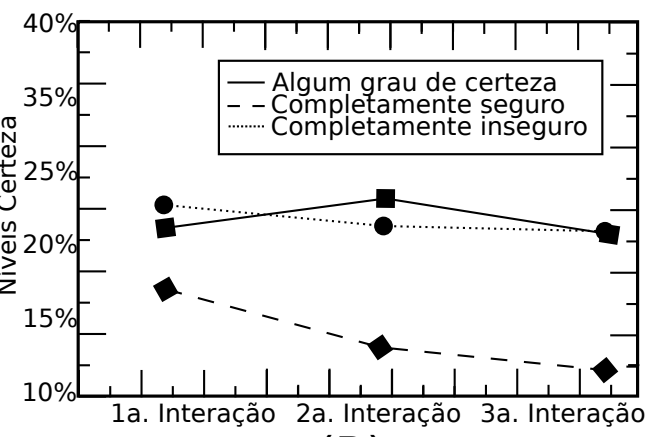

(B)

Figura 5.11: Comparativo do grau de certeza de médicos residentes e radiologistas ao classificar uma imagem pertencente as classes (A) Massa e (B) Calcificação.

O sistema também registrou o grau de certeza dos profissionais ao emitirem suas classificações, conforme visto no gráfico da Figura 5.11. Nota-se que o nível de certeza do especialista aumenta (especialmente quando ele se sente completamente seguro) no caso de classificações de massa enquanto ele diminui para a classe de calcificação. Esse comportamento aumenta a medida em que os ciclos de realimentação de relevância vão acontecendo.

\subsubsection{Discussões Parciais}

A ferramenta Higiia possibilitou trazer considerações as perguntas postuladas na Seção 5.4. Nesse experimento, constatou-se que um sistema CBMIR pode auxiliar e melhorar o nível de certeza dos profissionais da área de medicina, desde que seja considerada com muito cuidado a escolha dos parâmetros de percepção (extrator, função de distância). A escolha inadequada deste parâmetro prejudica o laudo da imagem, diminuindo o grau de certeza do especialista e gerando uma situação confusa que pode prejudicar a classificação da imagem.

Também foi verificado que o uso de técnicas de realimentação de relevância levam a dois possíveis cenários: caso a escolha do parâmetro de precepção seja adequada, ela leva ao crescimento do nível de certeza do especialista e à escolha mais correta do laudo a ser feito. No caso da escolha ser inadequada, o uso do Sistema CBMIR se torna prejudicial, diminuindo o nível de certeza do especialista indicando que a consulta está trazendo 
resultados irrelevantes e induz o especialista a erros que não cometeria sem o uso da ferramenta. Essa conclusão indica que o desenvolvimento de ferramentas CBMIR são importantes para auxiliar a comunidade de profissionais da saúde a melhorar a qualidade dos diagnósticos e a certeza nos laudos gerados, mas é importante que os sistemas tenham flexibilidade para que novas funções de distância e extratores de características possam ser introduzidas e/ou substituídas, a medida que o desenvolvimento natural da área vá produzindo essas classes de métodos cada vêz melhores.

\subsection{Conclusão}

Esse capítulo apresentou as contribuições deste trabalho de mestrado: uma biblioteca para tratamento de séries temporais, um aplicativo shell que provê suportes a consultas por similaridade via SQL estendido e um aplicativo CBMIR que utiliza todos os recursos implementados em um ambiente clínico real. 


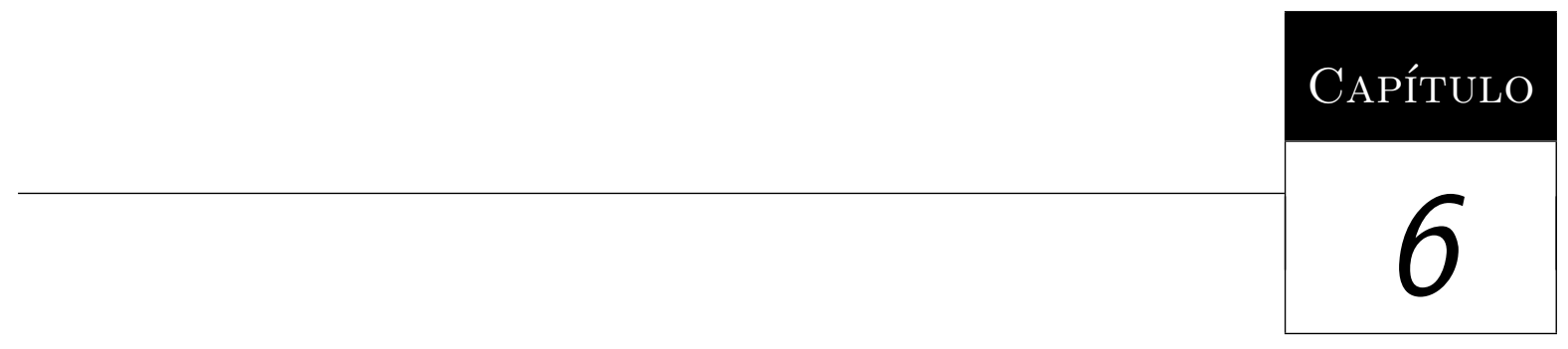

\section{Conclusão}

Neste capítulo apresentam-se as conclusões gerais dos resultados e discussões do trabalho de mestrado, as principais contribuições e as possibilidades de continuação em trabalhos futuros.

\subsection{Considerações Finais}

O paradigma de consultas por similaridade tem sido foco de investigação de pesquisadores de diversas áreas que envolvem tratamento de informação. Desenvolver uma arquitetura que possibilite que diversos tipos de dados complexos possam ser tratados pela mesma ótica, possibilita que haja uma robustez e contribui para o desenvolvimento de aplicativos, visto que existem já diversas técnicas consolidadas na literatura que aportam otimizações para cada um dos passos do paradigma.

Esse trabalho apresenta o desenvolvimento de uma arquitetura que é capaz de suportar, de forma modular, o acréscimo de novos dados complexos sem que haja a necessidade de desenvolver um sistema específico para cada nova alteração. Como um exemplo ilustrativo de extensão da arquitetura básica, esse trabalho propõe a implementação de uma biblioteca de séries-temporais financeiras e um extrator de característica para este tipo de dado complexo. Com esta extensão, mostrou-se que foi possível utilizar o paradigma de consulta por similaridade para realizar o forecasting de eventos financeiros com acurácia e baixo tempo de resposta (Bedo et al., 2013b).

Sendo essa biblioteca apenas um módulo da arquitetura proposta, esse trabalho também implementou um shell para dar suporte a consultas por similaridade que interpreta uma versão da linguagem SQL estendida que incorpora novos recursos, em particular para consultas a conjuntos de imagens médicas usando diversos extratores de 
características. A associação < extrator, função de distância > é realizada através de uma estrutura definida como métrica. Como exemplos foram mostrados esquemas para bases de imagens médicas de exames de mamografia.

Finalmente, foi implementado um CBMIR para exames de mamografia que foi testado em um ambiente clínico real, ressaltando a investigação por viabilidade desses sistemas em determinados domínios, limitações e vantagens. O sistema CBMIR foi construído tendo por base as implementações das bibliotecas modulares realizadas como parte deste trabalho. Uma demonstração do aplicativo foi realizada no Simpósio Brasileiro de Banco de Dados, o qual foi premiado como o melhor software da sessão de demos do evento realizado em $2012^{1}$.

\subsection{Principais Contribuições}

Destaca-se como principal contribuição deste trabalho a proposição de uma arquitetura modular para a efetiva implementação de consultas por similaridade sobre dados complexos em SGBDR. Como parte dessa modularização, foram definidas, implementadas e inicializadas as bibliotecas Hermes, Artemis, Midas, Apollo e Agathon. Além desta, pode-se citar como contribuições adicionais importantes:

- Proposição de um extrator de características para séries-temporais financeiras;

- Proposição de um método de classificação que integra a proposta do método IBL com métodos de acesso métrico;

- Implementação de um shell para a realização de consultas por similaridade incluindo suporte a diversas funções de distância e extratores de características, que interpreta uma versão da linguagem SQL estendida para comandos de consulta por similaridade e demais comandos de apoio na sublinguagem DDL;

- Análise com profissionais da área médica sobre o uso de aplicativos de recuperação de dados por conteúdo em ambientes reais e a importância de se reduzir o gap semântico entre as propostas e o domínio.

\subsection{Propostas para Trabalhos Futuros}

Como resultado dos trabalhos desenvolvidos neste programa de mestrado, abrem-se diversas propostas para trabalhos futuros, das quais destacam-se as seguintes:

- Análise e desenvolvimento de melhor esquema para armazenar séries temporais genéricas e espcializações para domínios dedicados, tal como é o caso para séries-temporais financeiras, em bases de dados relacionais;

\footnotetext{
${ }^{1}$ http://sws2012.ime.usp.br/sbbd/
} 
- Definição formal de sintaxe SQL para consulta por similaridade de séries-temporais genéricas e especialmente de séries financeiras;

- Incorporação de avaliadores de planos de consulta para otimizar as consultas por similaridade, assim como existem para dados tradicionais em SGBDR;

- Definição de técnicas de clusterização baseados em IBL para definição e estudos de classes de séries-temporais financeiras;

- Definição de novos operadores de agregação para dados complexos;

- Incorporação efetiva dos recursos propostos em um SGBDR. 


\section{Referências Bibliográficas}

ACR Breast imaging reporting and data system atlas (bi-rads - atlas). American College of Radiology, 2003.

AgGarwal, C. C. Managing and mining uncertain data. Springer Publishing Company, Incorporated, 2009.

AhA, D.; Kibler, D. Instance-based learning algorithms. Machine Learning, v. 6, p. 37-66, 1991.

Ares, L.; Brisaboa, N.; Esteller, M.; Pedreira, O.; Places, A. Optimal pivots to minimize the index size for metric access methods. In: Similarity Search and Applications, 2009. SISAP '09. Second International Workshop on, 2009, p. 74-80.

Armano, G.; Marchesi, M.; Murru, A. A hybrid genetic-neural architecture for stock indexes forecasting. Inf. Sci., v. 170, n. 1, p. 3-33, 2005.

Disponível em http://dx.doi.org/10.1016/j.ins.2003.03.023

Ashley, J.; Flickner, M.; Hafner, J.; Lee, D.; Niblack, W.; Petkovic, D. The query by image content (qbic) system. SIGMOD Rec., v. 24, n. 2, p. 475-, 1995.

Aslandogan, Y. A.; Yu, C. T. Techniques and systems for image and video retrieval. IEEE Trans. on Knowl. and Data Eng., v. 11, n. 1, p. 56-63, 1999.

Atsalakis, G. S.; Valavanis, K. P. Surveying stock market forecasting techniques. Expert Systems with Applications, v. 36, n. 3, Part 2, p. 5932 - 5941, 2009.

Ballesteros, J.; Cary, A.; Rishe, N. Spsjoin: parallel spatial similarity joins. In: Proceedings of the 19th ACM SIGSPATIAL International Conference on Advances in Geographic Information Systems, GIS '11, New York, NY, USA: ACM, 2011, p. 481-484 (GIS'11, ).

Disponível em http://doi.acm.org/10.1145/2093973.2094054

Bansal, M.; Sharma, V.; Singh, S. Comparison of texture models for efficient ultrasound image retrieval. SPIE Proceedings, v. 8670, p. 86702C-86702C-10, 2012. Disponível em http://dx.doi.org/10.1117/12.2007837 
BARIOni, M. C. N. Operações de consulta por similaridade em grandes bases de dados complexos. Tese de Doutoramento, Universidade de São Paulo (USP), 2006.

Barioni, M. C. N.; Razente, H.; Traina, A.; Traina, Jr., C. Siren: a similarity retrieval engine for complex data. In: Proceedings of the 32nd international conference on Very large data bases, VLDB '06, VLDB Endowment, 2006, p. 1155-1158 (VLDB '06, ).

Bedo, M. V. N.; Ponciano-Silva, M.; Kaster, D.; Buggati, P. H.; Traina, A. J. M.; Traina, JR., C. Higiia: A perceptual medical cbir system applied to mammography classification. In: Proceedings of 27th Brazilian Symposium on Databases, SBBD '12, 2013a (SBBD '12, ).

Bedo, M. V. N.; Santos, D. P.; Kaster, D.; Traina, JR., C. A similarity-based approach for financial time series analysis and forecasting. In: Proceedings of 24th International Conference on Database and Expert Systems Applications, DEXA '13, 2013b (DEXA'13, ).

Bedo, M. V. N.; Traina, JR., C. Apollo sound: Biblioteca para manipulação e extração de características de áudio. In: Anais 18o. Simpósio Internacional de Iniciação Científica, SIICUSP '10, 2010a (SIICUSP '10, ).

Bedo, M. V. N.; TrainA, JR., C. Artemis: biblioteca para manipulação e extração de características de imagens. In: Anais 19o. Congresso de Iniciação Científica UFSCar, CIC '10, 2010b (CIC'10, ).

Bedo, M. V. N.; Traina, JR., C. Hermes: Biblioteca para funções de distância. In: Anais 19o. Simpósio Internacional de Iniciação Científica, SIICUSP '11, 2011 (SIICUSP' '11, ).

Bengio, Y.; Mori, R.; Flammia, G.; Kompe, R. Global optimization of a neural network - hidden markov model hybrid. IEEE Transactions on Neural Networks, v. 3, p. 252-259, 1991.

Berthold, H.; Meyer-Wegener, K. Schema design and query processing in a federated multimedia database system. In: Proceedings of the 9th International Conference on Cooperative Information Systems, CooplS '01, London, UK, UK: Springer-Verlag, 2001, p. 285-300 (CooplS '01, ).

Box, G. E. P.; Jenkins, G. Time series analysis, forecasting and control. Holden-Day, Incorporated, 1990.

Bozkaya, T.; Ozsoyoglu, M. Indexing large metric spaces for similarity search queries. ACM Trans. Database Syst., v. 24, n. 3, p. 361-404, 1999. 
Bugatti, P. H.; Traina, A. J. M.; Traina, JR., C. Assessing the best integration between distance-function and image-feature to answer similarity queries. In: Proceedings of the 2008 ACM symposium on Applied computing, SAC '08, New York, NY, USA: ACM, 2008, p. 1225-1230 (SAC '08, ).

Butler, M.; Kazakov, D. Particle swarm optimization of bollinger bands. In: ANTS Conference, 2010, p. 504-511.

Carélo, C. C.; Pola, I. R.; Ciferri, R. R.; Traina, A. J.; Traina, Jr., C.; Aguiar Ciferri, C. D. The onion-tree: Quick indexing of complex data in the main memory. In: Proceedings of the 13th East European Conference on Advances in Databases and Information Systems, ADBIS '09, Berlin, Heidelberg: Springer-Verlag, 2009, p. 235-252 (ADBIS '09, ).

Carey, M. J.; Kossmann, D. On saying "enough already!"in sql. In: Peckham, J., ed. SIGMOD 1997, Proceedings ACM SIGMOD International Conference on Management of Data, May 13-15, 1997, Tucson, Arizona, USA, ACM Press, 1997, p. $219-230$.

Carrer, M.; Joshi, A.; Lin, P.; Srivastava, A. Metadata transformation and management with oracle intermedia. IEEE Data Eng. Bull., v. 22, n. 1, p. 15-18, 1999.

Chávez, E.; Navarro, G.; Baeza-Yates, R.; Marroquín, J. L. Searching in metric spaces. ACM Comput. Surv., v. 33, n. 3, p. 273-321, 2001.

Chen, T.; Khan, A.; Schneider, M.; Viswanathan, G. iblob: complex object management in databases through intelligent binary large objects. In: Proceedings of the Third international conference on Objects and databases, ICOODB'10, Berlin, Heidelberg: Springer-Verlag, 2010, p. 85-99 (ICOODB'10, ).

Disponível em http://dl.acm.org/citation. cfm?id=1926241.1926253

Ciaccia, P.; Patella, M.; Zezula, P. M-tree: An efficient access method for similarity search in metric spaces. In: Proceedings of the 23rd International Conference on Very Large Data Bases, VLDB '97, San Francisco, CA, USA: Morgan Kaufmann Publishers Inc., 1997, p. 426-435 (VLDB' '97, ).

Cios, K. J. Data mining in finance: Advances in relational and hybrid methods. boris kovalerchuk and evgenii vityaev, kluwer, dordrecht, 2000, 308 pp., isbn 0-7923-7804-0. Neurocomputing, v. 36, n. 1-4, p. 245-246, 2001.

Codd, E. F. A relational model of data for large shared data banks. Commun. ACM, v. 13, n. 6, p. 377-387, 1970. 
DAtTA, R.; Joshi, D.; Li, J.; WAng, J. Z. Image retrieval: Ideas, influences, and trends of the new age. ACM Comput. Surv., v. 40, n. 2, p. 5:1-5:60, 2008.

Dorini, L. B.; Leite, N. J. Multiscale methods for image processing: The wavelet and the scale-space approaches. In: Proceedings of the 2009 Tutorials of the XXII Brazilian Symposium on Computer Graphics and Image Processing, SIBGRAPI-TUTORIALS '09, Washington, DC, USA: IEEE Computer Society, 2009, p. 31-44 (SIBGRAPI-TUTORIALS'O9, ).

Doulkeridis, C.; Norvag, K. A survey of large-scale analytical query processing in mapreduce. The VLDB Journal, v. 1, 2013.

Eichelberg, M.; Aden, T.; Riesmeier, J.; Dogac, A.; Laleci, G. B. A survey and analysis of electronic healthcare record standards. ACM Comput. Surv., v. 37, n. 4, p. 277-315, 2005.

Eisa, M.; RefaAt, M.; El-Gamal, A. F. Preliminary diagnostics of mammograms using moments and texture features. ICGST International Journal on Graphics, Vision and Image Processing, GVIP, v. 09, p. 21-27, 2009.

Eisenberg, A.; Melton, J.; Kulkarni, K. G.; Michels, J.-E.; Zemke, F. Sql: 2003 has been published. SIGMOD Record, v. 33, n. 1, p. 119-126, 2004.

Eppstein, D.; Goodrich, M. T.; Simons, J. A. Set-difference range queries. CoRR, v. abs/1306.3482, 2013.

Felipe, J. C. Desenvolvimento de métodos para extração, comparação e análise de características intrínsecas de imagens médicas, visando à recuperação perceptual por conteúdo. Tese de Doutoramento, Universidade de São Paulo (USP), 2005.

Gonzalez, R. C.; Woods, R. E. Digital image processing (3rd edition). Upper Saddle River, NJ, USA: Prentice-Hall, Inc., 2006.

Graps, A. An introduction to wavelets. IEEE Comput. Sci. Eng., v. 2, n. 2, p. 50-61, 1995.

Gruhne, M.; Dittmar, C.; GÄrtner, D. Improving rhythmic similarity computation by beat histogram transformations. In: ISMIR, 2009, p. 177-182.

Guld, M. O.; Thies, C.; Fischer, B.; Lehmann, T. M. A generic concept for the implementation of medical image retrieval systems. In: Int J Med Info 2006; In, Press, 2007. 
Guliato, D.; De Melo, E. V.; Rangayyan, R. M.; Soares, R. C. Postgresql-ie: An image-handling extension for postgresql. J. Digital Imaging, v. 22, n. 2, p. 149-165, 2009.

Gupta, R.; Ghosh, S. K.; Sural, S.; Pramanik, S. Hybrid index-based image search from the web. IJDMMM, v. 3, n. 3, p. 252-276, 2011.

Hamilton, J. Time series analysis. Princeton, NJ: Princeton Univ. Press, 1994.

Haralick, R. M.; Shanmugam, K.; Dinstein, I. Textural features for image classification. Systems, Man and Cybernetics, IEEE Transactions on, v. SMC-3, n. 6, p. $610-621,1973$.

Hasan, S. Y.; Shaker, A. S. Study of zernike polynomials of an elliptical aperture obscured with an elliptical obscuration. Appl. Opt., v. 51, n. 35, p. 8490-8497, 2012. Disponível em http://ao.osa.org/abstract.cfm?URI=ao-51-35-8490

Hualtason, G. R.; Samet, H. Index-driven similarity search in metric spaces (survey article). ACM Trans. Database Syst., v. 28, n. 4, p. 517-580, 2003.

Hu, H.; LeE, D. L. Range nearest-neighbor query. IEEE Trans. Knowl. Data Eng., v. 18, n. 1, p. 78-91, 2006.

Huang, J.; Ravi Kumar, S.; Mitra, M.; Zhu, W.-J.; Zabih, R. Spatial color indexing and applications. Int. J. Comput. Vision, v. 35, n. 3, p. 245-268, 1999.

Ivanova, K.; Stanchev, P.; Velikova, E.; Vanhoof, K.; Depaire, B.; Kannan, R.; Mitov, I.; MARkov, K. Features for art painting classification based on vector quantization of mpeg-7 descriptors. In: ICDEM, 2010, p. 146-153.

Jyothi, B.; Latha, Y.; Mohan, P. Medical image retrieval using multiple features clustering technique. In: Computational Intelligence Computing Research (ICCIC), 2012 IEEE International Conference on, 2012, p. 1-4.

KaO, L.-J.; Chiu, C.-C.; Lu, C.-J.; Chang, C.-H. A hybrid approach by integrating wavelet-based feature extraction with MARS and SVR for stock index forecasting. Decision Support Systems, v. 54, n. 3, p. 1228 - 1244, 2013.

Disponível em http://www.sciencedirect.com/science/article/pii/S0167923612003442

Kaster, D. S.; Bugatti, P. H.; Traina, A. J. M.; Traina, JR., C. Incorporating metric access methods for similarity searching on oracle database. In: $S B B D, 2009$, p. $196-210$. 
Kaster, D. S.; Bugatti, P. H.; Traina, A. J. M.; Traina, Jr., C. Fmi-sir: A flexible and efficient module for similarity searching on oracle database. Journal of Information and Data Management (JIDM), v. 1, n. 2, p. 229-244, 2010.

Kaur, H.; Jyoti, K. Survey of techniques of high level semantic based image retrieval. IJRCCT, v. 2, n. 1, 2013.

Disponível em http://ijrcct.org/index.php/ojs/article/view/158

Keogh, E.; Kasetty, S. On the need for time series data mining benchmarks: a survey and empirical demonstration. In: Proceedings 8th ACM SIGKDD, KDD '02, New York, NY, USA: ACM, 2002, p. 102-111 (KDD '02, ).

Disponível em http://doi.acm.org/10.1145/775047.775062

Khamsi, M. A.; KIRK, W. A. An introduction to metric spaces and fixed point theory. Wiley, 2001.

KIM, H.-K.; KIM, J.-D.; Sim, D.-G.; OH, D.-I. A modified zernike moment shape descriptor invariant to translation, rotation and scale for similarity-based image retrieval. In: Multimedia and Expo, 2000. ICME 2000. 2000 IEEE International Conference on, 2000, p. $307-310$ vol.1.

Korn, F.; Sidiropoulos, N.; Faloutsos, C.; Siegel, E.; Protopapas, Z. Fast nearest neighbor search in medical image databases. In: Proceedings of the 22th International Conference on Very Large Data Bases, VLDB '96, San Francisco, CA, USA: Morgan Kaufmann Publishers Inc., 1996, p. 215-226 (VLDB '96, ).

Kovačević, A.; Milosavluević, B.; Konjović, Z. Tuning the feature space for content-based music retrieval. In: Proceedings of the 2006 conference on STAIRS 2006: Proceedings of the Third Starting AI Researchers' Symposium, Amsterdam, The Netherlands, The Netherlands: IOS Press, 2006, p. 62-71.

Kovačević, A.; Milosavluević, B.; Konjović, Z.; Vidaković, M. Adaptive content-based music retrieval system. Multimedia Tools Appl., v. 47, n. 3, p. 525-544, 2010.

Krishnamachari, S.; Yamada, A.; Abdel-Mottaleb, M.; Kasutani, E. Multimedia content filtering, browsing, and matching using mpeg-7 compact color descriptors. In: VISUAL, 2000, p. 200-211.

Krollner, B.; Vanstone, B.; Finnie, G. Financial time series forecasting with machine learning techniques: A survey. In: European symposium on ANN: Computational and machine learning, 2010.

Disponível em http://works.bepress.com/bruce_vanstone/17/ 
Kumaresan, R.; Tufts, D. Estimating the parameters of exponentially damped sinusoids and pole-zero modeling in noise. Acoustics, Speech and Signal Processing, IEEE Transactions on, v. 30, n. 6, p. 833-840, 1982.

Lange, D.; Naumann, F. Cost-aware query planning for similarity search. Inf. Syst., v. 38, n. 4, p. 455-469, 2013.

Disponível em http://dx.doi.org/10.1016/j.is.2012.11.009

LEE, K.; Jo, G. Expert system for predicting stock market timing using a candlestick chart. Expert Systems with Applications, v. 16, n. 4, p. 357 - 364, 1999.

Disponível em http://www.sciencedirect.com/science/article/pii/S0957417499000111

LeE, S. J.; OH, K. J.; Kim, T. Y. How many reference patterns can improve profitability for real-time trading in futures market? Expert Syst. Appl., v. 39, n. 8, p. 7458-7470, 2012.

Disponível em http://dx.doi.org/10.1016/j.eswa.2012.01.101

Levenshtein, V. Binary codes capable of correcting deletions, insertions, and reversals. Soviet Physics Doklady, v. 10, n. 8, p. 707-710, 1966.

LinA, J.-M. Image processing with complex daubechies wavelets. J. Math. Imaging Vis., v. 7, n. 3, p. 211-223, 1997.

Liu, Y.; Zhang, D.; Lu, G.; Ma, W.-Y. A survey of content-based image retrieval with high-level semantics. Pattern Recognition, v. 40, n. 1, p. 262-282, 2007.

LU, G. Indexing and retrieval of audio: A survey. Multimedia Tools Appl., v. 15, n. 3, p. 269-290, 2001.

Luz Jr., A.; Abdala, D. D.; Wangenheim, A. v.; Comunello, E. Improving performance and quality in content-based medical image retrieval. In: Proceedings of the Twentieth IEEE International Symposium on Computer-Based Medical Systems, CBMS '07, Washington, DC, USA: IEEE Computer Society, 2007, p. 147-152 (CBMS 'O', ).

Manjunath, B. S.; Ohm, J.-R.; Vasudevan, V. V.; Yamada, A. Color and texture descriptors. IEEE Trans. Circuits Syst. Video Techn., v. 11, n. 6, p. 703-715, 2001.

Martinez, L. C.; DA Hora, D. N.; De M. Palotti, J. R.; Meira, W.; Pappa, G. L. From an artificial nn to a stock market day-trading system: a case study on the bm\&f bovespa. In: Proceedings of the 2009 international joint conference on NN, IJCNN'09, Piscataway, NJ, USA: IEEE Press, 2009, p. 3251-3258 (IJCNN'09, ).

Disponível em http://dl .acm.org/citation. cfm?id=1704555.1704743 
Melton, J.; Eisenberg, A. Sql multimedia and application packages (sql $/ \mathrm{mm})$. SIGMOD Rec., v. 30, n. 4, p. 97-102, 2001.

Mills, T. C.; Markellos, R. N. The econometric modelling of financial time series. 3. ed ed. Cambridge [u.a.]: Cambridge Univ. Press, 2008.

Müller, H.; Michoux, N.; Bandon, D.; Geissbühler, A. A review of content-based image retrieval systems in medical applications - clinical benefits and future directions. I. J. Medical Informatics, v. 73, n. 1, p. 1-23, 2004.

Murphy, C.; Singh, H. Wavelet compression with set partitioning for low bandwidth telemetry from auvs. In: Proceedings of the Fifth ACM International Workshop on UnderWater Networks, WUWNet '10, New York, NY, USA: ACM, 2010, p. 1:1-1:8 (WUWNet'10, ).

Disponível em http://doi.acm.org/10.1145/1868812.1868813

Nixon, M.; Aguado, A. S. Feature extraction 85 image processing, second edition. 2nd ed. Academic Press, 2008.

Paliwal, K. K.; Alsteris, L. D. On the usefulness of stft phase spectrum in human listening tests. Speech Communication, v. 45, n. 2, p. 153-170, 2005.

PASS, G.; ZABIH, R. Histogram refinement for content-based image retrieval. In: Proceedings of the 3rd IEEE Workshop on Applications of Computer Vision (WACV '96), WACV '96, Washington, DC, USA: IEEE Computer Society, 1996, p. 96- (WACV '96, ).

Pianykh, O. Digital imaging and communications in medicine (dicom): A practical introduction and survival guide. Springer, 2008.

Ponciano-Silva, M. Processamento de consultas por similaridade em imagens médicas visando à recuperação perceptual guiada pelo usuário. 2008.

Ponciano-Silva, M.; Souza, J. P.; Buggati, P. H.; Kaster, D.; Braga, R. T. V.; Azevedo-Marques, P. M.; Bedo, M. V. N.; Traina, A. J. M.; TrainA, JR., C. Does a cbir system really impact decisions of physicians in a clinical environment? In: Proceedings of 26th IEEE International Symposium on Computer-Based Medical Systems, CBMS '13, 2013 (CBMS '13, ).

Preim, B.; BARTz, D. Visualization in medicine: Theory, algorithms, and applications. San Francisco, CA, USA: Morgan Kaufmann Publishers Inc., 2007.

Raposo, R. D. C. T.; De O. Cruz, A. J.; Mendes, S.; Da Silva, F. C.; De Costa, F. M. G.; Farias, J. M.; Silva, P. S. A.; Luiz, A.; Do Nascimento, 
W. O. Using multi-agents to predict the stock market evolution based on fundamentalist analysis and fuzzy-neural networks. In: Proceedings of the 5th WSEAS International Conference on Applied Informatics and Communications, AIC'05, Stevens Point, Wisconsin, USA: World Scientific and Engineering Academy and Society (WSEAS), 2005, p. 391-396 (AIC'05, ).

Disponível em http://dl .acm.org/citation.cfm?id=1366349.1366414

Ratanamahatana, C. Improving efficiency and effectiveness of dynamic time warping in large time series databases. Tese de Doutoramento, USA, aAI3179398, 2005.

Saidi, M.; Pietquin, O.; André-Obrecht, R. Application of the EMD decomposition to discriminate nasalized vs. vowels phones in French. In: Proceedings of the International Conference on Signal Processing, Pattern Recognition and Applications (SPPRA 2010), Innsbruck (Austria): ACTA Press, 2010, p. 128-132.

Santini, S.; Jain, R. Similarity measures. Pattern Analysis and Machine Intelligence, IEEE Transactions on, v. 21, n. 9, p. 871 -883, 1999.

Santosh, K. C.; Lamiroy, B.; Wendling, L. Dtw for matching radon features: a pattern recognition and retrieval method. In: Proceedings of the 13th international conference on Advanced concepts for intelligent vision systems, ACIVS'11, Berlin, Heidelberg: Springer-Verlag, 2011, p. 249-260 (ACIVS'11, ).

Silva, Y.; Aref, W.; Ali, M. The similarity join database operator. In: Data Engineering (ICDE), 2010 IEEE 26th International Conference on, 2010, p. 892-903.

Silva, Y. N.; Aref, W. G. Similarity-aware query processing and optimization. In: Rigaux, P.; Senellart, P., eds. VLDB PhD Workshop, VLDB Endowment, 2009.

Skopal, T. Where are you heading, metric access methods?: a provocative survey. In: Proceedings of the Third International Conference on SImilarity Search and APplications, SISAP '10, New York, NY, USA: ACM, 2010, p. 13-21 (SISAP '10, ) .

Smeulders, A. W. M.; Worring, M.; SAntini, S.; Gupta, A.; Jain, R. Content-based image retrieval at the end of the early years. IEEE Trans. Pattern Anal. Mach. Intell., v. 22, n. 12, p. 1349-1380, 2000.

Sonka, M.; Hlavác, V.; Boyle, R. Image processing, analysis and and machine vision (3. ed.). Thomson, I-XXV, 1-829 p., 2008.

Sookhanaphibarn, K.; Lursinsap, C. A new feature extractor invariant to intensity, rotation, and scaling of color images. Inf. Sci., v. 176, n. 14, p. 2097-2119, 2006. 
Stehling, R. O.; Nascimento, M. A.; Falcão, A. X. Cell histograms versus color histograms for image representation and retrieval. Knowl. Inf. Syst., v. 5, n. 3, p. 315-336, 2003.

Tang, J.; Rangayyan, R.; Xu, J.; El NaqA, I.; Yang, Y. Computer-aided detection and diagnosis of breast cancer with mammography: Recent advances. Information Technology in Biomedicine, IEEE Transactions on, v. 13, n. 2, p. 236-251, 2009.

Theodoridis, S.; Koutroumbas, K. Pattern recognition, third edition. Orlando, FL, USA: Academic Press, Inc., 2006.

Traina, A. J. M.; Traina, Jr., C.; Bueno, J. M.; Chino, F. J. T.; Azevedo-Marques, P. Efficient content-based image retrieval through metric histograms. World Wide Web, v. 6, n. 2, p. 157-185, 2003.

Traina, Jr., C.; Filho, R. F. S.; Traina, A. J. M.; Vieira, M. R.; Faloutsos, C. The omni-family of all-purpose access methods: a simple and effective way to make similarity search more efficient. $V L D B$ J., v. 16, n. 4, p. 483-505, 2007.

Traina, Jr., C.; Traina, A.; Faloutsos, C.; Seeger, B. Fast indexing and visualization of metric data sets using slim-trees. IEEE Trans. on Knowl. and Data Eng., v. 14, n. 2, p. 244-260, 2002.

Traina, Jr., C.; Traina, A. J. M.; Vieira, M. R.; Arantes, A. S.; Faloutsos, C. Efficient processing of complex similarity queries in rdbms through query rewriting. In: Proceedings of the 15th ACM international conference on Information and knowledge management, CIKM '06, New York, NY, USA: ACM, 2006, p. 4-13 (CIKM'06, ).

Disponível em http://doi.acm.org/10.1145/1183614.1183620

Vasconcelos, N.; Lippman, A. A unifying view of image similarity. In: Proceedings of the International Conference on Pattern Recognition - Volume 1, ICPR '00, Washington, DC, USA: IEEE Computer Society, 2000, p. 1038- (ICPR '00, ).

Vlachos, M.; Hadjieleftheriou, M.; Gunopulos, D.; Keogh, E. Indexing multidimensional time-series. The VLDB Journal, v. 15, n. 1, p. 1-20, 2006.

WelsteAD, S. Fractal and wavelet image compression techniques. Tutorial Texts in Optical Engineering. SPIE Optical Engineering Press, 1999.

Wilcoxon, F. Ranking methods. Biometrics Bulletin, v. 1, n. 6, p. 80-83, 1945. Disponível em http://dx.doi.org/10.2307/3001968 
Won, C. S. Feature extraction and evaluation using edge histogram descriptor in mpeg-7. In: Proceedings of the 5th Pacific Rim conference on Advances in Multimedia Information Processing - Volume Part III, PCM'04, Berlin, Heidelberg: Springer-Verlag, 2004, p. 583-590 (PCM'04, ).

Wu, S.; Li, F.; Menrotra, S.; Ooi, B. C. Query optimization for massively parallel data processing. In: Proceedings of the 2nd ACM Symposium on Cloud Computing, SOCC '11, New York, NY, USA: ACM, 2011, p. 12:1-12:13 (SOCC '11, ).

Disponível em http://doi.acm.org/10.1145/2038916.2038928

Yang, J.; Zhu, X.; Gross, R.; Kominek, J.; Pan, Y.; Waibel, A. Multimodal people id for a multimedia meeting browser. In: Proceedings of the seventh ACM international conference on Multimedia (Part 1), MULTIMEDIA '99, New York, NY, USA: ACM, 1999, p. 159-168 (MULTIMEDIA '99, ).

Yang, Y.; Nie, F.; Xu, D.; Luo, J.; Zhuang, Y.; PAn, Y. A multimedia retrieval framework based on semi-supervised ranking and relevance feedback. Pattern Analysis and Machine Intelligence, IEEE Transactions on, v. 34, n. 4, p. 723-742, 2012.

YiAnILOS, P. N. Data structures and algorithms for nearest neighbor search in general metric spaces. In: Proceedings of the fourth annual ACM-SIAM Symposium on Discrete algorithms, SODA '93, Philadelphia, PA, USA: Society for Industrial and Applied Mathematics, 1993, p. 311-321 (SODA '93, ).

Zezula, P.; Amato, G.; Dohnal, V.; Batko, M. Similarity search: The metric space approach. 1st ed. Springer Publishing Company, Incorporated, 2010.

Zhang, D.; Islam, M. M.; Lu, G. A review on automatic image annotation techniques. Pattern Recogn., v. 45, n. 1, p. 346-362, 2012.

Disponível em http://dx.doi.org/10.1016/j.patcog. 2011.05.013 